\title{
Indian stock market not efficient in weak form: An Empirical Analysis
}

\author{
Pankunni.V \\ 'Prasia' 'Nest', Palakkad, Kerala, India
}

\begin{abstract}
This paper studies the randomness of stock prices in India over the period from January 1999 to December 2009. The study is based on the closing prices of 20 stocks actively traded belonging to 20 different industries listed with the Bombay Stock Exchange (BSE) and BSE Sensex 30. The study used the parametric and nonparametric tests of randomness. The Parametric tests include autocorrelation, standard error, $t$ test and probable error. The nonparametric tests include the runs tests. Both the parametric and nonparametric tests rejected the null hypothesis that the prices are random. The study finds that the price distribution of the stocks and the market index is not normal. The data related to the skewness and kurtosis reveals large scale asymmetry in the distribution. There are strong evidences for non-randomness and interdependence of prices within the series implying that the Indian stock market is inefficient in weak form.
\end{abstract}

Keywords: Autocorrelation, Hypothesis, Interdependence, Randomness, Weak form.

\section{Introduction}

The stock market is a place where the economic and financial resources are allocated for magnifying the wealth of the nations. Stock market in the normal course reveals the true and fair price of the stocks. Stock price at ' $\mathrm{t}$ ' time will manifest its intrinsic value for that time. Therefore, in order to be so, the stock price reflects all information available at that time related to the stock. If stock prices manifest all the price details of the past so that the knowledge of the past price behavior will not be helpful for anyone to make excess return by virtue of being known to such information, the stock market is said to be efficient in weak form. A market is considered to be efficient when it expresses stock prices after assimilating all the available information related to the stocks. When stock market reveals all the available information, the stock prices will represent the intrinsic worth of the stocks. Therefore a person with the knowledge of past price behavior of the stocks or with any insider knowledge or with the financial expertise will not be able to reap any gain more than a naïve investor who simply posits buy-and- hold. A market in which prices always "fully reflect" available information is called efficient (E.F.Fama, 1970) ${ }^{1}$. The time lag in assimilating the new information may create differences between the price and the intrinsic value. But as and when the information reaches the market the prices will instantly assimilate, adjust and a new equilibrium price compatible to the value will be settled.

Stock prices move according to the new information. As the new information is supposed to be entirely new i.e. independent it is unpredictable. So the change in the price due to the incoming new information too is unpredictable. Therefore, the movement of prices will be stochastic and independently and identically distributed (IID). In this sense Fama in his study hypothesizes Efficient Market with random stock prices. In the random-walk hypothesis stock prices for the $t+1$ period is constituted by an unpredictable change in the expected price added with the current price. But what will be added to the current price is remaining stochastic. It will be absolutely a random value. As it is so the future stock prices are not amenable for prediction. Therefore with technical analysis the attempt to make extra gain with the knowledge of past price behavior or with any insider knowledge will be in vain.

A market can be efficient in weak, semi-strong and strong forms. In the weak form of market efficiency the stock prices will fully reflect the past price behavior of stocks. In this situation there is no scope for a person to manipulate the market and gain excess returns with the knowledge of any prior information as to the price behavior of stocks. He with his technical savvy could make only a return par with a naïve investor with a simple buy-and-hold.

When a market is semi-strong the stock prices will fully reflect not only the past price behavior but also all the publicly available information. In a semi-strong market a person with a prior knowledge of public information cannot make any excess return over a naïve investor. When a market is strong the stock prices will reveal fully all the publicly and privately available information. A person with information privy of any form will not be able to generate supernormal benefit over a naïve investor if the market is efficient in strong form.

The weak form efficient market concept is generally considered subject to the Random-Walk Hypothesis. According to Random-Walk Hypothesis stock prices are random. Current stock prices reveal fully the past price behavior and the publicly and privately available information. It is the intrinsic value of the stock or fair prices. In financial theory the intrinsic value of a stock is understood as the discounted cash streams of 
the stocks over periods. Stock prices according to Efficient Market Hypothesis (EMH) are equilibrium prices after taking in to consideration all hitherto available information pertaining to the stocks. Only a new piece of information can bring a change to the current price. But the change to the price by new information cannot be predicted since the information itself is unpredictable. A change caused by purely 'white noise' is absolutely unpredictable. The stock price movement in an efficient market is not linear. Trends lines cannot be constructed to project future stock prices due to the fact that the series are not trend-stationary. On the contrary, the trends in time series are variable and unpredictable i.e. difference-stationary (Seyyed Ali Paytakhti Oskooe et al., 2010) ${ }^{2}$.

Since the stock prices are random they are not amenable for prediction. When a new piece of information reaches the market randomly the stock prices will, then and there, instantly assimilate and expresses it. Therefore mispricing of stock prices becomes impossible in an efficient market. In this way the essence of efficient market hypothesis is that the stock prices are random.

The EMH content of randomness of stock prices has been subject to rampant challenges from different corners. The challengers posit different market anomalies like January effect, week-end effect, seasonal effect, small firm effect and so on (Philip S Russel and Violet M Torbey, 2002) ${ }^{3}$. The randomness of stock prices was widely disputed and debated all over the world. Studies were largely carried out to vouchsafe the randomness of stock prices of various countries. But very few studies were organized to look into the stock prices of Indian Stock Market. Hence this paper is to study the randomness of prices of 20 BSE stocks and the BSE Sensex 30 in India.

In this paper in section 1 a theoretical framework - introduction and the theory of EMH-is given. In section 2, the exploration of previous researches linked with the study of randomness of stock prices is carried on. In section 3, the objective of the study of this paper is stated. In Section 4, the hypotheses the study hold are listed. In section 5 , statement of data and methodology of the present study is made. In section 6 , the empirical test is carried out. In section 7, the empirical analysis is made. In section 8, the empirical results are given and in Section 9 , summary and conclusions are drawn.

\section{Previous Research}

An efficient market is a necessary corollary to the perfect market supposition. In the back drop of the perfect market premise there will be free and speedy mobility of information from one person to another person in the market. Information will not be hidden or concealed for long. The information will be available to the market without any time lag. The free and quick flow of information facilitates Stock Market efficiency. In such a situation, no one can make use of the information to make abnormal gain over the one who does not have such information. The stock prices in an efficient market are simply random. Price originates from the random fluctuation in the future stock prices. Expected future stock prices are not deterministic in nature. Every change in price that occurs for new information break is quite random. Hence prices are supposed to be random.

In a study by Ishmael Radikoko (2014) ${ }^{4}$, both the parametric and non-parametric tests of the equity return series of Botswana's equity market resulted in the findings that the returns series were serially correlated. It rejected the randomness of the stock prices due to the presence of data stationary. It was eventually found that the Botswana Stock Market was not bound by the Random-Walk hypothesis during the period of 2005-2013. Anup Agarwal \& Kishore Tandon (1994) $)^{5}$, in their joint work to study the five calendar anomalies of equity returns related to 18 countries other than USA found the persistence of anomalies in different countries at varying degrees which will ultimately repudiate the Efficient Market Hypothesis. The five calendar anomalies are the week-end effect, the Friday-the-thirteenth effect, the turn-of-the-month effect, the end-of-December effect, and the January effect. The various anomalies and inconsistencies found in the day to day operation of the stock market raise greater challenges to the paradigms of EMH. A cross examination made by the authors Russel and Torby (2002) in to the anomalies and inconsistencies in the stock market contrary to the Efficient Market Hypothesis had of the view to have a more coherent theory of stock market behavior. If the prices are random such anomalies never happen. The largest investor of the world Warren Buffet $(1995)^{6}$ in his sarcastic tone commented against the Random-Walk Hypothesis as "I'd be a bum in the street with a tin cup if the markets were efficient". A study by Arusha Cooray and Guneratne Wickremasinghe (2005) ${ }^{7}$ on Weak form efficiency in the stock markets of India, Sri Lanka, Pakistan and Bangladesh found support by the classical unit root tests. But in the case of Bangladesh, Dicky-Fuller and Elliot-Rothenber-Stock tests were not supporting the weak form. According to Fischer Black (1986) ${ }^{8}$, noise makes the market inefficient. The factors related to future demand and supplies are unknown. The future price of a stock of a portfolio is not known. They are all noises. These small events, which are many, known as noises, make a market inefficient since they prevent us from knowing the future prices of stocks. Most generally, noise makes it very difficult to test either practical or academic theories about the way that financial or economic markets work. One is forced to work in dark. Ibrahim Awad and Zahran Dharagma (2009) ${ }^{9}$ in a paper titled 'Testing the Weak-Form Efficiency of the Palestinian Securities Market (PSE)' examined the efficiency of the Palastine Securities Exchanges at the weak level for 35 stocks listed in the market by using daily observations of the PSE indices. They used the parametric 
and nonparametric tests for examining the randomness. The parametric tests include serial correlation and Augmented Dicky-Fuller(ADF) unit root tests. The nonparametric tests include runs tests, and the Philips-Peron unit root tests. The serial correlation tests and the runs tests both revealed that the daily returns are inefficient at the weak-form. Also, the unit root tests (Augmented Dickey-Fuller (ADF) unit root test and Phillips-Peron (PP) unit root test) suggest the weak-form inefficiency in the return series.

In the paper titled "Persistence in the Indian Stock Market Returns: An Application of Variance Ratio Test" T.P.Madhusoodanan (1998) ${ }^{\mathbf{1 0}}$ examined whether Indian Stock Market was following the Random-Walk Hypothesis. He had applied Serial Correlation and Variance Ratio tests to find both the heteroscedasticity and homoscedasticity. The tests were conducted at aggregate level of market indices and disaggregate level of individual stocks. The results of his study indicate that random walk hypothesis cannot be accepted in the Indian market. Pankunni.V (2013) $)^{11}$ in his doctoral dissertation titled "Stock Price Movement in India" studied the efficiency of 20 selected stocks of the Bombay Stock Exchange by using autocorrelation and found that the stocks were inefficient in weak form. S.K.Chaudhari $(1991)^{12}$ in a study titled "Short-run Share Price Behavior: New Evidence on Weak Form of Market Efficiency" attempts to find serial independence stock price changes on 93 actively traded stocks of BSE over the period January 1988 to April 1990. The study utilized the serial correlation tests and runs tests. The author concluded that the study failed to find any evidence for the serial independence of stock price changes and stated that the market did not seem to be efficient even in its weak form. D. Kwiatkowski et al.,(1992) ${ }^{13}$ in a study presented statistical tests of the hypothesis of stationarity, either around a level or around a linear trend. The tests were intended to complement unit root tests, such as DickyFuller tests. By testing both the unit root hypothesis and the stationary hypothesis the study was able to distinguish series that appear to be stationary, series that appear to have a unit root, and series for which the data are not sufficiently informative to be sure whether they were stationary or integrated. The main technical innovation of this paper was the allowance made for error autocorrelation. The main practical difficulty in performing the tests is the estimation of the long-run variance. The autocorrelation correction used in the paper was similar to the Phillips-Perron corrections for unit root tests.

Ankitha Mishra and Vinod Mishra (2011) $)^{14}$ in a study found that the Indian Stock prices follow Random Walk in spite of nonlinearities in the data. The study was to examine the efficiency of Indian Stock Market. The study applied the Caner and Hensen (2001) methodology to simultaneously test for the presence of nonlinearities and unit root in the stock prices data. M.A.Moustafa $(2004)^{15}$ in a paper titled "Testing the WeakForm Efficiency of the United Arab Emirates Stock Market" studied the behavior of stock prices in United Arab Emirates stock market. The study was based on the data of 43 stocks for a period from 2001 to 2003. As the returns were found not subject to normal distribution, the author used nonparametric runs to test randomness of stock prices. The results reveal that the returns of 40 stocks out of the 43 are random at $5 \%$ level of significance. The study supports the weak-form EMH of UAE stock market. Nikunj R. Patel, Nitesh Radadia and Juhi Dhawan (2012) ${ }^{16}$ in a joint study titled "An Empirical Study on Weak-Form of Market Efficiency of Selected Asian Stock Markets" investigated the weak form of market efficiency of Asian four selected stock markets. The period of study was in between 2000 and 2011. The authors applied tests like runs test, unit root test, variance ratio, and autocorrelation. The runs test with the BSE Index did not favor weak form efficiency in India.

P.K.Mishra and B.B.Pradhan $(2009)^{17}$ in a combined study tested the efficiency of Indian capital market in its weak form by employing the most popular unit root test. The study provides the evidence of weak form inefficiency of Indian capital market over the sample period 2001-2009. The study was based on the daily closing stock price index of BSE Sensex. This informational inefficiency has implications for predictability of stock prices. Precisely, by capitalising this pattern investors can make some super-normal profit. This opportunity for excess profit can provide impetus for successful financial innovation in emerging capital markets of India. Poterba and Summers $(1988)^{18}$ also found serial correlation positive in short periods and negative in long periods in stock prices. Priyanka Sing and Brajesh Kumar ${ }^{19}$ in a study found that the Indian stock market was efficient in weak form on the basis of the data of nifty index futures comprising of 50 large capitalization stocks during the period 2008. Sunita Mehla and S.K.Goyal (2012) ${ }^{20}$ in a study to test the hypothesis that Indian Stock Market is efficient in weak form used the parametric and nonparametric tests of randomness, that is, unit root test, autocorrelation test, runs test and variance ratio test and found no evidence for weak form efficiency. Saheli Das (2014) ${ }^{\mathbf{2 1}}$ in a recent study on the Indian Stock Market examined the efficiency in the stock market found that the Indian Stock Market was inefficient in the pre-crisis and the crisis period, but found evidences for efficiency during the post-crisis period.

\section{Objective of the study}

The study intends to examine the randomness of the price series of 20 stocks and BSE Sensex 30 market index over a period of 11 years from January 1999 to December 2009. 


\section{Hypothesis}

Null Hypothesis $\left(\mathrm{H}_{0}\right)$ : The daily closing stock price series of 20 stocks and the BSE Sensex30 are random. Alternative Hypothesis $\left(\mathrm{H}_{\mathrm{a}}\right)$ : The daily closing stock price series of 20 stocks and the BSE Sensex are trendstationary and non-random.

\section{Data and methodology}

In order to study the randomness of stock prices of Bombay Stock Exchange in India 20 industries were selected at convenience. From among the 20 industries 20 stocks were randomly picked out. The stocks selected were 1) ACC 2) Appollo Tyres, 3) Aravind Mills, 4) Ashok Leyland, 5) Asian Paints, 6) Axis Bank, 7) Ballarpur Industries, 8) Castrol, 9) Colgate Palmolive, 10) Crompton Greaves, 11) Garware Polyester, 12) Gujarat Narmada, 13) Harrisons Malayalam, 14) Hindalco, 15) Indian Hotels, 16) Indian Reyons, 17) ITC, 18) ONGC, 19) Tata Steel Ltd, and 20) WIPRO. The closing price index of the BSE Sensitive index comprised of 30 stocks (BSE SENSEX30) and the closing stock prices of the twenty stocks were collected from the official website of the Bombay Stock Exchange for a period ranging from $1^{\text {st }}$ January 1999 to $31^{\text {st }}$ December 2009 . The closing prices of twenty stocks and the price index of BSE Sensex 30 were put to empirical study to test the randomness of stock prices. Descriptive statistics like mean, standard deviation, skewness and kurtosis were calculated to study the symmetry and normalcy of stock prices. Similarly parametric and non- parametric tests were employed to test whether the prices were independently and identically distributed. The parametric statistics used in the study were serial correlation (auto correlation), Standard error and probable error. The nonparametric statistics used was run tests. Graphs and tables were appropriately employed and given in the analytical part succinctly.

\section{Empirical test}

The closing stock prices of 20 stocks from January 1999 to $31^{\text {st }}$ December 2009 were tested for their symmetry, normalcy and randomness by using summary statistics and auto correlation. Non-parametric test of runs was also used to test the randomness of the stock prices to see whether the variables in the series show any interdependence.

\subsection{Summary Statistics:}

Summary Statistics include range, mean, median, standard deviation, skewness and kurtosis. In a normal distribution the mean will occupy the central position and will coincide with the mode and median. The sum of the deviations on either side of the mean will be zero. $99 \%$ of the area will be covered by the Gaussian curve up to $3 \sigma$ to the right and left of the mean. The standard deviation from the mean records the price or return volatility in the distribution. The bigger the standard deviation, the higher will be the volatility. When prices are normally distributed there is little room for volatility. Gaussian distribution knows no skewness. Zero skewness is the property of normal distribution. If the value of skewness is positive, it means the distribution is skewed to the right of the mean and vice versa. Kurtosis represents the peakedness of the distribution. The Greater the peakedness the greater will be the smaller and bigger deviations in the distribution. The coefficient of kurtosis for a normal distribution is 3 . If the coefficient of kurtosis is more than 3 , it is leptokurtic and less than 3 , it is platykurtic.

\subsection{Parametric Test}

Assuming price distribution as normal, parametric test autocorrelation is utilized. Autocorrelation is further tested for its significance by the $t$ test, standard error and probable error.

\subsubsection{Autocorrelation}

Autocorrelation or serial correlation is a parametric test used to check interdependency within variables in a time series. It is used to find out the existence of any form of autoregressive constants or covariances or intra-correlation within the variables in a series. The formula used to calculate autocorrelation is:

Given measurements, $\mathrm{Y}_{1}, \mathrm{Y}_{2}, \ldots, \mathrm{Y}_{\mathrm{N}}$ at time $\mathrm{X}_{1}, \mathrm{X}_{2}, \ldots, \mathrm{X}_{\mathrm{N}}$, the lag $\mathrm{k}$ autocorrelation function is defined as

$$
r_{k}=\frac{\sum_{i=1}^{N-k}\left(Y_{i}-\bar{Y}\right)\left(Y_{i+k}-\bar{Y}\right)}{\sum_{i=1}^{N}\left(Y_{i}-\bar{Y}\right)^{2}}
$$

The time variable $\mathrm{X}$ is not used in the formula on the assumption that the observations are equi-spaced.

$\mathrm{I}_{\mathrm{k}}=$ autocorrelation at $\mathrm{k}$ lags.

$\mathrm{k}=$ time lag

$\left(\mathrm{Y}_{\mathrm{i}}-\overline{\mathrm{Y}}\right)=$ Deviation of variable from mean at $\mathrm{k}=0$.

$\left(\mathrm{Y}_{\mathrm{i}+\mathrm{k}}-\overline{\mathrm{Y}}\right)=$ Deviation of variable from mean at $1+\mathrm{k}$ lags. 
Correlation as a rule varies in between 1 and 0 . If the coefficient of autocorrelation is zero, it means there is no interdependence. The variables are random. A high coefficient of autocorrelation tells interdependence of variables in the series. The significance of the coefficient of autocorrelation is tested by employing the student ' $t$ ' test and by Standard Error (S.E) and probable error(P.E).

The student ' $t$ ' is calculated by the following formula:

$\mathrm{t}$ value $=\frac{\mathrm{r}}{\sqrt{1-\mathrm{r}^{2}}} \sqrt{\mathrm{n}-2}$

where,

$\mathrm{r}=$ coefficient of autocorrelation

$\mathrm{n}=$ sample size

If calculated ' $t$ ' exceeds the table value at $n-2$ degree of freedom at 0.05 level, $r$ is significant and vice versa.

4.2.2. Probable Error (PE)

The standard error of the autocorrelation is calculated as below:

$\mathrm{SE}=\frac{1-\mathrm{r}^{2}}{\sqrt{\mathrm{N}}}$

Probable Error $=0.6745(\mathrm{SE})=0.6745 \frac{1-\mathrm{r}^{2}}{\sqrt{\mathrm{N}}}$

\subsubsection{Decision rule}

If the value of $r$ is less than the probable error there is no evidence of correlation. If the value of $r$ is more than 6 times the probable error, the correlation is certain.

\subsection{Non-Parametric Test:}

\subsubsection{Runs Test}

In case the distribution is not normal optimum results will not available from parametric tests. In such cases non-parametric tests will be employed for optimal results. Runs Test for randomness is nonparametric test. Runs test is used for examining whether or not a set of observations constitutes a random sample from an infinite population. Here,

$\mathrm{H}_{0}=$ Sample value come from a random sequence

$\mathrm{H}_{1}=$ Sample value come from a non-random sequence

\subsubsection{Test statistic}

The letter ' $r$ ' is used to denote runs in the series. A run is a sequence of signs of same kind bounded by signs of other kind. Too few runs indicate that the sequence is not random (It means the sequence has persistency). Too many runs also indicate that the sequence is not random (It means the sequence is zigzag).

\subsubsection{Critical Value}

Critical value for the test is obtained from the table for a given value of $\mathrm{n}$ and desired level of significance $(\alpha) . r_{c}$ denotes this critical value. If the sample size is more than 25 the critical value $r_{c}$ can be obtained using a normal distribution approximate that is $\mathrm{Z}$ value.

\subsubsection{Decision Rule}

If $\mathrm{r}_{\mathrm{c}}$ (lower) $\leq \mathrm{r} \leq \mathrm{r}_{\mathrm{c}}$ (upper), accept $\mathrm{H}_{0}$. Otherwise reject $\mathrm{H}_{0}$.

The upper and lower $r_{c}$ can be found:

The critical values for the two sided test at $5 \%$ level of significance are

$\mathrm{r}_{\mathrm{c}}$ lower $=\mu-1.96 \sigma$

$\mathrm{r}_{\mathrm{c}}$ (upper) $=\mu+1.96 \sigma$

For one sided test

$r_{c}($ left tailed $)=\mu-1.65 \sigma$, if $r \leq r_{c}$, reject $H_{0}$.

$r_{c}$ (right tailed) $=\mu+1.65 \sigma$, if $r \geq r_{c}$, reject $H_{0}$.

Where $\mu=\frac{2 n-1}{3}$ and $\sigma=\sqrt{\frac{16 n-29}{90}}$

When the sample size is greater than 25 , the standard normal variate $\mathrm{z}$ value will be the test statistic. Where

Here,

$$
\mathrm{Z}=\frac{\mathrm{R}-\overline{\mathrm{R}}}{\mathrm{SR}}
$$

$\mathrm{R}=$ Observed number of runs

$\overline{\mathrm{R}}=$ Expected number of runs

$\mathrm{SR}=$ Standard deviation of the number of runs

Where, 
$\overline{\mathrm{R}}=1+\frac{2 \mathrm{n} 1 \mathrm{n} 2}{\mathrm{n} 1+\mathrm{n} 2}$

$\mathrm{S}_{\mathrm{R}}^{2}=\frac{2 \mathrm{n} 1 \mathrm{n} 2(2 \mathrm{n} 1 \mathrm{n} 2-\mathrm{n} 1-\mathrm{n} 2)}{(\mathrm{n} 1+\mathrm{n} 2)^{2}(\mathrm{n} 1+\mathrm{n} 2-1)}$

with $\mathrm{n} 1$ and $\mathrm{n} 2$ denoting the number of positive and negative values in the series.

Significance Level --- $\alpha$

\subsubsection{Critical region}

The run test rejects null hypothesis if

$$
\mathrm{Z}>\mathrm{Z}_{1-\alpha / 2}
$$

For a large sample run test (where $n 1>10$ and $n 2>10$ ) the test statistic is compared to a standard normal table. That is at 5\% significance level, a test statistic with an absolute value greater than 1.96 indicates non-randomness, on the upper side. On the lower side, a test statistic with an absolute value which is lower than -1.96 indicates non-randomness. \{If $\mathrm{z}<-1.96 \quad 11 \quad \mathrm{z}>1.96$ strong evidence at $5 \%$ significance the pattern is not random\}.

\section{Empirical Analysis}

The closing stock prices of twenty stocks and the Bombay Stock Exchange price index SENSEX 30 for a period of 11 years from 1999 to 2009 over an average 2750 observations were put to test for randomness with parametric and nonparametric measures and results were obtained. A detailed stock-wise analysis was carried out hereafter. The null hypothesis $\left(\mathrm{H}_{0}\right)$ at the onset of the analysis is that the stock prices of all the twenty stocks and BSE SENSEX30 are random.

Table No.7.1 Descriptive Statistics of the stocks and BSE Sensex30

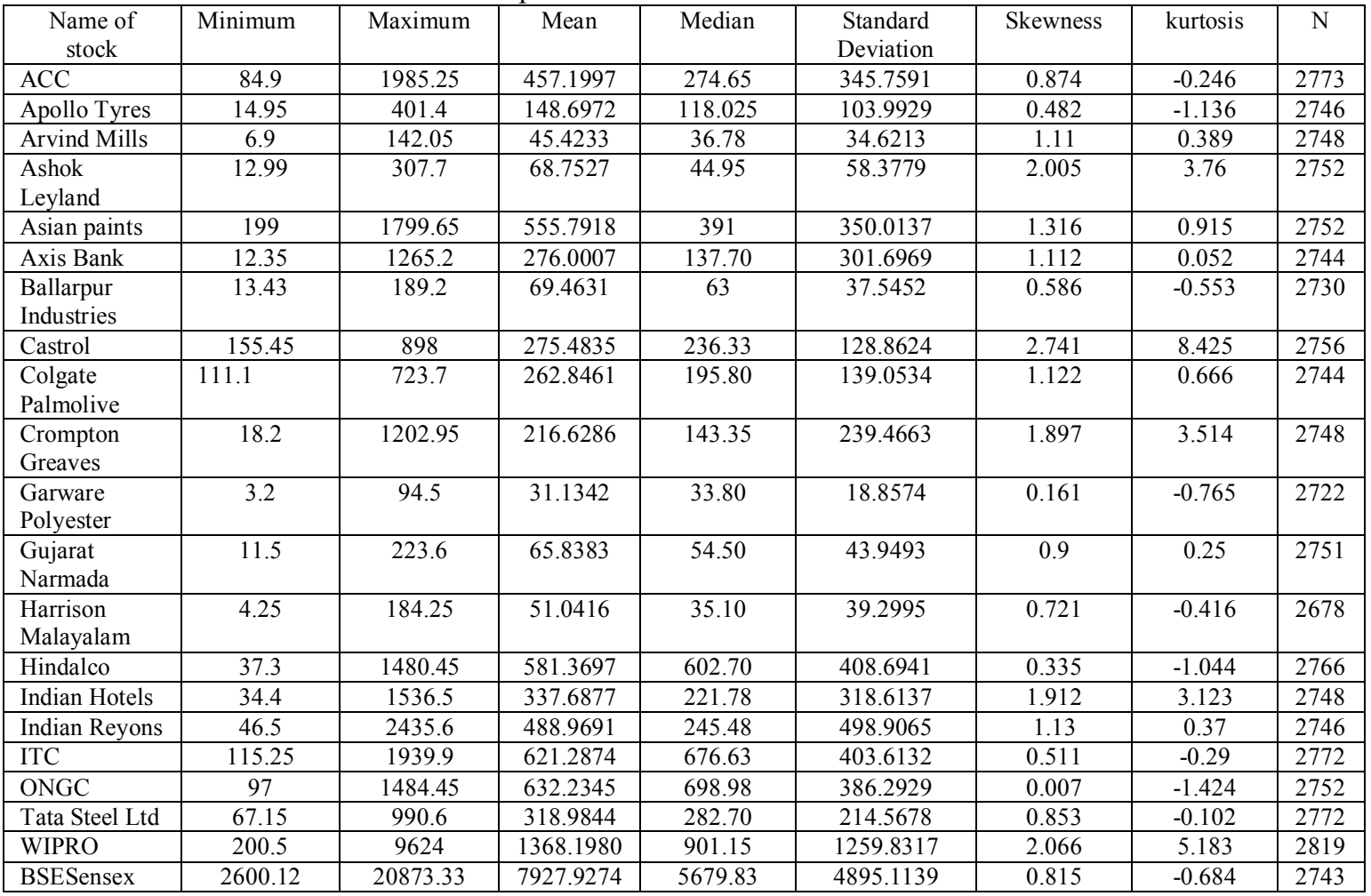

TABLE No.7.1 above shows the summary statistics of the 20 stocks and the Bombay Stock Exchange Sensitive index. The difference between minimum and maximum price for stocks and BSE Sensex 30 is wide. The standard deviations of the stocks and the index are also very high. It shows that the price volatility of the stocks is very high during the period. There is considerable difference between mean and median values of stock prices. It indicates that the distribution is not normal. In normal distributions the mean and median have to coincide with each other. All the stocks and Sensex 30 are having greater amount of positive skewness. It is an indication that the distribution is not normal since normal distribution is zero skewness. The coefficient of kurtosis of the stocks is either above or below 3, means not normal. In normal distributions the kurtosis value will be 3 . Above 3 means leptokurtic, below 3 means platykurtic. 
Table No.7.2 Autocorrelation in 16 lags

Table No.6.1

Coefficient of Auto Correlation

\begin{tabular}{|c|c|c|c|c|c|c|c|c|c|c|c|c|c|c|c|c|}
\hline STOCKS & & & & $\begin{array}{l}\text { AUTO } \\
\text { CORR }\end{array}$ & LATIC & & & & & & & & & & & \\
\hline Lags & 1 & 2 & 3 & 4 & 5 & 6 & 7 & 8 & 9 & 10 & 11 & 12 & 13 & 14 & 15 & 16 \\
\hline ACC & $\begin{array}{r}0.99 \\
3\end{array}$ & $\begin{array}{r}0.98 \\
7\end{array}$ & $\begin{array}{r}0.98 \\
1\end{array}$ & $\begin{array}{r}0.97 \\
6\end{array}$ & $\begin{array}{r}0.97 \\
0\end{array}$ & $\begin{array}{r}0.96 \\
5\end{array}$ & $\begin{array}{r}0.96 \\
0\end{array}$ & $\begin{array}{r}0.95 \\
6\end{array}$ & $\begin{array}{r}0.95 \\
2\end{array}$ & $\begin{array}{r}0.94 \\
7\end{array}$ & $\begin{array}{r}0.94 \\
3\end{array}$ & $\begin{array}{r}0.93 \\
9\end{array}$ & $\begin{array}{r}0.93 \\
5\end{array}$ & $\begin{array}{r}0.93 \\
0\end{array}$ & $\begin{array}{r}0.92 \\
6\end{array}$ & 0.921 \\
\hline Apollo & $\begin{array}{r}0.99 \\
7\end{array}$ & $\begin{array}{r}0.99 \\
3\end{array}$ & $\begin{array}{r}0.99 \\
0\end{array}$ & $\begin{array}{r}0.98 \\
6\end{array}$ & $\begin{array}{r}0.98 \\
3\end{array}$ & $\begin{array}{r}0.97 \\
9\end{array}$ & $\begin{array}{r}0.97 \\
6\end{array}$ & $\begin{array}{r}0.97 \\
2\end{array}$ & $\begin{array}{r}0.96 \\
9\end{array}$ & $\begin{array}{r}0.96 \\
6\end{array}$ & $\begin{array}{r}0.96 \\
2\end{array}$ & $\begin{array}{r}0.95 \\
9\end{array}$ & $\begin{array}{r}0.95 \\
5\end{array}$ & $\begin{array}{r}0.95 \\
2\end{array}$ & $\begin{array}{r}0.94 \\
8\end{array}$ & 0.944 \\
\hline Araavind & $\begin{array}{r}0.99 \\
9\end{array}$ & $\begin{array}{r}0.99 \\
7\end{array}$ & $\begin{array}{r}0.99 \\
6\end{array}$ & $\begin{array}{r}0.99 \\
5\end{array}$ & $\begin{array}{r}0.99 \\
3\end{array}$ & $\begin{array}{r}0.99 \\
2\end{array}$ & $\begin{array}{r}0.99 \\
1\end{array}$ & $\begin{array}{r}0.98 \\
9\end{array}$ & $\begin{array}{r}0.98 \\
8\end{array}$ & $\begin{array}{r}0.98 \\
7\end{array}$ & $\begin{array}{r}0.98 \\
5\end{array}$ & $\begin{array}{r}0.98 \\
4\end{array}$ & $\begin{array}{r}0.98 \\
3\end{array}$ & $\begin{array}{r}0.98 \\
1\end{array}$ & $\begin{array}{r}0.98 \\
0\end{array}$ & 0.979 \\
\hline Ashoklay & $\begin{array}{r}0.99 \\
7\end{array}$ & $\begin{array}{r}0.99 \\
3\end{array}$ & $\begin{array}{r}0.99 \\
0\end{array}$ & $\begin{array}{r}0.98 \\
7\end{array}$ & $\begin{array}{r}0.98 \\
4\end{array}$ & $\begin{array}{r}0.98 \\
0\end{array}$ & $\begin{array}{r}0.97 \\
7\end{array}$ & $\begin{array}{r}0.97 \\
4\end{array}$ & $\begin{array}{r}0.97 \\
0\end{array}$ & $\begin{array}{r}0.96 \\
7\end{array}$ & $\begin{array}{r}0.96 \\
4\end{array}$ & $\begin{array}{r}0.96 \\
0\end{array}$ & $\begin{array}{r}0.95 \\
7\end{array}$ & $\begin{array}{r}0.95 \\
4\end{array}$ & $\begin{array}{r}0.95 \\
0\end{array}$ & 0.947 \\
\hline Asian & $\begin{array}{r}0.99 \\
7\end{array}$ & $\begin{array}{r}0.99 \\
4\end{array}$ & $\begin{array}{r}0.99 \\
1\end{array}$ & $\begin{array}{r}0.98 \\
8\end{array}$ & $\begin{array}{r}0.98 \\
5\end{array}$ & $\begin{array}{r}0.98 \\
2\end{array}$ & $\begin{array}{r}0,97 \\
9\end{array}$ & $\begin{array}{r}0.97 \\
6\end{array}$ & $\begin{array}{r}0.97 \\
3\end{array}$ & $\begin{array}{r}0.97 \\
0\end{array}$ & $\begin{array}{r}0.96 \\
7\end{array}$ & $\begin{array}{r}0.96 \\
4\end{array}$ & $\begin{array}{r}0.96 \\
1\end{array}$ & $\begin{array}{r}0.95 \\
8\end{array}$ & $\begin{array}{r}0.95 \\
6\end{array}$ & 0.953 \\
\hline Axis bank & $\begin{array}{r}0.99 \\
8\end{array}$ & $\begin{array}{r}0.99 \\
6\end{array}$ & $\begin{array}{r}0.99 \\
3\end{array}$ & $\begin{array}{r}0.99 \\
1\end{array}$ & $\begin{array}{r}0.98 \\
9\end{array}$ & $\begin{array}{r}0.98 \\
7\end{array}$ & $\begin{array}{r}0.98 \\
6\end{array}$ & $\begin{array}{r}0.98 \\
4\end{array}$ & $\begin{array}{r}0.98 \\
2\end{array}$ & $\begin{array}{r}0.98 \\
0\end{array}$ & $\begin{array}{r}0.97 \\
8\end{array}$ & $\begin{array}{r}0.97 \\
6\end{array}$ & $\begin{array}{r}0.97 \\
4\end{array}$ & $\begin{array}{r}0.97 \\
2\end{array}$ & $\begin{array}{r}0.97 \\
0\end{array}$ & 0.968 \\
\hline Ballarpur & $\begin{array}{r}0.99 \\
6\end{array}$ & $\begin{array}{r}0.99 \\
2\end{array}$ & $\begin{array}{r}0.98 \\
9\end{array}$ & $\begin{array}{r}0.98 \\
5\end{array}$ & $\begin{array}{r}0.98 \\
1\end{array}$ & $\begin{array}{r}0.97 \\
8\end{array}$ & $\begin{array}{r}0.97 \\
4\end{array}$ & $\begin{array}{r}0.97 \\
0\end{array}$ & $\begin{array}{r}0.96 \\
6\end{array}$ & $\begin{array}{r}0.96 \\
3\end{array}$ & $\begin{array}{r}0.95 \\
9\end{array}$ & $\begin{array}{r}0.95 \\
5\end{array}$ & $\begin{array}{r}0.95 \\
2\end{array}$ & $\begin{array}{r}0.94 \\
8\end{array}$ & $\begin{array}{r}0.94 \\
4\end{array}$ & 0.940 \\
\hline Castrol & $\begin{array}{r}0.99 \\
3\end{array}$ & $\begin{array}{r}0.98 \\
6\end{array}$ & $\begin{array}{r}0.98 \\
0\end{array}$ & $\begin{array}{r}0.97 \\
3\end{array}$ & $\begin{array}{r}0.96 \\
6\end{array}$ & $\begin{array}{r}0.96 \\
0\end{array}$ & $\begin{array}{r}0.95 \\
3\end{array}$ & $\begin{array}{r}0.94 \\
7\end{array}$ & $\begin{array}{r}0.94 \\
1\end{array}$ & $\begin{array}{r}0.93 \\
5\end{array}$ & $\begin{array}{r}0.92 \\
8\end{array}$ & $\begin{array}{l}0.92 \\
2\end{array}$ & $\begin{array}{r}0.91 \\
5\end{array}$ & $\begin{array}{r}0.90 \\
9\end{array}$ & $\begin{array}{r}0.90 \\
2\end{array}$ & 0.895 \\
\hline Colgate & $\begin{array}{r}0.99 \\
7\end{array}$ & $\begin{array}{r}0.99 \\
5\end{array}$ & $\begin{array}{r}0.99 \\
3\end{array}$ & $\begin{array}{r}0.99 \\
0\end{array}$ & $\begin{array}{r}0.98 \\
8\end{array}$ & $\begin{array}{r}0.98 \\
5\end{array}$ & $\begin{array}{r}0.98 \\
3\end{array}$ & $\begin{array}{r}0.98 \\
0\end{array}$ & $\begin{array}{r}0.97 \\
8\end{array}$ & $\begin{array}{r}0.97 \\
5\end{array}$ & $\begin{array}{r}0.97 \\
3\end{array}$ & $\begin{array}{r}0.97 \\
0\end{array}$ & $\begin{array}{r}0.96 \\
8\end{array}$ & $\begin{array}{r}0.96 \\
5\end{array}$ & $\begin{array}{r}0.96 \\
3\end{array}$ & 0.960 \\
\hline crompton & $\begin{array}{r}0.99 \\
8\end{array}$ & $\begin{array}{r}0.99 \\
7\end{array}$ & $\begin{array}{r}0.99 \\
5\end{array}$ & $\begin{array}{r}0.99 \\
4\end{array}$ & $\begin{array}{r}0.99 \\
3\end{array}$ & $\begin{array}{r}0.99 \\
2\end{array}$ & $\begin{array}{r}0.99 \\
0\end{array}$ & $\begin{array}{r}0.98 \\
9\end{array}$ & $\begin{array}{r}0.98 \\
7\end{array}$ & $\begin{array}{r}0.98 \\
6\end{array}$ & $\begin{array}{r}0.98 \\
4\end{array}$ & $\begin{array}{r}0.98 \\
2\end{array}$ & $\begin{array}{r}0.98 \\
0\end{array}$ & $\begin{array}{r}0.97 \\
9\end{array}$ & $\begin{array}{r}0.97 \\
7\end{array}$ & $\begin{array}{l}0.977 \\
5\end{array}$ \\
\hline Garware & $\begin{array}{r}0.99 \\
7\end{array}$ & $\begin{array}{r}0.99 \\
3\end{array}$ & $\begin{array}{r}0.99 \\
0\end{array}$ & $\begin{array}{r}0.98 \\
7\end{array}$ & $\begin{array}{r}0.98 \\
4\end{array}$ & $\begin{array}{r}0.98 \\
0\end{array}$ & $\begin{array}{r}0.97 \\
7\end{array}$ & $\begin{array}{r}0.97 \\
4\end{array}$ & $\begin{array}{r}0.97 \\
0\end{array}$ & $\begin{array}{r}0.96 \\
7\end{array}$ & $\begin{array}{r}0.96 \\
3\end{array}$ & $\begin{array}{r}0.95 \\
9\end{array}$ & $\begin{array}{r}0.95 \\
5\end{array}$ & $\begin{array}{r}0.95 \\
1\end{array}$ & $\begin{array}{r}0.94 \\
7\end{array}$ & 0.943 \\
\hline Gujrat nar & $\begin{array}{r}0.99 \\
8\end{array}$ & $\begin{array}{r}0.99 \\
6\end{array}$ & $\begin{array}{r}0.99 \\
3\end{array}$ & $\begin{array}{r}0.99 \\
1\end{array}$ & $\begin{array}{r}0.98 \\
9\end{array}$ & $\begin{array}{r}0.98 \\
8\end{array}$ & $\begin{array}{r}0.98 \\
6\end{array}$ & $\begin{array}{r}0.98 \\
4\end{array}$ & $\begin{array}{r}0.98 \\
3\end{array}$ & $\begin{array}{r}0.98 \\
1\end{array}$ & $\begin{array}{r}0.97 \\
9\end{array}$ & $\begin{array}{r}0.97 \\
7\end{array}$ & $\begin{array}{r}0.97 \\
5\end{array}$ & $\begin{array}{r}0.97 \\
4\end{array}$ & $\begin{array}{r}0.97 \\
2\end{array}$ & 0.969 \\
\hline Harrison & $\begin{array}{r}0.99 \\
7\end{array}$ & $\begin{array}{r}0.99 \\
3\end{array}$ & $\begin{array}{r}0.98 \\
9\end{array}$ & $\begin{array}{r}0.98 \\
5\end{array}$ & $\begin{array}{r}0.98 \\
2\end{array}$ & $\begin{array}{r}0.97 \\
8\end{array}$ & $\begin{array}{r}0.97 \\
5\end{array}$ & $\begin{array}{r}0.97 \\
1\end{array}$ & $\begin{array}{r}0.96 \\
8\end{array}$ & $\begin{array}{r}0.96 \\
5\end{array}$ & $\begin{array}{r}0.96 \\
2\end{array}$ & $\begin{array}{r}0.95 \\
9\end{array}$ & $\begin{array}{r}0.95 \\
6\end{array}$ & $\begin{array}{r}0.95 \\
3\end{array}$ & $\begin{array}{r}0.94 \\
9\end{array}$ & 0.945 \\
\hline Hindalco & $\begin{array}{r}0.99 \\
7\end{array}$ & $\begin{array}{r}0.99 \\
5\end{array}$ & $\begin{array}{r}0.99 \\
2\end{array}$ & $\begin{array}{r}0.98 \\
9\end{array}$ & $\begin{array}{r}0.98 \\
6\end{array}$ & $\begin{array}{r}0.98 \\
4\end{array}$ & $\begin{array}{r}0.98 \\
1\end{array}$ & $\begin{array}{r}0.97 \\
8\end{array}$ & $\begin{array}{r}0.97 \\
5\end{array}$ & $\begin{array}{r}0.97 \\
2\end{array}$ & $\begin{array}{r}0.97 \\
0\end{array}$ & $\begin{array}{r}0.96 \\
7\end{array}$ & $\begin{array}{r}0.96 \\
4\end{array}$ & $\begin{array}{r}0.96 \\
2\end{array}$ & $\begin{array}{r}0.95 \\
9\end{array}$ & 0.957 \\
\hline Ind.Hotel & $\begin{array}{r}0.99 \\
6\end{array}$ & $\begin{array}{r}0.99 \\
2\end{array}$ & $\begin{array}{r}0.98 \\
9\end{array}$ & $\begin{array}{r}0.98 \\
5\end{array}$ & $\begin{array}{r}0.98 \\
1\end{array}$ & $\begin{array}{r}0.97 \\
7\end{array}$ & $\begin{array}{r}0.97 \\
4\end{array}$ & $\begin{array}{r}0.97 \\
0\end{array}$ & $\begin{array}{r}0.96 \\
7\end{array}$ & $\begin{array}{r}0.96 \\
3\end{array}$ & $\begin{array}{r}0.96 \\
0\end{array}$ & $\begin{array}{r}0.95 \\
6\end{array}$ & $\begin{array}{r}0.95 \\
3\end{array}$ & $\begin{array}{r}0.94 \\
9\end{array}$ & $\begin{array}{r}0.94 \\
6\end{array}$ & 0.942 \\
\hline Ind.Reyon & $\begin{array}{r}0.99 \\
9\end{array}$ & $\begin{array}{r}0.99 \\
8\end{array}$ & $\begin{array}{r}0.99 \\
6\end{array}$ & $\begin{array}{r}0.99 \\
5\end{array}$ & $\begin{array}{r}0.99 \\
4\end{array}$ & $\begin{array}{r}0.99 \\
2\end{array}$ & $\begin{array}{r}0.99 \\
1\end{array}$ & $\begin{array}{r}0.99 \\
0\end{array}$ & $\begin{array}{r}0.98 \\
8\end{array}$ & $\begin{array}{r}0.98 \\
7\end{array}$ & $\begin{array}{r}0.98 \\
6\end{array}$ & $\begin{array}{r}0.98 \\
4\end{array}$ & $\begin{array}{r}0.98 \\
3\end{array}$ & $\begin{array}{r}0.98 \\
1\end{array}$ & $\begin{array}{r}0.98 \\
0\end{array}$ & 0.978 \\
\hline ITC badra & $\begin{array}{r}0.99 \\
5\end{array}$ & $\begin{array}{r}0.99 \\
1\end{array}$ & $\begin{array}{r}0.98 \\
7\end{array}$ & $\begin{array}{r}0.98 \\
2\end{array}$ & $\begin{array}{r}0.97 \\
8\end{array}$ & $\begin{array}{r}0.97 \\
3\end{array}$ & $\begin{array}{r}0.96 \\
9\end{array}$ & $\begin{array}{r}0.96 \\
5\end{array}$ & $\begin{array}{r}0.96 \\
1\end{array}$ & $\begin{array}{r}0.95 \\
7\end{array}$ & $\begin{array}{r}0.95 \\
3\end{array}$ & $\begin{array}{r}0.94 \\
9\end{array}$ & $\begin{array}{r}0.94 \\
5\end{array}$ & $\begin{array}{r}0.94 \\
2\end{array}$ & $\begin{array}{r}0.93 \\
8\end{array}$ & 0.935 \\
\hline ONGC & $\begin{array}{r}0.99 \\
8\end{array}$ & $\begin{array}{r}0.99 \\
6\end{array}$ & $\begin{array}{r}0.99 \\
4\end{array}$ & $\begin{array}{r}0.99 \\
2\end{array}$ & $\begin{array}{r}0.99 \\
0\end{array}$ & $\begin{array}{r}0.98 \\
9\end{array}$ & $\begin{array}{r}0.98 \\
7\end{array}$ & $\begin{array}{r}0.98 \\
5\end{array}$ & $\begin{array}{r}0.98 \\
3\end{array}$ & $\begin{array}{r}0.98 \\
1\end{array}$ & $\begin{array}{r}0.98 \\
0\end{array}$ & $\begin{array}{r}0.97 \\
8\end{array}$ & $\begin{array}{r}0.97 \\
6\end{array}$ & $\begin{array}{r}0.97 \\
6\end{array}$ & $\begin{array}{r}0.97 \\
4\end{array}$ & 0.970 \\
\hline Tata Steel & $\begin{array}{r}0.99 \\
8\end{array}$ & $\begin{array}{r}0.99 \\
6\end{array}$ & $\begin{array}{r}0.99 \\
3\end{array}$ & $\begin{array}{r}0.99 \\
1\end{array}$ & $\begin{array}{r}0.98 \\
9\end{array}$ & $\begin{array}{r}0.98 \\
7\end{array}$ & $\begin{array}{r}0.98 \\
5\end{array}$ & $\begin{array}{r}0.98 \\
3\end{array}$ & $\begin{array}{r}0.98 \\
0\end{array}$ & $\begin{array}{r}0.97 \\
8\end{array}$ & $\begin{array}{r}0.97 \\
6\end{array}$ & $\begin{array}{r}0.97 \\
3\end{array}$ & $\begin{array}{r}0.97 \\
1\end{array}$ & $\begin{array}{r}0.96 \\
9\end{array}$ & $\begin{array}{r}0.96 \\
7\end{array}$ & 0.964 \\
\hline Wipro & $\begin{array}{r}0.99 \\
3\end{array}$ & $\begin{array}{r}0.98 \\
7\end{array}$ & $\begin{array}{r}0.97 \\
9\end{array}$ & $\begin{array}{r}0.97 \\
2\end{array}$ & $\begin{array}{r}0.96 \\
5\end{array}$ & $\begin{array}{r}0.95 \\
8\end{array}$ & $\begin{array}{r}0.95 \\
3\end{array}$ & $\begin{array}{r}0.94 \\
8\end{array}$ & $\begin{array}{r}0.94 \\
2\end{array}$ & $\begin{array}{r}0.93 \\
7\end{array}$ & $\begin{array}{r}0.93 \\
1\end{array}$ & $\begin{array}{r}0.92 \\
5\end{array}$ & $\begin{array}{r}0.91 \\
8\end{array}$ & $\begin{array}{r}0.91 \\
0\end{array}$ & $\begin{array}{r}0.90 \\
3\end{array}$ & 0.895 \\
\hline BSE & 0.99 & 0.99 & 0.99 & 0.99 & 0.99 & 0.99 & 0.99 & 0.98 & 0.98 & 0.98 & 0.98 & 0.98 & 0.98 & 0.97 & 0.97 & 0.976 \\
\hline
\end{tabular}




\begin{tabular}{|l|l|l|l|l|l|l|l|l|l|l|l|l|l|l|l|l|l|}
\hline Sensex30 & 8 & 7 & 5 & 4 & 2 & 1 & & 8 & 7 & 5 & 4 & 2 & 1 & 9 & 8 & & \\
\hline
\end{tabular}

TABLE No.7.2 shows the coefficient of autocorrelation of 20 stocks and BSE Sensex 30. It can be noted that all stocks have autocorrelation above 0.9 . The $t$ test and probable error confirm the significance of autocorrelation. Therefore the null hypothesis that the price series of stocks and BSE Sensex 30 are random is rejected and it is resolved that the series have serial correlation, interdependence and non-randomness. The descriptive statistics of 20 stocks and the BSE index reveal that the price distribution is not normal. The autocorrelation test is not dependable if the distribution is not normal since the test is parametric. Therefore nonparametric test runs is used to test randomness.

Table No.7.3 Runs Test

\begin{tabular}{|c|c|c|c|c|c|c|}
\hline Scrips & $\mathrm{N}$ & Exp.Runs & Runs & Std.Dev. & $\mathrm{Z}$ & Table value \\
\hline $\mathrm{ACC}$ & 2773 & 1343.32 & 13 & 25.49 & -52.2 & 1.96 \\
\hline Appollo & 2746 & 1353.2 & 11 & 25.80 & -52.02 & 1.96 \\
\hline Aravind Mills & 2748 & 1308.18 & 69 & 24.93 & -49.7 & 1.96 \\
\hline Ashok Leyland & 2752 & 1192.4 & 45 & 22.71 & -50.53 & 1.96 \\
\hline Asian Paints & 2752 & 1265.33 & 10 & 24.10 & -52.1 & 1.96 \\
\hline Axis Bank & 2744 & 1267.2 & 16 & 24.17 & -51.77 & 1.96 \\
\hline Ballarpur Industries & 2730 & 1334.91 & 51 & 25.52 & -50.3 & 1.96 \\
\hline Castrol & 2756 & 1185.03 & 65 & 22.55 & -49.67 & 1.96 \\
\hline Colgate Palmolive & 2744 & 1298.36 & 20 & 24.76 & -51.63 & 1.96 \\
\hline Crompton Greeves & 2748 & 1303.7 & 24 & 24.85 & -51.51 & 1.96 \\
\hline Garware Polyester & 2722 & 1344.35 & 36 & 25.74 & -50.82 & 1.96 \\
\hline Gujarat Narmada & 2751 & 1336.18 & 16 & 25.45 & -51.87 & 1.96 \\
\hline Harrisons Malayalam & 2678 & 1316.6 & 14 & 25.42 & -51.25 & 1.96 \\
\hline Hindalco & 2766 & 1379.02 & 25 & 26.20 & -51.69 & 1.96 \\
\hline Indian Hotels & 2748 & 1234.1 & 28 & 23.52 & -51.29 & 1.96 \\
\hline Indian Reyons & 2746 & 1291.28 & 8 & 24.62 & -52.13 & 1.96 \\
\hline ITC & 2772 & 1341.91 & 26 & 25.46 & -51.68 & 1.96 \\
\hline ONGC & 2752 & 1363.16 & 26 & 25.96 & -51.51 & 1.96 \\
\hline Tata Steel Ltd. & 2772 & 1380.49 & 14 & 26.20 & -52.16 & 1.96 \\
\hline Wipro & 2819 & 1338.53 & 42 & 25.19 & -51.48 & 1.96 \\
\hline BSE Sensex30 & 2743 & 1303.56 & 6 & 24.87 & -52.18 & 1.96 \\
\hline Average & 2750 & 1309 & 27 & 25 & -51 & 1.96 \\
\hline
\end{tabular}

TABLE No.7.3 shows the runs details of the stocks and the BSE index. The sum of above and below the test values on an average $(\mathrm{N})$ is 2750 cases. The runs observed on average are 27 in contrast to the expected 1309. The standard deviation of runs from the expected is 25 , which is normal at $5 \%$ level of significance. The standard normal approximate ' $Z$ ' in all cases is on average is -51. For randomness the $Z$ value should be in between \pm 1.96 . Here, the $Z$ is not in between \pm 1.96 . The $Z$ value is lower than -1.96 on the left tail. Hence, the null hypothesis that the price series is random is rejected. There is non-randomness in the series.

The prices of the stocks and market index are analyzed below separately and individually.

\subsection{ACC}

Table No.7.1.1 Descriptive Statistics of ACC

\begin{tabular}{|l|l|}
\hline MINIMUM & 84.9 \\
\hline MAXIMUM & 1985.25 \\
\hline MEAN & 457.20 \\
\hline MEDIAN & 274.65 \\
\hline STANDARD DEVIATION & 345.75 \\
\hline SKEWNESS & 0.046 \\
\hline KURTOSIS & -0.246 \\
\hline NO. OF OBSERVATION & 2773 \\
\hline
\end{tabular}

TABLE No.7.1.1 above provides evidence for asymmetrical distribution of stock prices. The distribution is not normal. In normal distribution mean and median should coincide. But in the case of ACC there is wide difference between the mean and median. There is big difference between the minimum and maximum prices. The standard deviation is Rs. 345.75 which is bigger. The coefficient of variation $=\frac{\sigma}{\bar{x}}=\frac{345.75}{457.20}=$ $75.62 \%$. The standard deviation of the stock price of ACC is very high. It denotes the presence of large amount of volatility and large scale mispricing of stocks. There is a little positive skewness to the value of 0.046 . The distribution is positively skewed. Normal distribution is zero skewness state. It is a very strong evidence for that the distribution is not normal. The coefficient of kurtosis in a normal distribution is 3 . Here the kurtosis is -0.246 which denotes a platykurtic shape to the left tail. The evidence given by the difference in the mean and median, the copious standard deviation, the positive skewness, and a kurtosis below 3, all provide strong evidences for saying that the series is not normally distributed. Efficient market envisages normal distribution where the value 
and price of stocks coincide when successive changes in prices are random. Hence, the descriptive statistics negate the null hypothesis and provides evidences for non-randomness of ACC Stock.

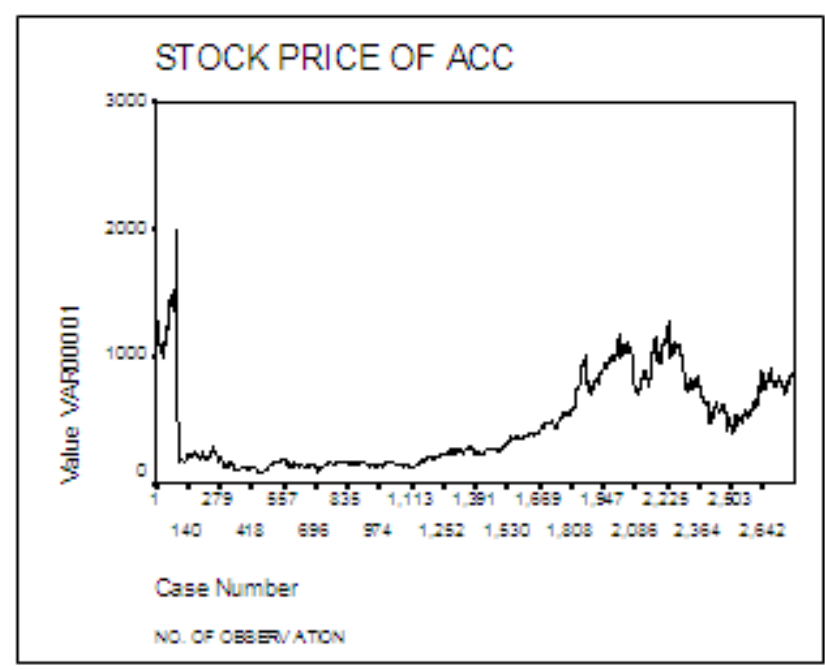

Figure 7.1.1: Stock price of ACC over 2773 days during 1999-2009

Fig.7.1.1 depicts the movement of stock price of ACC. Stock price starts from Rs.1010 on Jan 1999, rises sharply about Rs.2000 and falls steadily to Rs. 162 on $17^{\text {th }}$ May 1999. It is a great fall for ACC, thereafter the price is in the same range up to the observation of 1391. Then the price rises to the level of 1000. High volatility in the distribution can be seen from the figure. Minimum and maximum prices can be detected from the figure.

Table No.7.1.2 Autocorrelation of prices of ACC in 16 lags

\begin{tabular}{|l|r|r|r|r|r|r|r|r|r|r|r|r|r|r|r|r|}
\hline Lags & $\mathbf{1}$ & $\mathbf{2}$ & $\mathbf{3}$ & $\mathbf{4}$ & $\mathbf{5}$ & $\mathbf{6}$ & $\mathbf{7}$ & $\mathbf{8}$ & $\mathbf{9}$ & $\mathbf{1 0}$ & $\mathbf{1 1}$ & $\mathbf{1 2}$ & $\mathbf{1 3}$ & $\mathbf{1 4}$ & $\mathbf{1 5}$ & $\mathbf{1 6}$ \\
\hline ACC & 0.993 & 0.987 & 0.981 & 0.976 & 0.970 & 0.965 & 0.960 & 0.956 & 0.952 & 0.947 & 0.943 & 0.939 & 0.935 & 0.930 & 0.926 & 0.921 \\
\hline
\end{tabular}

TABLE No7.1.2 provides autocorrelation coefficient of ACC price series in 16 lags. Although correlation is given for 16 lags the value of correlation in the first lag is statistically significant. It can be seen from the table that the auto correlation in all 16 lags is above 0.9. Auto correlation above 0.5 is significant. Therefore, the null hypothesis that the price series is random is rejected. It signals significant evidence for interdependence.

Table No.7.1.3 Student's ' $t$ ' test

\begin{tabular}{|l|c|c|c|r|r|r|r|r|r|}
\hline Stock & $\mathrm{r}$ & $\mathrm{N}-2$ & $\sqrt{\mathrm{N}-2}$ & $\mathrm{r}^{2}$ & $1-\mathrm{r}^{2}$ & $\sqrt{1-\mathrm{r}^{2}}$ & $\mathrm{r} / \sqrt{1-\mathrm{r}^{2}}$ & $\mathrm{H} * \mathrm{D}(\mathrm{t})$ & $\mathrm{Table} @ 5 \%$ \\
\hline ACC & 0.993 & 2770 & 52.63079 & 0.986 & 0.014 & 0.118 & 8.39 & 442 & 1.96 \\
\hline
\end{tabular}

As per TABLE No.7.1.3, the auto correlation of ACC in the first lag is 0.993 . The $t$ value calculated is 442 and table value at $5 \%$ significance is 1.96 . T value calculated is greater than the table value $(442>1.96)$. Therefore, the autocorrelation coefficient is significant in the first lag.

Table No.7.1.4 Student's t test for Lag 16

\begin{tabular}{|l|l|l|l|l|l|l|l|l|l|}
\hline Scrip & $\mathrm{r}$ & $\mathrm{N}-2$ & $\sqrt{\mathrm{N}}-2$ & $\mathrm{r}^{2}$ & $1-\mathrm{r}^{2}$ & $\sqrt{1-\mathrm{r}^{2}}$ & $\mathrm{r} / \sqrt{ } 1-\mathrm{r}^{2}$ & $\mathrm{H} * \mathrm{D}$ & Table \\
\hline ACC & 0.921 & 2770 & 52.63079 & 0.848 & 0.152 & 0.390 & 2.36 & 124 & 1.96 \\
\hline
\end{tabular}

TABLE No.7.1.4 shows t test for the 16th lag of price of stock ACC. Auto correlation in the 16th lag is 0.921 . The calculated value of $t$ is given as 124 . The table value for the same is 1.96 . The calculated $t$ value 124 is greater than the table value 1.96. Hence the autocorrelation in 16th lag is significant.

Table No.7.1.5 Calculation of Probable Error in Lag 1

\begin{tabular}{|l|l|r|r|r|r|r|r|r|l|}
\hline Stock & $\mathrm{r}$ & \multicolumn{1}{|c|}{$\mathrm{r}^{2}$} & $1-\mathrm{r}^{2}$ & $\mathrm{~N}$ & $\sqrt{\mathrm{N}}$ & $1-\mathrm{r}^{2} / \sqrt{\mathrm{N}}$ & multiplier & $\mathrm{PE}$ & $6(\mathrm{PE})$ \\
\hline ACC & 0.993 & 0.986 & 0.014 & 2772 & 52.64979 & 0.00027 & 0.6745 & 0.00018 & 0.00108 \\
\hline
\end{tabular}

Probable error for the autocorrelation 0.993 in the first lag is 0.00018. See TABLE No.7.1.5 above. The coefficient of autocorrelation is greater than the PE $(0.993>0.00018)$. The autocorrelation 0.993 is still higher than the 6 times PE 0.00108 ( $r>6(P E))$. Hence the autocorrelation 0.993 is significant.

Table No.7.1.6 Calculation of Probable Error in Lag 16

\begin{tabular}{|l|l|l|l|l|l|r|r|r|r|}
\hline Stock & $\mathrm{r}$ & \multicolumn{1}{|c|}{$\mathrm{r}^{2}$} & $1-\mathrm{r}^{2}$ & $\mathrm{~N}$ & $\sqrt{\mathrm{N}}$ & $1-\mathrm{r}^{2} / \sqrt{\mathrm{N}}$ & multiplier & PE & $6(\mathrm{PE})$ \\
\hline ACC & 0.921 & 0.848 & 0.152 & 2772 & 52.64 & 0.00289 & 0.6745 & 0.00195 & 0.0117 \\
\hline
\end{tabular}


Probable error for the autocorrelation 0.921 in lag 16 is 0.00195 . See TABLE No.7.1.6 above. The coefficient of autocorrelation is greater than the PE $(0.993>0.0195)$. The autocorrelation 0.921 is still higher than the 6 times PE 0.0117 ( $r>6(\mathrm{PE})$ ). Hence the autocorrelation 0.921 in lag 16 is significant.

Table No. 7.1.7 Runs test descriptive statistics

\begin{tabular}{|l|l|}
\hline Test Values & 457.1997 \\
\hline Cases $<$ Test Values & 1634 \\
\hline Cases $>$ Test Values & 1139 \\
\hline Total Cases & 2773 \\
\hline No. of runs & 13 \\
\hline Z & -52.1990 \\
\hline Asym.sig (2-tailed) & 0.0 \\
\hline Expected runs R & 1343.32 \\
\hline$\sigma$ of runs & 25.49 \\
\hline Table Value @ 5\% significance & -1.96 \\
\hline
\end{tabular}

TABLE No.7.1.7 above shows the descriptive statistics for the runs test. The mean value of stock price is 457.1997. Cases below the mean are 1634 and above are 1139. There are 13 runs in the series. The expected runs are 1343 and the standard deviation of runs is 25.49 . The actual runs in the price series are lower than the expected $(13<1343)$. Too few runs indicate stationary state of the series. The $\mathrm{z}$ value calculated is -52.2 whereas the table value for the same at $5 \%$ level of significance is -1.96 on the left tail. The $\mathrm{z}$ calculated is lower than the table value $(-52.2<-1.96)$. Therefore the null hypothesis that the series is random is rejected and resolved that there is interdependence and non-randomness in the closing price series of ACC.

\subsection{Appollo Tyres}

Table No.7.2.1 Descriptive Statistics of ACC

\begin{tabular}{|l|l|}
\hline MINIMUM & 14.95 \\
\hline MAXIMUM & 401.4 \\
\hline MEAN & 148.6972 \\
\hline MEDIAN & 118.0250 \\
\hline STANDARD DEVIATION & 103.9929 \\
\hline SKEWNESS & 0.482 \\
\hline KURTOSIS & -1.136 \\
\hline NO. OF OBSERVATION & 2746 \\
\hline
\end{tabular}

TABLE No.7.2.1 above provides evidence for asymmetrical distribution of stock prices of Appollo. The distribution is not normal. In normal distribution mean and median should coincide. But in the case of Appollo there is wide difference between the mean and median. The difference between the minimum and maximum price is very high. The standard deviation is Rs.103.99 which is bigger. The coefficient of variation= $\frac{\sigma}{\overline{\mathrm{X}}}=\frac{103.9929}{148.6972}=69.94 \%$. The standard deviation beyond $3 \sigma$ is significant. The standard deviation of the stock price of Appollo is very high. It denotes the presence of large amount of volatility and large scale mispricing of stocks. There is positive skewness to the value of 0.482 . The distribution is positively skewed. Normal distribution is zero skewness state. It is a strong evidence that the distribution is not normal. The coefficient of kurtosis in a normal distribution is 3 . Here the kurtosis is -1.136 which denotes a platykurtic shape to the left tail. The evidence given by the difference in the mean and median, the large standard deviation, the positive skewness, and a kurtosis below 3 are all provide strong evidences for saying that the series is not normally distributed. Efficient market envisages normal distribution where the value and price of stocks coincide when successive changes in prices are random. Hence, the descriptive statistics negate the null hypothesis and provides evidences for non-randomness of Appollo’s Stock. 


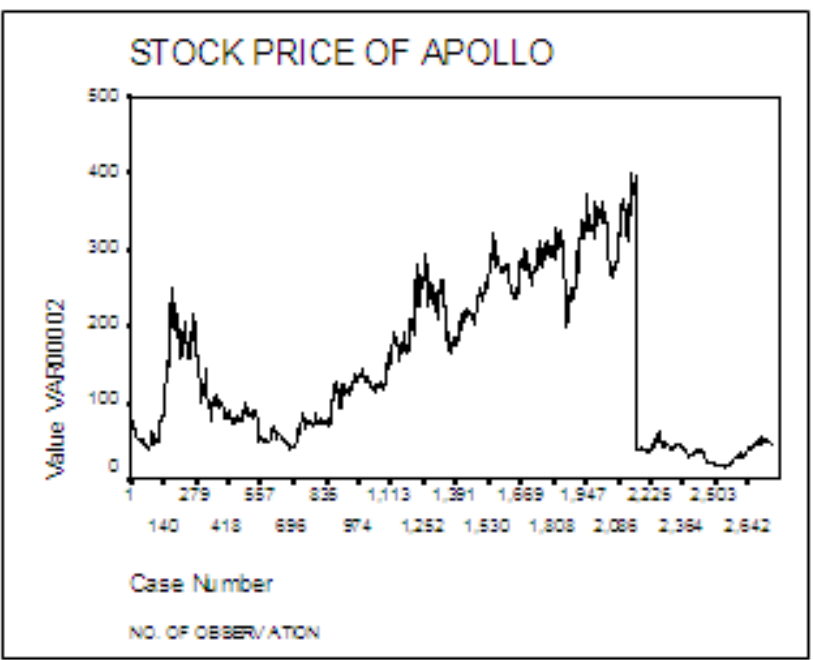

Figure No.7.2.1: Stock price of Appollo over 2746 days during 1999-2009

Fig.7.2.1 depicts the movement of stock price of Appollo. Stock price starts from Rs.64.85 on Jan 1999, rises sharply to Rs.200-300 during the close of the year and declines sharply below Rs.100 during 200001. It gradually tends to increase and reach more than 400 after 2000days. Then the price nosedives to below Rs. 50 at $2225^{\text {th }}$ observation. It is a great fall for Appollo. The overall tendency of the price is to zigzag overwhelmingly and to decline. High volatility in the distribution can be seen from the figure.

Table No.7.2.2 Autocorrelation of prices of Appollo Tyres in 16 lags

\begin{tabular}{|l|r|r|r|r|r|r|r|r|r|r|r|r|r|r|r|r|}
\hline Lags & 1 & 2 & 3 & 4 & 5 & 6 & 7 & 8 & 9 & 10 & 11 & 12 & 13 & 14 & 15 & 16 \\
\hline Apollo & 0.997 & 0.993 & 0.990 & 0.986 & 0.983 & 0.979 & 0.976 & 0.972 & 0.969 & 0.966 & 0.962 & 0.959 & 0.955 & 0.952 & 0.948 & 0.944 \\
\hline
\end{tabular}

TABLE No.7.2.2 provides autocorrelation coefficient of Appollo Tyres' price series in 16 lags. Although correlation is given for 16 lags the value of correlation in the first lag is statistically significant. It can be seen from the table that the auto correlation in all 16 lags is above 0.9 . Auto correlation above 0.5 is significant. Therefore, the null hypothesis that the price series is random is rejected. It signals significant evidence for interdependence.

Table No. 7.2.3 Student's 't' test Lag 1

\begin{tabular}{|l|l|l|l|l|l|l|l|l|r|}
\hline Stock & $\mathbf{r}$ & $\mathbf{N}-2$ & $\sqrt{\mathrm{N}}-2$ & $\mathbf{r}^{2}$ & $\mathbf{1 - \mathbf { r } ^ { 2 }}$ & $\sqrt{\mathbf{1}-\mathbf{r}^{\mathbf{2}}}$ & $\mathbf{r} / \sqrt{\mathbf{1}-\mathbf{r}^{2}}$ & $\mathbf{H}^{*} \mathbf{D}$ & Table \\
\hline Apollo & $\mathbf{0 . 9 9 7}$ & $\mathbf{2 7 4 3}$ & 52.37366 & $\mathbf{0 . 9 9 4}$ & $\mathbf{0 . 0 0 6}$ & $\mathbf{0 . 0 7 7}$ & $\mathbf{1 2 . 8 7}$ & $\mathbf{6 7 4}$ & $\mathbf{1 . 9 6}$ \\
\hline
\end{tabular}

As per TABLE No.7.2.3, the auto correlation of Appollo Tyres' in the first lag is 0.997. The $t$ value calculated is 674 and table value at $5 \%$ significance is 1.96 . T value calculated is greater than the table value $(674>1.96)$. The autocorrelation coefficient is significant in the first lag.

Table No.7.2.4 Student's t test Lag 16

\begin{tabular}{|c|c|c|c|c|c|r|r|r|r|}
\hline Scrip & $\mathrm{r}$ & $\mathrm{N}-2$ & $\sqrt{\mathrm{N}-2}$ & $\mathrm{r}^{2}$ & $1-\mathrm{r}^{2}$ & $\sqrt{1-\mathrm{r}^{2}}$ & $\mathrm{r} / \sqrt{1-\mathrm{r}^{2}}$ & $\mathrm{H}^{*} \mathrm{D}$ & \multicolumn{1}{|c|}{ Table } \\
\hline Apollo & 0.944 & 2743 & 52.37366 & 0.891 & 0.109 & 0.330 & 2.86 & 150 & 1.96 \\
\hline
\end{tabular}

TABLE No.7.2.4 cites t test for the $16^{\text {th }}$ lag of price of stock Appollo Tyres. Auto correlation in the $16^{\text {th }}$ lag is 0.944 . The calculated value of $t$ is given in as 150 . The table value for the same is 1.96 . The calculated $t$ value 150 is greater than the table value 1.96 . Hence the autocorrelation in $16^{\text {th }}$ lag is significant.

Table No.7.2.5 Calculation of Probable Error in Lag 1

\begin{tabular}{|c|c|c|c|c|c|c|c|c|c|}
\hline Stock & $\mathrm{r}$ & $r^{2}$ & $1-r^{2}$ & $\mathrm{~N}$ & $\sqrt{N}$ & $1-\mathrm{r}^{2} / \sqrt{\mathrm{N}}$ & multiplier & PE & $6(\mathrm{PE})$ \\
\hline Apollo & 0.997 & 0.994 & 0.006 & 2745 & 52.39275 & 0.00011 & 0.6745 & 0.00007 & 0.00042 \\
\hline
\end{tabular}
coefficient of autocorrelation is greater than the PE $(0.997>0.00007)$. The autocorrelation 0.997 is still higher than the 6 times PE 0.00042 ( $r>6(\mathrm{PE}))$. Hence the autocorrelation 0.997 of Appollo Tyres is significant.

Table No.7.2.6 Calculation of Probable Error in Lag 16.

\begin{tabular}{|l|l|l|l|l|l|l|l|l|l|}
\hline Stock & $\mathrm{r}$ & $\mathrm{r}^{2}$ & $1-\mathrm{r}^{2}$ & $\mathrm{~N}$ & $\sqrt{\mathrm{N}}$ & $1-\mathrm{r}^{2} / \sqrt{\mathrm{N}}$ & multiplier & $\mathrm{PE}$ & $6(\mathrm{PE})$ \\
\hline Apollo & 0.944 & 0.891 & 0.109 & 2745 & 52.39275 & 0.00208 & 0.6745 & 0.0014 & 0.0084 \\
\hline
\end{tabular}
coefficient of autocorrelation is greater than the PE $(0.944>0.0014)$. The autocorrelation 0.944 is still higher than the 6 times PE 0.0084 ( $>$ 6(PE)). Hence the autocorrelation 0.944 of Appollo Tyres in lag 16 is significant. 
Table No.7.2.7 Run test descriptive statistics of Appollo Tyres

\begin{tabular}{|l|l|}
\hline Test Values & 148.6972 \\
\hline Cases $<$ Test Values & 1542 \\
\hline Cases $>$ Test Values & 1204 \\
\hline Total Cases & 2746 \\
\hline No. of runs & 11 \\
\hline Z & -52.03 \\
\hline Asym.sig (2-tailed) & 0.0 \\
\hline Expected runs R & 1353.2 \\
\hline$\sigma$ of runs & 25.80 \\
\hline Table Value @ 5\% significance & 1.96 \\
\hline
\end{tabular}

As per TABLE No.7.2.7, the mean value of stock price is 148.69. Cases below the mean are 1542 and above are 1204. There are 11 runs in the series. The expected runs are 1353 and the standard deviation of runs is 25.80. The actual runs in the price series are lower than the expected $(11<1353)$. Too few runs indicate stationary state of the series. The $\mathrm{z}$ value calculated is -52.03 whereas the table value for the same at $5 \%$ level of significance is -1.96 on the left tail. The $\mathrm{z}$ calculated is lower than the table value $(-52.2<-1.96)$. Therefore the null hypothesis that the series is random is rejected and resolved that there is interdependence and nonrandomness in the closing price series of ACC.

\subsection{Aravind Mills}

Table No.7.3.1: Descriptive Statistics of Aravind Mills

\begin{tabular}{|l|l|}
\hline MINIMUM & 6.9 \\
\hline MAXIMUM & 142.05 \\
\hline MEAN & 45.4233 \\
\hline MEDIAN & 36.78 \\
\hline STANDARD DEVIATION & 34.62 \\
\hline SKEWNESS & 1.11 \\
\hline KURTOSIS & 0.389 \\
\hline NO. OF OBSERVATION & 2748 \\
\hline
\end{tabular}

TABLE No.7.3.1 above shows that the mean of the price series of Aravind Mills is 45.42. The median value is 36.78 . There is difference between mean and median. Therefore the distribution is not normal because in normal distribution the mean and median are the same. RWH (Random-walk Hypothesis) presupposes a normal distribution to constitute an efficient market. The standard deviation 34.62 is bigger. The coefficient of variation $=\frac{\sigma}{\bar{x}}=\frac{34.62}{45.42}=76.22 \%$. The $\sigma$ is too large for normal distribution. The difference between the minimum price and maximum price is greater. There is high degree of positive skewness to the tune of 1.11. In a normal distribution skewness will be zero. The high positive skewness nullifies the null hypothesis and confirms nonrandomness. The statistic kurtosis is lower than 3. The shape of the distribution, therefore, is platykurtic once again confirms asymmetry and non-randomness in the series.

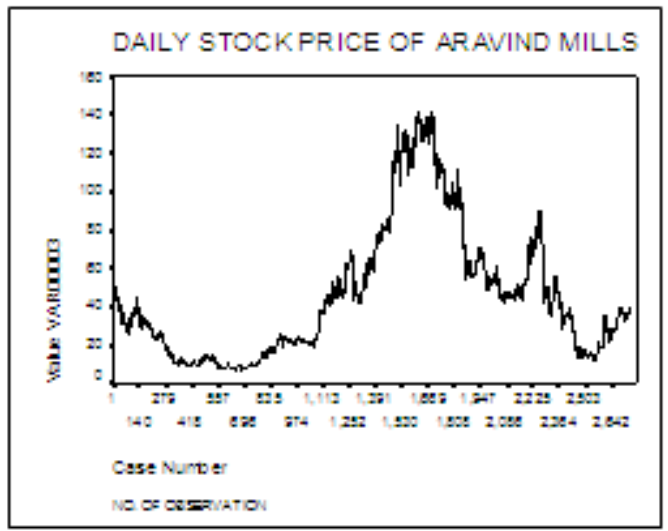

Figure 7.3.1: Stock price of Aravind Mills over 2748 days during 1999-2009

Fig.7.3.1 depicts the behavior of stock price of Aravind Mills. On the first day of January 1999 the stock starts with a price of Rs.39. Then it falls below Rs.20 for some time and then rise to more than Rs. 140 after $1391^{\text {st }}$ day of observation. After that it again falls down to Rs.20. The overall tendency of the price is to decline. The price is never stable. It was highly volatile during the period.

Table No.7.3.2 Autocorrelation of prices of Aravind Mills in 16 lags

\begin{tabular}{|c|c|c|c|c|c|c|c|c|c|c|c|c|c|c|c|c|}
\hline Lags & 1 & 2 & 3 & 4 & 5 & 6 & 7 & 8 & 9 & 10 & 11 & 12 & 13 & 14 & 15 & 16 \\
\hline Araavin & 0.99 & 0.99 & 0.99 & 0.99 & 0.99 & 0.99 & 0.99 & 0.98 & 0.98 & 0.98 & 0.98 & 0.98 & 0.98 & 0.98 & 0.98 & 0.97 \\
\hline $\mathrm{d}$ & 9 & 7 & 6 & 5 & 3 & 2 & 1 & 9 & 8 & 7 & 5 & 4 & 3 & 1 & 0 & 9 \\
\hline
\end{tabular}


TABLE No.7.3.2 provides autocorrelation coefficient of Aravind Mills' price series in 16 lags. Although correlation is given for 16 lags the value of correlation in the first lag is statistically significant. It can be seen from the table that the auto correlation in all 16 lags is above 0.9. Auto correlation above 0.5 is significant. Therefore, the null hypothesis that the price series is random is rejected. It signals significant evidence for interdependence non-randomness.

Table No.7.3.3: Student's 't' test in Lag 1

\begin{tabular}{|l|l|l|l|l|l|l|l|l|l|}
\hline Stock & $\mathrm{r}$ & \multicolumn{1}{|c|}{$\mathrm{N}-2$} & $\sqrt{\mathrm{N}}-2$ & $\mathrm{r}^{2}$ & $1-\mathrm{r}^{2}$ & $\sqrt{1-\mathrm{r}^{2}}$ & $\mathrm{r} / \sqrt{1-r^{2}}$ & $\mathrm{H}^{*} \mathrm{D}$ & $\mathrm{Tab}_{\mathrm{e}}$ \\
\hline Aravind & 0.999 & 2746 & 52.40229 & 0.998 & 0.002 & 0.045 & 22.34 & 1171 \\
\hline
\end{tabular}

As per TABLE No.7.3.3, the auto correlation of Aravind Mills in the first lag is 0.999 . The $t$ value calculated is 1171 and table value at $5 \%$ significance is 1.96 . T value calculated is greater than the table value (1171>1.96). The autocorrelation coefficient is significant in the first lag.

Table No.7.3.4: Student's t test in Lag 16

\begin{tabular}{|c|c|c|c|c|c|c|r|r|r|}
\hline Scrip & $\mathrm{r}$ & $\mathrm{N}-2$ & $\sqrt{\mathrm{N}-2}$ & $\mathrm{r}^{2}$ & $1-\mathrm{r}^{2}$ & $\sqrt{1-\mathrm{r}^{2}}$ & $\mathrm{r} / \sqrt{1-\mathrm{r}^{2}}$ & $\mathrm{H}^{*} \mathrm{D}$ & Table \\
\hline Aravind & 0.979 & 2746 & 52.40229 & 0.958 & 0.042 & 0.205 & 4.78 & 250 & 1.96 \\
\hline
\end{tabular}

TABLE No. 7.3.4 cites t test for the $16^{\text {th }}$ lag of price of stock Aravind Mills. Auto correlation in the $16^{\text {th }}$ lag is 0.979 . The calculated value of $t$ is given as 250 . The table value for the same is 1.96 . The calculated $t$ value 250 is greater than the table value 1.96 . Hence the autocorrelation in $16^{\text {th }}$ lag is significant.

Table No.7.3.5: Calculation of Probable Error in Lag 1

\begin{tabular}{|c|c|c|c|c|c|c|c|c|c|}
\hline Stock & $\mathrm{r}$ & $r^{2}$ & $1-r^{2}$ & $\mathrm{~N}$ & $\sqrt{N}$ & $1-\mathrm{r}^{2} / \sqrt{\mathrm{N}}$ & multiplier & $\mathrm{PE}$ & $6(\mathrm{PE})$ \\
\hline Aravind & 0.999 & 0.998 & 0.002 & 2748 & 52.42137 & 0.00004 & 0.6745 & 0.00003 & 0.00018 \\
\hline
\end{tabular}

Probable error for the autocorrelation 0.999 in the first lag is 0.00003. See TABLE No.7.3.5 above. The coefficient of autocorrelation is greater than the PE (0.999>0.00003). The autocorrelation 0.999 is still higher than the 6 times PE (0.00018) i.e., $r>6(\mathrm{PE}))$. Hence the autocorrelation 0.999 of Aravind Mills is significant.

Table No.7.3.6: Calculation of Probable Error in Lag 16.

\begin{tabular}{|l|l|l|l|l|l|r|r|r|r|}
\hline Stock & $\mathrm{r}$ & \multicolumn{1}{|l|}{$\mathrm{r}^{2}$} & $1-\mathrm{r}^{2}$ & $\mathrm{~N}$ & $\sqrt{\mathrm{N}}$ & $1-\mathrm{r}^{2} / \sqrt{\mathrm{N}}$ & multiplier & PE & $6(\mathrm{PE})$ \\
\hline Araavind & 0.979 & 0.958 & 0.042 & 2748 & 52.42 & 0.0008 & 0.6745 & 0.00054 & 0.00324 \\
\hline
\end{tabular}

Probable error for the autocorrelation 0.979 in lag 16 is 0.00054 . See TABLE No.7.3.6 above. The coefficient of autocorrelation is greater than the PE $(0.979>0.00054)$. The autocorrelation 0.979 is still higher than the 6 times PE (0.00324) i.e., $r>6(\mathrm{PE})$. Hence the autocorrelation 0.979 of Aravind Mills in lag 16 is significant.

Table No. 7.3.7: Runs test descriptive statistics of Aravind Mills

\begin{tabular}{|l|l|}
\hline Test Values & 45.42 \\
\hline Cases $<$ Test Values & 1677 \\
\hline Cases $>$ Test Values & 1071 \\
\hline Total Cases & 2748 \\
\hline No. of runs & 69 \\
\hline Z & -49.7 \\
\hline Asym.sig (2-tailed) & 0.0 \\
\hline Expected runs R & 1308.18 \\
\hline$\sigma$ of runs & 24.93 \\
\hline Table Value @ 5\% significance & 1.96 \\
\hline
\end{tabular}

As per TABLE No.7.3.7, the mean value of stock price is 45.42. Cases below the mean are 1677 and above are 1071. There are 69 runs in the series. The expected runs are 1308 and the standard deviation of runs is 24.93. The actual runs in the price series are lower than the expected $(69<1308)$. Too few runs indicate stationary state of the series. The $\mathrm{z}$ value calculated is -49.7 whereas the table value for the same at $5 \%$ level of significance is -1.96 on the left tail. The $\mathrm{z}$ calculated is lower than the table value $(-49.7<-1.96)$. Therefore the null hypothesis that the series is random is rejected and resolved that there is interdependence and nonrandomness in the closing price series of Aravind Mills.

\subsection{Ashok Leyland}

Table No.7.4.1 Descriptive Statistics of Ashok Leyland

\begin{tabular}{|l|l|}
\hline Minimum & 12.99 \\
\hline Maximum & 307.7 \\
\hline MEAN & 68.75 \\
\hline MEDIAN & 44.95 \\
\hline STANDARD DEVIATION & 58.38 \\
\hline SKEWNESS & 2.005 \\
\hline
\end{tabular}




\begin{tabular}{l|l} 
NO. OF OBSERVATION & 2752
\end{tabular}

TABLE No.7.4.1 above shows that the mean of the price series of Ashok Leyland is 68.75. The median value is 44.95 . There is difference between mean and median. Therefore the distribution is not normal because in normal distribution the mean and median are the same. RWH (Random-walk Hypothesis) presupposes a normal distribution to constitute an efficient market. The standard deviation 58.38 is bigger. The coefficient of variation $=\frac{\sigma}{\overline{\mathrm{x}}}=\frac{58.38}{68.75}=84.92 \%$. The $\sigma$ is too large for normal distribution. The range shown by the minimum and maximum price is very high. There is high degree of positive skewness to the tune of 2.005 . In a normal distribution skewness will be zero. The high positive skewness nullifies the null hypothesis and confirms nonrandomness. The coefficient of kurtosis the price series is 3.76. A kurtosis value with 3 is the normal distribution. Since the actual kurtosis is more than the normal i.e.3.76>3 the shape of the distribution is leptokurtic. The descriptive statistics of price series of Ashok Leyland confirms asymmetry and non-randomness in the series.

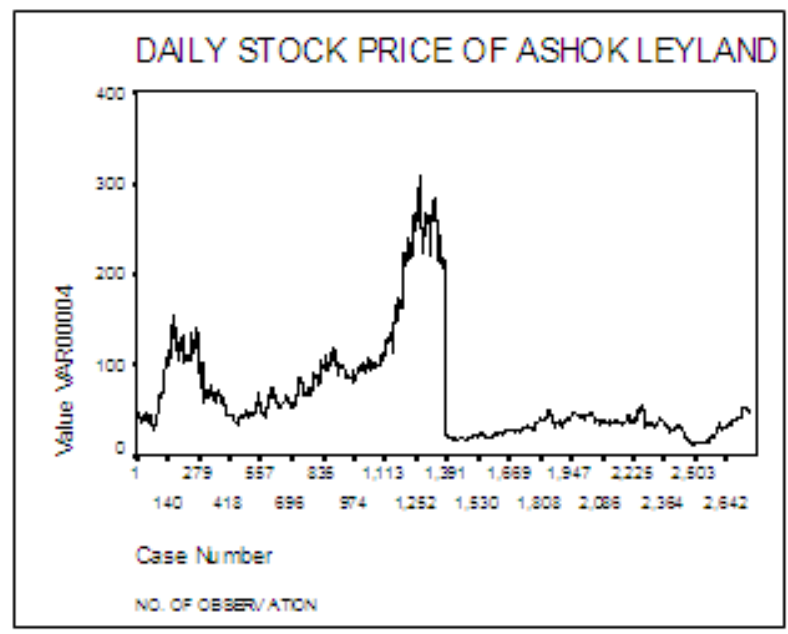

Figure 7.4.1: Daily Stock Price of Ashok Leyland for 2752 days.

Fig.7.4.1 depicts the behavior of stock price of Ashok Leyland. On the first day of January 1999 the stock starts with a price of Rs.44.8. Then it goes beyond Rs.100 on $140^{\text {th }}$ day and falls down. On $1391^{\text {st }}$ observation the price shoot up sharply to Rs.300 range. Then again falls down to Rs. 25 range after 1391 range continues the position till 2009. The overall tendency is to decline. The price line has a lot of turbulent fluctuations throughout the period. The price is never stable. It has been highly volatile during the period.

Table No.7.4.2: Autocorrelation of prices of Ashok Leyland in 16 lags

\begin{tabular}{|c|c|c|c|c|c|c|c|c|c|c|c|c|c|c|c|c|}
\hline Lags & 1 & 2 & 3 & 4 & 5 & 6 & 7 & 8 & 9 & 10 & 11 & 12 & 13 & 14 & 15 & 16 \\
\hline Ashokla & 0.99 & 0.99 & 0.99 & 0.98 & 0.98 & 0.98 & 0.97 & 0.97 & 0.97 & 0.96 & 0.96 & 0.96 & 0.95 & 0.95 & 0.95 & 0.94 \\
\hline $\mathrm{y}$ & 7 & 3 & 0 & 7 & 4 & 0 & 7 & 4 & 0 & 7 & 4 & 0 & 7 & 4 & 0 & 7 \\
\hline
\end{tabular}

TABLE No.7.4.2 provides autocorrelation coefficient of Ashok Leyland's price series in 16 lags. Although correlation is given for 16 lags the value of correlation in the first lag is statistically significant. It can be seen from the table that the auto correlation in all 16 lags is above 0.9. Auto correlation above 0.5 is significant. Therefore, the null hypothesis that the price series is random is rejected. It signals significant evidence for interdependence and non-randomness.

Table 7.4.3: Student's 't' test in Lag 1

\begin{tabular}{|l|l|l|l|l|l|l|l|l|l|}
\hline Stock & $\mathbf{r}$ & $\mathbf{N}-2$ & $\sqrt{\mathrm{N}}-2$ & $\mathbf{r}^{\mathbf{2}}$ & $\mathbf{1}^{\mathbf{2}}$ & $\sqrt{\mathbf{1}-\mathbf{r}^{\mathbf{2}}}$ & $\mathbf{r} / \sqrt{\mathbf{1}-\mathbf{r}^{\mathbf{2}}}$ & $\mathbf{H}^{*} \mathbf{D}$ & \multicolumn{1}{|c|}{ Table } \\
\hline Ashoklay & 0.997 & 2749 & 52.43091 & 0.994 & 0.006 & 0.077 & 12.87 & 675 & 1.96 \\
\hline
\end{tabular}

As per TABLE No.7.4.3 above, the auto correlation of Ashok Leyland in the first lag is 0.997. The $t$ value calculated is 675 and table value at $5 \%$ significance is 1.96 . T value calculated is greater than the table value $(675>1.96)$. The autocorrelation coefficient is significant in the first lag.

Table No.7.4.4: Student's t test in Lag 16

\begin{tabular}{|l|l|l|l|l|l|l|l|l|l|}
\hline A & B & C & D & E & F & G & H & I & J \\
\hline Scrip & $\mathrm{r}$ & $\mathrm{N}-2$ & $\sqrt{\mathrm{N}-2}$ & $\mathrm{r}^{2}$ & $1-\mathrm{r}^{2}$ & $\sqrt{1-\mathrm{r}^{2}}$ & $\mathrm{r} / \sqrt{ } 1-\mathrm{r}^{2}$ & $\mathrm{H} * \mathrm{D}$ & $\mathrm{Table}$ \\
\hline Ashoklay & 0.947 & 2749 & 52.43091 & 0.897 & 0.103 & 0.321 & 2.95 & 155 & 1.96 \\
\hline
\end{tabular}

TABLE No.7.4.4 above shows t test for the $16^{\text {th }}$ lag of price of stock Ashok Leyland. Auto correlation in the $16^{\text {th }}$ lag is 0.947 . The calculated value of $t$ is given as 155 . The table value for the same is 1.96 . The calculated $t$ value 155 is greater than the table value 1.96 . Hence the autocorrelation in $16^{\text {th }}$ lag is significant. 
Table No.7.4.5: Calculation of Probable Error in Lag 1

\begin{tabular}{|l|r|r|r|r|r|r|r|r|r|}
\hline Stock & $\mathrm{r}$ & $\mathrm{r}^{2}$ & $1-\mathrm{r}^{2}$ & $\mathrm{~N}$ & $\sqrt{\mathrm{N}}$ & $1-\mathrm{r}^{2} / \sqrt{\mathrm{N}}$ & \multicolumn{1}{l|}{ multiplier } & PE & $6(\mathrm{PE})$ \\
\hline Ashoklay & 0.997 & 0.994 & 0.006 & 2751 & 52.44998 & 0.00011 & 0.6745 & 0.00007 & 0.00042 \\
\hline
\end{tabular}

Probable error for the autocorrelation 0.997 in the first lag is 0.00007. See TABLE No.7.4.5 above. The coefficient of autocorrelation is greater than the PE $(0.997>0.00007)$. The autocorrelation 0.997 is still higher than the 6 times PE (0.00042) i.e., $r>6(\mathrm{PE})$. Hence the autocorrelation 0.997 of Ashok Leyland is significant.

Table No.7.4.6: Calculation of Probable Error in Lag 16.

\begin{tabular}{|l|r|r|r|r|r|r|r|r|l|}
\hline Stock & $\mathrm{r}$ & \multicolumn{1}{|c|}{$\mathrm{r}^{2}$} & $1-\mathrm{r}^{2}$ & $\mathrm{~N}$ & $\sqrt{\mathrm{N}}$ & $1-\mathrm{r}^{2} / \sqrt{\mathrm{N}}$ & multiplier & PE & $6(\mathrm{PE})$ \\
\hline Ashoklay & 0.947 & 0.897 & 0.103 & 2751 & 52.44 & 0.00196 & 0.6745 & 0.00132 & 0.00792 \\
\hline
\end{tabular}

Probable error for the autocorrelation 0.947 in lag 16 is 0.00132 . See TABLE No.7.4.6 above. The coefficient of autocorrelation is greater than the PE $(0.947>0.00132)$. The autocorrelation 0.947 is still higher than the 6 times PE (0.00792) i.e., r $>6(\mathrm{PE})$. Hence the autocorrelation 0.947 of Ashok Leyland in lag 16 is significant.

Table No.7.4.7: Runs test descriptive statistics of Ashok Leyland

\begin{tabular}{|l|l|}
\hline Test Values & 68.75 \\
\hline Cases $<$ Test Values & 1880 \\
\hline Cases $>$ Test Values & 872 \\
\hline Total Cases & 2752 \\
\hline No. of runs & 45 \\
\hline Z & -50.5 \\
\hline Asym.sig (2-tailed) & 0.0 \\
\hline Expected runs R & 1192 \\
\hline$\sigma$ of runs & 22.71 \\
\hline Table Value @ 5\% significance & 1.96 \\
\hline
\end{tabular}

As per TABLE No.7.4.7, the mean value of stock price is 68.75. Cases below the mean are 1880 and above are 872 . There are 45 runs in the series. The expected runs are 1192 and the standard deviation of runs is 22.71. The actual runs in the price series are lower than the expected $(45<1192)$. Too few runs indicate stationary state of the series. The $\mathrm{z}$ value calculated is -50.5 whereas the table value for the same at $5 \%$ level of significance is -1.96 on the left tail. The $\mathrm{z}$ calculated is lower than the table value $(-50.5<-1.96)$. Therefore the null hypothesis that the series is random is rejected and resolved that there is interdependence and nonrandomness in the closing price series of Ashok Leyland.

\subsection{Asian Paints}

Table No.7.5.1 Descriptive Statistics of Asian Paints

\begin{tabular}{|l|l|}
\hline Minimum & 199 \\
\hline Maximum & 1799.65 \\
\hline MEAN & 555.79 \\
\hline MEDIAN & 391 \\
\hline STANDARD DEVIATION & 350.02 \\
\hline SKEWNESS & 1.316 \\
\hline KURTOSIS & 0.915 \\
\hline NO. OF OBSERVATION & 2752 \\
\hline
\end{tabular}

TABLE No.7.5.1 above shows that the mean of the price series of Asian Paints is 555.79. The median value is 391. There is difference between mean and median. Therefore the distribution is not normal because in normal distribution the mean, median and mode are the same. RWH (Random-walk Hypothesis) presupposes a normal distribution to constitute an efficient market. The standard deviation 350.02 is bigger. The coefficient of variation $=\frac{\sigma}{\overline{\mathrm{X}}}=\frac{350.02}{555.79}=62.98 \%$. The $\sigma$ is too large for normal distribution. The difference between the minimum and maximum price is very high. There is high degree of positive skewness to the tune of 1.316. In a normal distribution, skewness will be zero. The high positive skewness nullifies the null hypothesis and confirms non-randomness. The coefficient of kurtosis of the price series is 0.915 . A kurtosis value with 3 is the normal distribution. Since the actual kurtosis is less than the standard normal i.e. $0.915<3$ the shape of the distribution is platykurtic. The descriptive statistics of price series of Asian Paints confirms asymmetry and nonrandomness in the series. 


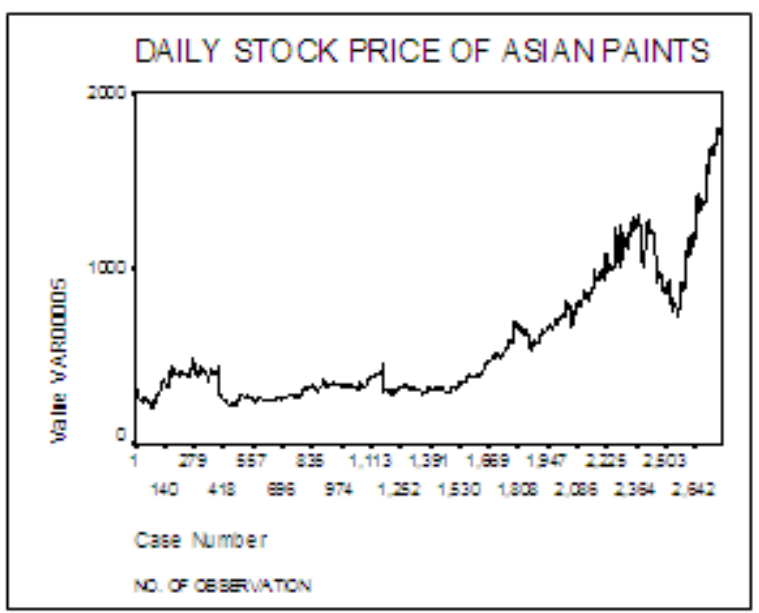

Figure 7.5.1: Daily Stock Price of Asian Paints for 2752 days.

Fig.7.5.1 depicts the behavior of stock price of Asian Paints. The daily stock prices of Asian Paints have lot of fluctuations. The price is steadily increasing with numerous ups and downs and corrections. As the standard deviation denoted, the price series is expressing major and minor surprises along its movement. The stock price was rising right from Rs.285.5 in 1999 to Rs.1796.25 in 2009. This steady flow of the line with turbulent zigzags can be viewed from the graph.

Table No.7.5.2 Autocorrelation of prices of Asian Paints in 16 lags

\begin{tabular}{|c|c|c|c|c|c|c|c|c|c|c|c|c|c|c|c|c|}
\hline Lags & 1 & 2 & 3 & 4 & 5 & 6 & 7 & 8 & 9 & 10 & 11 & 12 & 13 & 14 & 15 & 16 \\
\hline Asia & 0.99 & 0.99 & 0.99 & 0.98 & 0.98 & 0.98 & 0,97 & 0.97 & 0.97 & 0.97 & 0.96 & 0.96 & 0.96 & 0.95 & 0.95 & 0.95 \\
\hline $\mathrm{n}$ & 7 & 4 & 1 & 8 & 5 & 2 & 9 & 6 & 3 & 0 & 7 & 4 & 1 & 8 & 6 & 3 \\
\hline
\end{tabular}

TABLE No.7.5.2 provides autocorrelation coefficient of Asian Paints' price series in 16 lags. Although correlation is given for 16 lags the value of correlation in the first lag is statistically significant. It can be seen from the table that the auto correlation in all 16 lags is above 0.9. Auto correlation above 0.5 is significant. Therefore, the null hypothesis that the price series is random is rejected. It signals significant evidence for interdependence and non-randomness.

Table No.7.5.3: Student's ' $t$ ' test in Lag 1

\begin{tabular}{|c|c|c|c|c|c|c|c|c|c|}
\hline Stock & $\mathrm{r}$ & $\mathrm{N}-2$ & $\sqrt{\mathrm{N}-2}$ & $\mathrm{r}^{2}$ & $1-\mathrm{r}^{2}$ & $\sqrt{1-\mathrm{r}^{2}}$ & $r / \sqrt{1-r^{2}}$ & $\mathrm{H} * \mathrm{D}$ & Table \\
\hline Asian & 0.997 & 2749 & 52.43091 & 0.994 & 0.006 & 0.077 & 12.87 & 675 & 1.96 \\
\hline
\end{tabular}

As per TABLE No.7.5.3 above, the auto correlation of Asian Paints in the first lag is 0.997. The $t$ value calculated is 675 and table value at 5\% significance is 1.96 . T value calculated is greater than the table value $(675>1.96)$. The autocorrelation coefficient is significant in the first lag.

Table No.7.5.4: Student's t test in Lag 16

\begin{tabular}{|c|r|r|r|r|r|r|r|r|r|}
\hline Scrip & $\mathrm{r}$ & $\mathrm{N}-2$ & $\sqrt{\mathrm{N}-2}$ & $\mathrm{r}^{2}$ & $1-\mathrm{r}^{2}$ & $\sqrt{1-\mathrm{r}^{2}}$ & $\mathrm{r} / \sqrt{1-\mathrm{r}^{2}}$ & $\mathrm{H} * \mathrm{D}$ & Table \\
\hline Asian & 0.953 & 2749 & 52.43091 & 0.908 & 0.092 & 0.303 & 3.14 & 165 & 1.96 \\
\hline
\end{tabular}

TABLE No.7.5.4 above shows that $t$ test for the $16^{\text {th }}$ lag of price of stock Asian Paints. Auto correlation in the $16^{\text {th }}$ lag is 0.953 . The calculated value of $t$ is given in column $I$ as 165 . The table value for the same is 1.96. The calculated t value 165 is greater than the table value 1.96 . Hence the autocorrelation in $16^{\text {th }}$ lag is significant.

Table No.7.5.5: Calculation of Probable Error in Lag 1

\begin{tabular}{|l|r|r|r|r|r|r|r|l|l|}
\hline Stock & $\mathrm{r}$ & $\mathrm{r}^{2}$ & $1-\mathrm{r}^{2}$ & $\mathrm{~N}$ & $\sqrt{\mathrm{N}}$ & $1-\mathrm{r}^{2} / \sqrt{\mathrm{N}}$ & multiplier & PE & $6(\mathrm{PE})$ \\
\hline Asian & 0.997 & 0.994 & 0.006 & 2751 & 52.44998 & 0.00011 & 0.6745 & 0.00007 & 0.00042 \\
\hline
\end{tabular}

Probable error for the autocorrelation 0.997 in the first lag is 0.00007 . See TABLE No.7.5.5 above. The coefficient of autocorrelation is greater than the PE $(0.997>0.00007)$. The autocorrelation 0.997 is still higher than the 6 times PE (0.00042) i.e., $r>6(P E)$. Hence the autocorrelation 0.997 of Asian Paints is significant.

Table No.7.5.6: Calculation of Probable Error in Lag 16.

\begin{tabular}{|l|l|l|l|l|l|l|l|l|l|}
\hline Stock & $\mathrm{r}$ & $\mathrm{r}^{2}$ & $1-\mathrm{r}^{2}$ & $\mathrm{~N}$ & $\sqrt{\mathrm{N}}$ & $1-\mathrm{r}^{2} / \sqrt{\mathrm{N}}$ & multiplier & PE & $6(\mathrm{PE})$ \\
\hline Asian & 0.953 & 0.908 & 0.092 & 2751 & 52.45 & 0.00175 & 0.6745 & 0.00118 & 0.00708 \\
\hline
\end{tabular}

Probable error for the autocorrelation 0.953 in lag 16 is 0.00118. See TABLE No.7.5.6 above. The coefficient of autocorrelation is greater than the PE $(0.953>0.00118)$. The autocorrelation 0.953 is still higher than the 6 times PE (0.00708) i.e., $r>6(\mathrm{PE})$. Hence the autocorrelation 0.953 of Asian Paints in lag 16 is significant. 
Table No.7.5.7: Runs test descriptive statistics of Asian Paints

\begin{tabular}{|l|l|}
\hline Test Values & 555.79 \\
\hline Cases $<$ Test Values & 1768 \\
\hline Cases $>$ Test Values & 984 \\
\hline Total Cases & 2752 \\
\hline No. of runs & 10 \\
\hline Z & -52.10 \\
\hline Asym.sig (2-tailed) & 0.0 \\
\hline Expected runs $\bar{R}$ & 1265.33 \\
\hline$\sigma$ of runs & 24.1 \\
\hline Table Value @ 5\% significance & 1.96 \\
\hline
\end{tabular}

As per TABLE No.7.5.7, the mean value of stock price is 555.79. Cases below the mean are 1768 and above are 984 . There are 10 runs in the series. The expected runs are 1265.33 and the standard deviation of runs is 24.1. The actual runs in the price series are lower than the expected $(10<1265.33)$. Too few runs indicate stationary state of the series. The $\mathrm{z}$ value calculated is -52.1 whereas the table value for the same at $5 \%$ level of significance is -1.96 on the left tail. The $\mathrm{z}$ calculated is lower than the table value $(-52.1<-1.96)$. Therefore the null hypothesis that the series is random is rejected and resolved that there is interdependence and nonrandomness in the closing price series of Asian Paints.

\subsection{Axis Bank}

Table No.7.6.1: Descriptive Statistics of Axis Bank

\begin{tabular}{|l|l|}
\hline Minimum & 12.35 \\
\hline Maximum & 1265.2 \\
\hline MEAN & 276 \\
\hline MEDIAN & 137.7 \\
\hline STANDARD DEVIATION & 301.7 \\
\hline SKEWNESS & 1.112 \\
\hline KURTOSIS & 0.052 \\
\hline NO. OF OBSERVATION & 2744 \\
\hline
\end{tabular}

TABLE No.7.6.1 above shows that the mean of the price series of Axis Bank is 276. The median value is 137.7. There is difference between mean and median. Therefore the distribution is not normal because in normal distribution the mean, median and mode are the same. RWH (Random-walk Hypothesis) presupposes a normal distribution to constitute an efficient market. The standard deviation 301.7 is bigger. The coefficient of variation $=\frac{\sigma}{\overline{\mathrm{x}}}=\frac{301.7}{276}=109.31 \%$. The $\sigma$ is too large for normal distribution. The difference between the minimum and maximum prices is very high. There is high degree of positive skewness to the tune of 1.112 . In a normal distribution, skewness will be zero. The high positive skewness nullifies the null hypothesis and confirms non-randomness. The coefficient of kurtosis of the price series is 0.052 . A kurtosis value with 3 is the normal distribution. Since the actual kurtosis is lower than the normal i.e. $0.052<3$ the shape of the distribution is platykurtic. The descriptive statistics of price series of Axis Bank confirms asymmetry and non-randomness in the series.

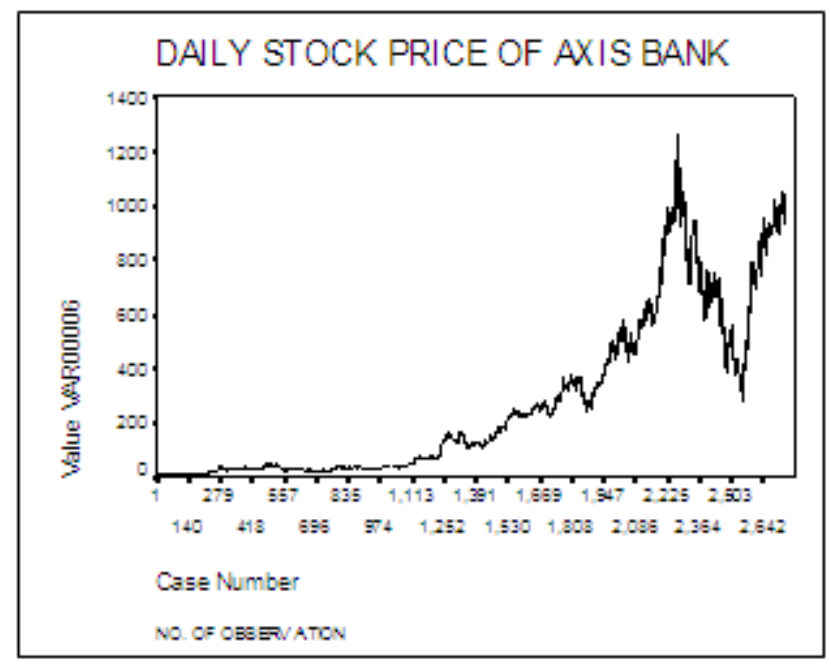

Figure 7.6.1: Daily Stock Price of Axis Bank for 2744 days.

Fig.7.6.1 depicts the behavior of stock price of Axis Bank. The daily stock prices of Axis Bank has lot of fluctuations. The price is steadily increasing with numerous ups and downs and corrections. As the standard deviation denoted, the price series is expressing major and minor surprises along its movement. The stock price was rising right from Rs.16.35 in 1999 to Rs.988.7 in 2009. This steady flow of the line with turbulent zigzags 
can be viewed from the graph. There is high volatility in prices. This shows large scale mispricing in the market, an evidence for the absence of market efficiency in weak form.

Table No.7.6.2: Autocorrelation of prices of Axis Bank in 16 lags

\begin{tabular}{|l|r|r|r|r|r|r|r|r|r|r|r|r|r|r|r|r|}
\hline Lags & 1 & 2 & 3 & 4 & 5 & 6 & 7 & 8 & 9 & 10 & 11 & 12 & 13 & 14 & 15 & 16 \\
\hline Axis & 0.99 & 0.99 & 0.99 & 0.99 & 0.98 & 0.98 & 0.98 & 0.98 & 0.98 & 0.98 & 0.97 & 0.97 & 0.97 & 0.97 & 0.97 & 0.96 \\
bank & 8 & 6 & 3 & 1 & 9 & 7 & 6 & 4 & 2 & 0 & 8 & 6 & 4 & 2 & 0 & 8 \\
\hline
\end{tabular}

TABLE No.7.6.2 provides autocorrelation coefficient of Axis Bank's price series in 16 lags. Although correlation is given for 16 lags the value of correlation in the first lag is statistically significant. It can be seen from the table that the auto correlation in all $16 \mathrm{lags}$ is above 0.9 . Auto correlation above 0.5 is significant. Therefore, the null hypothesis that the price series is random is rejected. It signals significant evidence for interdependence and non-randomness.

Table No.7.6.3: Student's 't' test in Lag 1

\begin{tabular}{|l|l|l|l|l|l|l|l|l|r|}
\hline Stock & $\mathrm{r}$ & $\mathrm{N}-2$ & $\sqrt{\mathrm{N}}-2$ & $\mathrm{r}^{2}$ & $1-\mathrm{r}^{2}$ & $\sqrt{1-\mathrm{r}^{2}}$ & $\mathrm{r} / \sqrt{1-\mathrm{r}^{2}}$ & $\mathrm{H} * \mathrm{D}$ & Table \\
\hline Axis bank & 0.998 & 2741 & 52.35456 & 0.996 & 0.004 & 0.063 & 15.78 & 826 & 1.96 \\
\hline
\end{tabular}

As per TABLE No.7.6.3 above, the auto correlation of Axis Bank in the first lag is 0.998. The $t$ value calculated is 826 and table value at $5 \%$ significance is 1.96 . T value calculated is greater than the table value $(826>1.96)$. The autocorrelation coefficient is significant in the first lag.

Table No.7.6.4: Student's t test in Lag 16

\begin{tabular}{|c|r|r|r|r|r|r|r|r|r|}
\hline Scrip & $\mathrm{r}$ & $\mathrm{N}-2$ & $\sqrt{\mathrm{N}-2}$ & $\mathrm{r}^{2}$ & $1-\mathrm{r}^{2}$ & $\sqrt{ } 1-\mathrm{r}^{2}$ & $\mathrm{r} / \sqrt{ } 1-\mathrm{r}^{2}$ & \multicolumn{1}{l}{$\mathrm{H}^{*} \mathrm{D}$} & Table \\
\hline Axis bank & 0.968 & 2741 & 52.35456 & 0.937 & 0.063 & 0.251 & 3.86 & 202 & 1.96 \\
\hline
\end{tabular}

TABLE No.7.6.4 above shows that $\mathrm{t}$ test for the $16^{\text {th }}$ lag of price of stock Axis Bank. Auto correlation in the $16^{\text {th }}$ lag is 0.968 . The calculated value of $t$ is given in column $I$ as 202 . The table value for the same is 1.96. The calculated $t$ value 202 is greater than the table value 1.96 . Hence the autocorrelation in $16^{\text {th }}$ lag is significant.

Table No.7.6.5: Calculation of Probable Error in Lag 1

\begin{tabular}{|l|l|l|l|l|l|l|l|l|l|}
\hline Stock & $\mathrm{r}$ & \multicolumn{1}{|c|}{$\mathrm{r}^{2}$} & \multicolumn{1}{|c|}{$1-\mathrm{r}^{2}$} & $\mathrm{~N}$ & $\sqrt{\mathrm{N}}$ & $1-\mathrm{r}^{2} / \sqrt{\mathrm{N}}$ & multiplier & PE & $6(\mathrm{PE})$ \\
\hline Axis bank & 0.998 & 0.996 & 0.004 & 2743 & 52.37366 & 0.00008 & 0.6745 & 0.00005 & 0.0003 \\
\hline
\end{tabular}

Probable error for the autocorrelation 0.998 in the first lag is 0.00005. See TABLE No.7.6.5 above. The coefficient of autocorrelation is greater than the PE $(0.998>0.00005)$. The autocorrelation 0.998 is still higher than the 6 times PE (0.0003) i.e., $r>6(\mathrm{PE})$. Hence the autocorrelation 0.998 of Axis Bank is significant.

Table 7.6.6: Calculation of Probable Error in Lag 16.

\begin{tabular}{|l|l|l|l|l|l|l|l|l|l|}
\hline Stock & $\mathrm{r}$ & $\mathrm{r}^{2}$ & $1-\mathrm{r}^{2}$ & $\mathrm{~N}$ & $\sqrt{\mathrm{N}}$ & $1-\mathrm{r}^{2} / \sqrt{\mathrm{N}}$ & multiplier & $\mathrm{PE}$ & $6(\mathrm{PE})$ \\
\hline Axis bank & 0.968 & 0.937 & 0.063 & 2743 & 52.37366 & 0.0012 & 0.6745 & 0.00081 & 0.00486 \\
\hline
\end{tabular}

Probable error for the autocorrelation 0.968 in lag 16 is 0.00081 . See TABLE No.7.6.6 above. The coefficient of autocorrelation is greater than the PE $(0.968>0.00081)$. The autocorrelation 0.968 is still higher than the 6 times PE (0.00486) i.e., r $>6(\mathrm{PE})$. Hence the autocorrelation 0.968 of Axis Bank in lag 16 is significant.

Table No.7.6.7: Runs test descriptive statistics of Axis Bank

\begin{tabular}{|l|l|}
\hline Test Values & 276 \\
\hline Cases $<$ Test Values & 1753 \\
\hline Cases $>$ Test Values & 991 \\
\hline Total Cases & 2744 \\
\hline No. of runs & 16 \\
\hline Z & -51.77 \\
\hline Asym.sig (2-tailed) & 0.0 \\
\hline Expected runs R & 1267.2 \\
\hline$\sigma$ of runs & 24.17 \\
\hline Table Value @ 5\% significance & 1.96 \\
\hline
\end{tabular}

As per TABLE No.7.6.7, the mean value of stock price is 276. Cases below the mean are 1753 and above are 991. There are 16 runs in the series. The expected runs are 1267.2 and the standard deviation of runs is 24.17.The actual runs in the price series are lower than the expected $(16<1267.2)$. Too few runs indicate stationary state of the series. The $\mathrm{z}$ value calculated is -51.77 whereas the table value for the same at $5 \%$ level of significance is -1.96 on the left tail. The $\mathrm{z}$ calculated is lower than the table value $(-51.77<-1.96)$. Therefore the null hypothesis that the series is random is rejected and resolved that there is interdependence and nonrandomness in the closing price series of Axis Bank. 


\subsection{Ballarpur Industries}

Table No.7.7.1: Descriptive Statistics of Ballarpur Industries

\begin{tabular}{|l|l|}
\hline Minimum & 13.43 \\
\hline Maximum & 189.2 \\
\hline MEAN & 69.46 \\
\hline MEDIAN & 63 \\
\hline STANDARD DEVIATION & 37.55 \\
\hline SKEWNESS & 0.586 \\
\hline KURTOSIS & -0.553 \\
\hline NO. OF OBSERVATION & 2730 \\
\hline
\end{tabular}

TABLE No.7.7.1 above shows that the mean of the price series of Ballarpur Industries for 2730 days of observation is 69.46 . The median value is 63 . There is difference between mean and median. Therefore the distribution is not normal because in normal distribution the mean, median and mode are the same. RWH (Random-walk Hypothesis) presupposes a normal distribution to constitute an efficient market. The range of minimum and maximum prices is very wide. The standard deviation 37.55 is bigger. The coefficient of variation $=\frac{\sigma}{\overline{\mathrm{x}}}=\frac{37.55}{69.46}=54.06 \%$. The $\sigma$ is too large for normal distribution. There is high degree of positive skewness to the tune of 0.586. In a normal distribution, skewness will be zero. The high positive skewness nullifies the null hypothesis and confirms non-randomness. The coefficient of kurtosis of the price series is -0.553 . A kurtosis value with 3 is the normal distribution. Since the actual kurtosis is lower than the normal i.e. $-0.553<3$ the shape of the distribution is platykurtic on the left to the mean. The descriptive statistics of price series of Ballarpur Industries confirms asymmetry and non-randomness in the series.

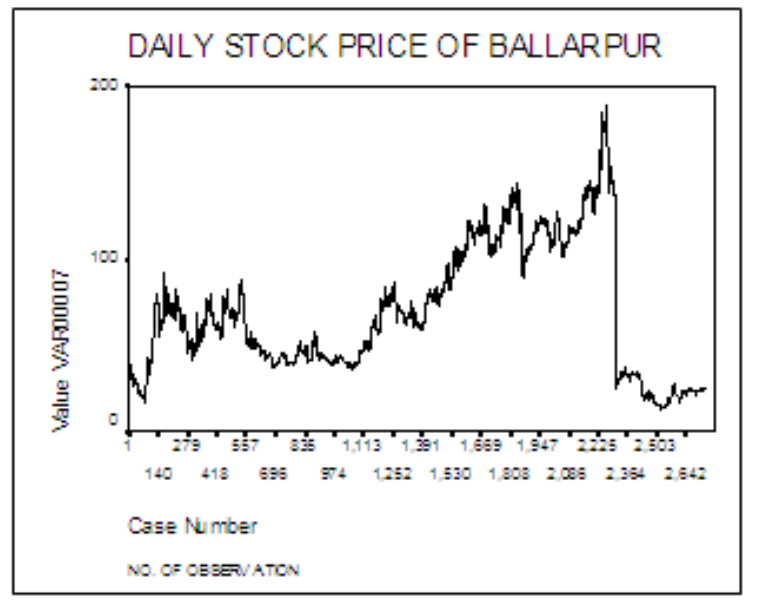

Figure 7.7.1: Daily Stock Price of Ballarpur Industries for 2730 days.

Fig.7.7.1 depicts the behavior of stock price of Ballarpur Industries. The daily stock prices of Ballarpur Industries had lot of fluctuations. The price was steadily increasing with numerous ups and downs and corrections. As the standard deviation denoted, the price series was expressing major and minor surprises along its movement. The stock price was rising right from Rs.27.85 in the beginning of 1999 to a height of 173.4 in 2007 at $2225^{\text {th }}$ observation. After that the price went down to 23.95 in 2009 . This steady flow of the line with turbulent zigzags can be viewed from the graph. There is high volatility in prices. This shows large scale mispricing in the market, an evidence for the absence of market efficiency.

Table No.7.7.2: Autocorrelation of prices of Ballarpur Industries in 16 lags

\begin{tabular}{|l|l|l|l|l|l|r|r|r|r|r|r|r|r|r|r|r|}
\hline Lags & 1 & 2 & 3 & 4 & 5 & 6 & 7 & 8 & 9 & 10 & 11 & 12 & 13 & 14 & 15 & 16 \\
\hline Ballarp & 0.99 & 0.99 & 0.98 & 0.98 & 0.98 & 0.97 & 0.97 & 0.97 & 0.96 & 0.96 & 0.95 & 0.95 & 0.95 & 0.94 & 0.94 & 0.94 \\
ur & 6 & 2 & 9 & 5 & 1 & 8 & 4 & 0 & 6 & 3 & 9 & 5 & 2 & 8 \\
4
\end{tabular}

TABLE No.7.7.2 provides autocorrelation coefficient of Ballarpur Industries' price series in 16 lags. Although correlation is given for 16 lags the value of correlation in the first lag is statistically significant. It can be seen from the table that the auto correlation in all 16 lags is above 0.9. Auto correlation above 0.5 is significant. Therefore, the null hypothesis that the price series is random is rejected. It signals significant evidence for interdependence and non-randomness.

Table No.7.7.3: Student's ' $t$ ' test in Lag 1

\begin{tabular}{|l|l|l|l|l|l|l|l|l|l|}
\hline Stock & $\mathrm{r}$ & $\mathrm{N}-2$ & $\sqrt{\mathrm{N}}-2$ & $\mathrm{r}^{2}$ & $1-\mathrm{r}^{2}$ & $\sqrt{1-\mathrm{r}^{2}}$ & $\mathrm{r} / \sqrt{ } 1-\mathrm{r}^{2}$ & $\mathrm{H}^{*} \mathrm{D}$ & Table \\
\hline Ballarpur & 0.996 & 2727 & 52.22069 & 0.992 & 0.008 & 0.089 & 11.14 & 582 & 1.96 \\
\hline
\end{tabular}


As per TABLE No.7.7.3 above, the auto correlation of Ballarpur Industries in the first lag is 0.996. The $\mathrm{t}$ value calculated is 582 and table value at $5 \%$ significance is 1.96 . T value calculated is greater than the table value $(582>1.96)$. Therefore, the autocorrelation coefficient is significant in the first lag.

Table No.7.7.4: Student's t test in Lag 16

\begin{tabular}{|c|c|c|c|r|r|r|r|r|r|}
\hline Scrip & $\mathrm{r}$ & $\mathrm{N}-2$ & $\sqrt{\mathrm{N}-2}$ & $\mathrm{r}^{2}$ & \multicolumn{1}{l|}{$1-\mathrm{r}^{2}$} & $\sqrt{1-\mathrm{r}^{2}}$ & $\mathrm{r} / \sqrt{1-\mathrm{r}^{2}}$ & \multicolumn{1}{l|}{$\mathrm{H}^{*} \mathrm{D}$} & Table \\
\hline Ballarpur & 0.94 & 2727 & 52.22069 & 0.884 & 0.116 & 0.341 & 2.76 & 144 & 1.96 \\
\hline
\end{tabular}

TABLE No.7.74 above shows that $t$ test for the $16^{\text {th }}$ lag of price of stock Ballarpur Industries. Auto correlation in the $16^{\text {th }}$ lag is 0.94 . The calculated value of $t$ is given in column I as 144 . The table value for the same is 1.96 . The calculated t value 144 is greater than the table value 1.96 . Hence the autocorrelation in $16^{\text {th }}$ lag is significant.

Table No.7.7.5: Calculation of Probable Error in Lag 1

\begin{tabular}{|l|l|l|l|l|l|l|l|l|}
\hline Stock & $\mathrm{r}$ & $\mathrm{r}^{2}$ & $1-\mathrm{r}^{2}$ & $\mathrm{~N}$ & $\sqrt{\mathrm{N}}$ & $1-\mathrm{r}^{2} / \sqrt{\mathrm{N}}$ & multiplier & $\mathrm{PE}$ \\
\hline Ballarpur & 0.996 & 0.992 & 0.008 & 2729 & 52.23983 & 0.00015 & 0.6745 & 0.0001 \\
\hline
\end{tabular}

Probable error for the autocorrelation 0.996 in the first lag is 0.0001. See TABLE No.7.7.5 above. The coefficient of autocorrelation is greater than the PE $(0.996>0.0001)$. The autocorrelation 0.996 is still higher than the 6 times PE (0.0006) i.e., $r>6(\mathrm{PE})$. Hence the autocorrelation 0.996 of Ballarpur Industries is significant.

Table No.7.7.6: Calculation of Probable Error in Lag 16.

\begin{tabular}{|l|l|l|l|l|l|l|l|l|l|}
\hline Stock & $\mathrm{r}$ & $\mathrm{r}^{2}$ & $1-\mathrm{r}^{2}$ & $\mathrm{~N}$ & $\sqrt{\mathrm{N}}$ & $1-\mathrm{r}^{2} / \sqrt{\mathrm{N}}$ & multiplier & $\mathrm{PE}$ & $6(\mathrm{PE})$ \\
\hline Ballarpur & 0.94 & 0.884 & 0.116 & 2729 & 52.23983 & 0.00222 & 0.6745 & 0.0015 & 0.009 \\
\hline
\end{tabular}
coefficient of autocorrelation is greater than the PE $(0.94>0.0015)$. The autocorrelation 0.94 is still higher than the 6 times PE (0.009) i.e., $r>6(\mathrm{PE})$. Hence the autocorrelation 0.94 of Ballarpur Industries in lag 16 is significant.

Table No.7.7.7: Run test descriptive statistics of Ballarpur Industries

\begin{tabular}{|l|l|}
\hline Test Values & 69.46 \\
\hline Cases $<$ Test Values & 1571 \\
\hline Cases $>$ Test Values & 1159 \\
\hline Total Cases & 2730 \\
\hline No. of runs & 51 \\
\hline$Z$ & -50.30 \\
\hline Asym.sig (2-tailed) & 0.0 \\
\hline Expected runs $\bar{R}$ & 1334.91 \\
\hline$\sigma$ of runs & 25.52 \\
\hline Table Value @ 5\% significance & -1.96 \\
\hline
\end{tabular}

As per TABLE No.7.7.7, the mean value of stock price is 69.46. Cases below the mean are 1571 and above are 1159. There are 51 runs in the series. The expected runs are 1334.91 and the standard deviation of runs is 25.52 . The actual runs in the price series are lower than the expected $(51<1334.91)$. Too few runs indicate stationary state of the series. The $\mathrm{z}$ value calculated is -50.30 whereas the table value for the same at $5 \%$ level of significance is -1.96 on the left tail. The $\mathrm{z}$ calculated is lower than the table value $(-51.77<-1.96)$. Therefore the null hypothesis that the series is random is rejected and resolved that there is interdependence and non-randomness in the closing price series of Ballarpur Industries.

\subsection{Castrol}

Table No.7.8.1: Descriptive Statistics of Castrol

\begin{tabular}{|l|l|}
\hline Minimum & 155.45 \\
\hline Maximum & 898 \\
\hline MEAN & 275.48 \\
\hline MEDIAN & 236.33 \\
\hline STANDARD DEVIATION & 127.86 \\
\hline SKEWNESS & 2.741 \\
\hline KURTOSIS & 8.425 \\
\hline NO. OF OBSERVATION & 2756 \\
\hline
\end{tabular}

TABLE No.7.8.1 above shows that the mean of the price series of Castrol for 2756 days of observation is 275.48 . The median value is 236.33 . There is difference between mean and median. Therefore the distribution is not normal because in normal distribution the mean, median and mode are the same. RWH (Random-walk Hypothesis) presupposes a normal distribution to constitute an efficient market. The difference between the minimum and maximum prices is very high. The standard deviation 127.86 is bigger. The coefficient of variation $=\frac{\sigma}{\overline{\mathrm{X}}}=\frac{127.86}{275.48}=46.41 \%$. The $\sigma$ is too large for normal distribution. There is high degree of positive 
skewness to the tune of 2.741. In a normal distribution, skewness will be zero. The high positive skewness nullifies the null hypothesis and confirms non-randomness. The coefficient of kurtosis of the price series is 8.425. A kurtosis value with 3 is the normal distribution. Since the actual kurtosis is higher than the normal i.e. $8.425>3$ the shape of the distribution is leptokurtic. The descriptive statistics of price series of Castrol confirms asymmetry and non-randomness in the series.

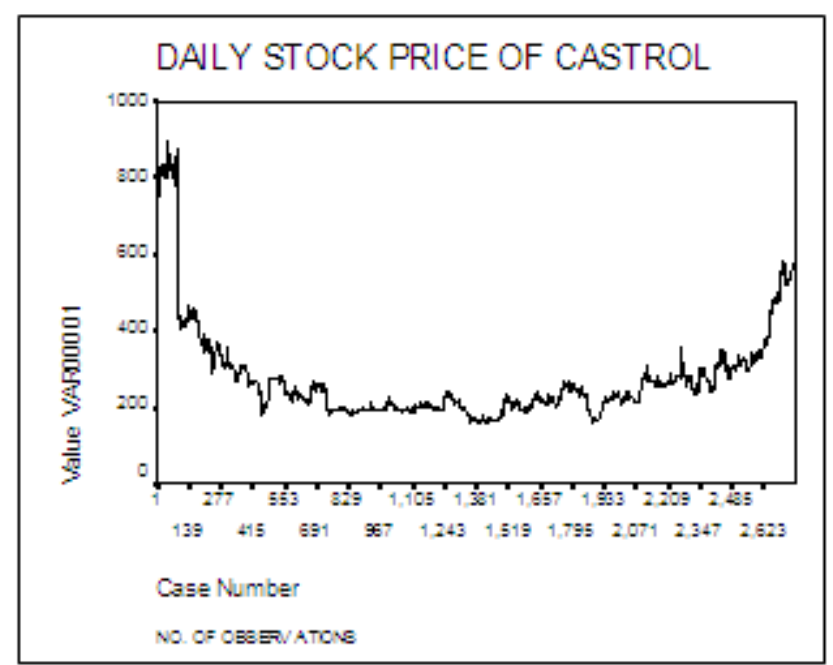

Figure 7.8.1: Daily Stock Price of Castrol for 2756 days.

Fig.7.8.1 depicts the behavior of stock price of Castrol. The daily stock prices of Castrol have lot of fluctuations. The price was very high in 1999 with Rs.758.25. In 2001 the price reduced to Rs.210. Then the price was about the mean till reaches Rs.605 in 2009 . The shape of the price line is boat-like. As the standard deviation denoted, the price series was expressing major and minor fluctuations along its movement. The steady flow of the line with turbulent zigzags can be viewed from the graph. There is high volatility in prices. This shows large scale mispricing in the market, an evidence for the absence of market efficiency.

Table No.7.8.2: Autocorrelation of prices of Castrol in 16 lags

\begin{tabular}{|l|l|l|l|l|l|r|r|r|r|r|r|r|r|r|r|r|r|}
\hline Lags & \multicolumn{1}{|l}{1} & 2 & 3 & 4 & 5 & 6 & 7 & 8 & 9 & 10 & 11 & 12 & 13 & 14 & 15 & 16 \\
\hline Castr & 0.99 & 0.98 & 0.98 & 0.97 & 0.96 & 0.96 & 0.95 & 0.94 & 0.94 & 0.93 & 0.92 & 0.92 & 0.91 & 0.90 & 0.90 & 0.89 \\
ol & 3 & 6 & 0 & 3 & 6 & 0 & 3 & 7 & 1 & 5 & 8 & 2 & 5 & 9 & 2 \\
5
\end{tabular}

TABLE No.7.8.2 provides autocorrelation coefficient of Castrol's price series in 16 lags. Although correlation is given for 16 lags, the value of correlation in the first lag is statistically significant. It can be seen from the table that the auto correlation in all 15 lags is above 0.9 and $16^{\text {th }}$ lag is above 0.8 . Auto correlation above 0.5 is significant. Therefore, the null hypothesis that the price series is random is rejected. It signals significant evidence for interdependence and non-randomness.

Table No.7.8.3: Student's ' $t$ ' test in Lag 1

\begin{tabular}{|l|l|l|l|l|l|l|l|l|r|}
\hline Stock & $\mathrm{r}$ & $\mathrm{N}-2$ & $\sqrt{\mathrm{N}-2}$ & $\mathrm{r}^{2}$ & $1-\mathrm{r}^{2}$ & $\sqrt{1-\mathrm{r}^{2}}$ & $\mathrm{r} / \sqrt{ } 1-\mathrm{r}^{2}$ & $\mathrm{H} * \mathrm{D}$ & Table \\
\hline Castrol & 0.993 & 2753 & 52.46904 & 0.986 & 0.014 & 0.118 & 8.39 & 440 & 1.96 \\
\hline
\end{tabular}

As per TABLE No.7.8.3 above, the auto correlation of Castrol in the first lag is 0.993. The t value calculated is 440 and table value at $5 \%$ significance is 1.96 . T value calculated is greater than the table value $(440>1.96)$. Therefore, the autocorrelation coefficient is significant in the first lag.

Table No.7.8.4: Student's t test in Lag 16

\begin{tabular}{|c|c|c|c|r|r|r|r|r|r|}
\hline Scrip & $\mathrm{r}$ & $\mathrm{N}-2$ & $\sqrt{\mathrm{N}-2}$ & $\mathrm{r}^{2}$ & $1-\mathrm{r}^{2}$ & $\sqrt{1-\mathrm{r}^{2}}$ & $\mathrm{r} / \sqrt{1-\mathrm{r}^{2}}$ & $\mathrm{H}^{*} \mathrm{D}$ & Table \\
\hline Castrol & 0.895 & 2753 & 52.46904 & 0.801 & 0.199 & 0.446 & 2.01 & 105 & 1.96 \\
\hline
\end{tabular}

TABLE No.7.8.4 above shows that $t$ test for the $16^{\text {th }}$ lag of price of stock Castrol. Auto correlation in the $16^{\text {th }}$ lag is 0.895 . The calculated value of $t$ is given in column $\mathrm{I}$ as 105 . The table value for the same is 1.96 . The calculated $\mathrm{t}$ value 105 is greater than the table value 1.96 . Hence the autocorrelation in $16^{\text {th }}$ lag is significant.

Table No.7.8.5: Calculation of Probable Error in Lag 1

\begin{tabular}{|l|l|l|l|l|l|l|l|l|l|}
\hline Stock & $\mathrm{r}$ & $\mathrm{r}^{2}$ & $1-\mathrm{r}^{2}$ & $\mathrm{~N}$ & $\sqrt{\mathrm{N}}$ & $1-\mathrm{r}^{2} / \sqrt{\mathrm{N}}$ & multiplier & $\mathrm{PE}$ & $6(\mathrm{PE})$ \\
\hline Castrol & 0.993 & 0.986 & 0.014 & 2755 & 52.48809 & 0.00027 & 0.6745 & 0.00018 & 0.00108 \\
\hline
\end{tabular}

Probable error for the autocorrelation 0.993 in the first lag is 0.00018 . See TABLE No.7.8.5 above. The coefficient of autocorrelation is greater than the PE $(0.993>0.00018)$. The autocorrelation 0.993 is still higher than the 6 times PE (0.00108) i.e., $r>6(\mathrm{PE})$. Hence the autocorrelation 0.993 of Castrol is significant. 
Table No.7.8.6: Calculation of Probable Error in Lag 16.

\begin{tabular}{|l|l|l|l|l|l|l|l|l|l|}
\hline Stock & $\mathrm{r}$ & $\mathrm{r}^{2}$ & $1-\mathrm{r}^{2}$ & $\mathrm{~N}$ & $\sqrt{\mathrm{N}}$ & $1-\mathrm{r}^{2} / \sqrt{\mathrm{N}}$ & multiplier & $\mathrm{PE}$ & $6(\mathrm{PE})$ \\
\hline Castrol & 0.895 & 0.801 & 0.199 & 2755 & 52.48809 & 0.00379 & 0.6745 & 0.00256 & 0.01536 \\
\hline
\end{tabular}

Probable error for the autocorrelation 0.895 in lag 16 is 0.00256 . See Table No.7.8.6 above. The coefficient of autocorrelation is greater than the PE $(0.895>0.00256)$. The autocorrelation 0.895 is still higher than the 6 times PE (0.01536) i.e., $r>6(P E)$. Hence the autocorrelation 0.895 of Castrol in lag 16 is significant.

Table No.7.8.7: Run test descriptive statistics of Castrol

\begin{tabular}{|l|l|}
\hline Test Values & 275.48 \\
\hline Cases $<$ Test Values & 1895 \\
\hline Cases $>$ Test Values & 861 \\
\hline Total Cases & 2756 \\
\hline No. of runs & 65 \\
\hline Z & -49.67 \\
\hline Asym.sig (2-tailed) & 0.0 \\
\hline Expected runs R & 1185.03 \\
\hline$\sigma$ of runs & 22.55 \\
\hline Table Value @ 5\% significance & -1.96 \\
\hline
\end{tabular}

As per TABLE No.7.8.7, the mean value of stock price is 275.48. Cases below the mean are 1895 and above are 861 . There are 65 runs in the series. The expected runs are 1185.03 and the standard deviation of runs is 22.55 . The actual runs in the price series are lower than the expected $(65<1185.03)$. Too few runs indicate stationary state of the series. The $\mathrm{z}$ value calculated is -49.67 whereas the table value for the same at $5 \%$ level of significance is -1.96 on the left tail. The $z$ calculated is lower than the table value $(-49.67<-1.96)$. Therefore the null hypothesis that the series is random is rejected and resolved that there is interdependence and nonrandomness in the closing price series of Castrol.

\subsection{Colgate Palmolive}

Table 7.9.1: Descriptive Statistics of Colgate Palmolive

\begin{tabular}{|l|l|}
\hline MINIMUM & 111.1 \\
\hline MAXIMUM & 723.7 \\
\hline MEAN & 262.85 \\
\hline MEDIAN & 195.80 \\
\hline STANDARD DEVIATION & 139.05 \\
\hline SKEWNESS & 1.122 \\
\hline KURTOSIS & 0.666 \\
\hline NO. OF OBSERVATION & 2744 \\
\hline
\end{tabular}

TABLE No.7.9.1 above shows that the mean of the price series of Colgate Palmolive for 2744 days of observation is 262.85 . The median value is 195.80 . There is difference between mean and median. Therefore the distribution is not normal because in normal distribution the mean, median and mode are the same. RWH (Random-walk Hypothesis) presupposes a normal distribution to constitute an efficient market. The minimum and maximum prices show wide difference. The standard deviation 139.05 is bigger. The coefficient of variation $=\frac{\sigma}{\overline{\mathrm{X}}}=\frac{139.05}{262.85}=52.90 \%$. The $\sigma$ is too large for normal distribution. There is high degree of positive skewness to the tune of 1.122. In a normal distribution, skewness will be zero. The high positive skewness nullifies the null hypothesis and confirms non-randomness. The coefficient of kurtosis of the price series is 0.666 . A kurtosis value with 3 is the normal distribution. Since the actual kurtosis is lower than the normal i.e. $0.666<3$ the shape of the distribution is platykurtic. The descriptive statistics of price series of Colgate Palmolive confirms asymmetry and non-randomness in the series. 


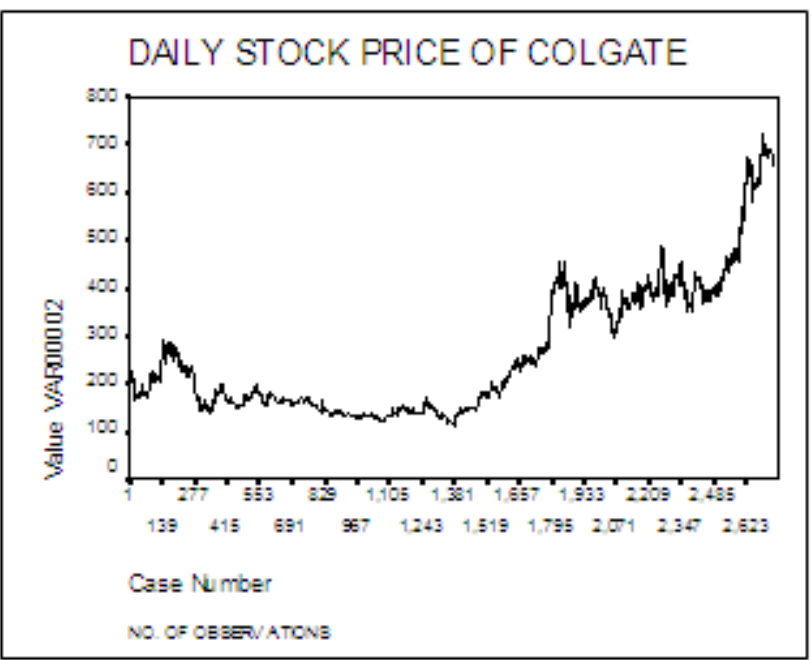

Figure 7.9.1: Daily Stock Price of Colgate Palmolive for 2744 days.

Fig.7.9.1 depicts the behavior of stock price of Colgate Palmolive. The daily stock prices of Colgate Palmolive have lot of fluctuations. The opening price of the stock in 1999 was Rs.197.1. With lot of minor and major fluctuations the price reached to the peak level at Rs.659 in 2009. The overall tendency of the stock of Colgate Palmolive is to rise upwards. As the standard deviation denoted, the price series is expressing major and minor fluctuations along its movement. The steady flow of the line with turbulent zigzags can be viewed from the graph. There is high volatility in prices. This shows large scale mispricing in the market, an evidence for the absence of market efficiency.

Table No. 7.9.2: Autocorrelation of prices of Colgate Palmolive in 16 lags

\begin{tabular}{|l|l|l|l|l|l|l|r|r|r|r|r|r|r|r|r|r|r|}
\hline Lags & 1 & 2 & 3 & 4 & 5 & 6 & 7 & 8 & 9 & 10 & 11 & 12 & 13 & 14 & 15 & 16 \\
\hline Colgat & 0.99 & 0.99 & 0.99 & 0.99 & 0.98 & 0.98 & 0.98 & 0.98 & 0.97 & 0.97 & 0.97 & 0.97 & 0.96 & 0.96 & 0.96 & 0.96 \\
$\mathrm{e}$ & 7 & 5 & 3 & 0 & 8 & 5 & 3 & 0 & 8 & 5 & 3 & 0 & 8 & 5 & 3 \\
\hline
\end{tabular}

TABLE No.7.9.2 provides autocorrelation coefficient of Colgate Palmolive's price series in 16 lags. Although correlation is given for 16 lags the value of correlation in the first lag is statistically significant. It can be seen from the table that the auto correlation in all 16 lags is above 0.9. Auto correlation above 0.5 is significant. Therefore, the null hypothesis that the price series is random is rejected. It signals significant evidence for interdependence and non-randomness.

Table No.7.9.3: Student's ' $t$ ' test in Lag 1

\begin{tabular}{|l|l|l|l|l|l|l|l|l|l|}
\hline Stock & $\mathrm{r}$ & $\mathrm{N}-2$ & $\sqrt{\mathrm{N}}-2$ & $\mathrm{r}^{2}$ & $1-\mathrm{r}^{2}$ & $\sqrt{1-\mathrm{r}^{2}}$ & $\mathrm{r} / \sqrt{ } 1-\mathrm{r}^{2}$ & $\mathrm{H}^{*} \mathrm{D}$ & Table \\
\hline Colgate & 0.997 & 2741 & 52.35456 & 0.994 & 0.006 & 0.077 & 12.87 & 674 & 1.96 \\
\hline
\end{tabular}

As per TABLE No.7.9.3 above, the auto correlation of Colgate Palmolive in the first lag is 0.997. The $t$ value calculated is 674 and table value at $5 \%$ significance is 1.96 . T value calculated is greater than the table value (674>1.96). Therefore, the autocorrelation coefficient is significant in the first lag.

Table 7.9.4: Student's t test in Lag 16

\begin{tabular}{|c|c|c|c|c|c|c|r|r|r|}
\hline Scrip & $\mathrm{r}$ & $\mathrm{N}-2$ & $\sqrt{\mathrm{N}}-2$ & $\mathrm{r}^{2}$ & $1-\mathrm{r}^{2}$ & $\sqrt{1-\mathrm{r}^{2}}$ & $\mathrm{r} / \sqrt{ } 1-\mathrm{r}^{2}$ & $\mathrm{H}^{*} \mathrm{D}$ & Table \\
\hline Colgate & 0.96 & 2741 & 52.35456 & 0.922 & 0.078 & 0.279 & 3.44 & 180 & 1.96 \\
\hline
\end{tabular}

TABLE No.7.9.5 above shows that $\mathrm{t}$ test for the $16^{\text {th }}$ lag of price of stock Colgate Palmolive. Auto correlation in the $16^{\text {th }}$ lag is 0.96 . The calculated value of $t$ is given as 180 . The table value for the same is 1.96 . The calculated $\mathrm{t}$ value 180 is greater than the table value 1.96 . Hence the autocorrelation in $16^{\text {th }}$ lag is significant.

Table No.7.9.5: Calculation of Probable Error in Lag 1

\begin{tabular}{|l|l|l|l|l|l|l|l|l|l|}
\hline Stock & $\mathrm{r}$ & $\mathrm{r}^{2}$ & $1-\mathrm{r}^{2}$ & $\mathrm{~N}$ & $\sqrt{\mathrm{N}}$ & $1-\mathrm{r}^{2} / \sqrt{\mathrm{N}}$ & multiplier & $\mathrm{PE}$ & $6(\mathrm{PE})$ \\
\hline Colgate & 0.997 & 0.994 & 0.006 & 2743 & 52.37366 & 0.00011 & 0.6745 & 0.00007 & 0.00042 \\
\hline
\end{tabular}

Probable error for the autocorrelation 0.997 in the first lag is 0.00007. See TABLE No.7.9.5 above. The coefficient of autocorrelation is greater than the PE $(0.997>0.00007)$. The autocorrelation 0.997 is still higher than the 6 times PE (0.00042) i.e., $r>6(\mathrm{PE})$. Hence the autocorrelation 0.997 of Colgate Palmolive is significant.

Table No.7.9.6: Calculation of Probable Error in Lag 16 .

\begin{tabular}{|c|c|c|c|c|c|c|c|c|c|}
\hline Stock & $\mathrm{r}$ & $\mathrm{r}^{2}$ & $1-r^{2}$ & $\mathrm{~N}$ & $\sqrt{N}$ & $1-\mathrm{r}^{2} / \sqrt{\mathrm{N}}$ & multiplier & $\mathrm{PE}$ & $6(\mathrm{PE})$ \\
\hline Colgate & 0.96 & 0.922 & 0.078 & 2743 & 52.37366 & 0.00149 & 0.6745 & 0.00101 & 0.00606 \\
\hline
\end{tabular}


Probable error for the autocorrelation 0.96 in lag 16 is 0.00101 . See TABLE No.7.9.6 above. The coefficient of autocorrelation is greater than the PE $(0.96>0.00101)$. The autocorrelation 0.96 is still higher than the 6 times PE (0.00606) i.e., $r>6(\mathrm{PE})$. Hence the autocorrelation 0.96 of Colgate Palmolive in lag 16 is significant.

Table No.7.9.7: Run test descriptive statistics of Colgate Palmolive

\begin{tabular}{|l|l|}
\hline Test Values & 262.85 \\
\hline Cases $<$ Test Values & 1692 \\
\hline Cases $>$ Test Values & 1052 \\
\hline Total Cases & 2744 \\
\hline No. of runs & 20 \\
\hline Z & -51.63 \\
\hline Asym.sig (2-tailed) & 0.0 \\
\hline Expected runs R & 1298.36 \\
\hline$\sigma$ of runs & 24.76 \\
\hline Table Value @ 5\% significance & -1.96 \\
\hline
\end{tabular}

As per TABLE No.7.9.7, the mean value of stock price is 262.85. Cases below the mean are 1692 and above are 1052. There are 20 runs in the series. The expected runs are 1298.36 and the standard deviation of runs is 24.76. The actual runs in the price series are lower than the expected $(20<1298.36)$. Too few runs indicate stationary state of the series. The $\mathrm{z}$ value calculated is -51.63 whereas the table value for the same at $5 \%$ level of significance is -1.96 on the left tail. The $\mathrm{z}$ calculated is lower than the table value $(-51.63<-1.96)$. Therefore the null hypothesis that the series is random is rejected and resolved that there is interdependence and non-randomness in the closing price series of Colgate Palmolive.

\subsection{Cromton Greeves}

Table No.7.10.1: Descriptive Statistics of Crompton Greeves

\begin{tabular}{|l|l|}
\hline MINIMUM & 18.2 \\
\hline MAXIMUM & 1202.95 \\
\hline MEAN & 216.63 \\
\hline MEDIAN & 143.35 \\
\hline STANDARD DEVIATION & 239.47 \\
\hline SKEWNESS & 1.897 \\
\hline KURTOSIS & 3.514 \\
\hline NO. OF OBSERVATION & 2748 \\
\hline
\end{tabular}

TABLE No.7.10.1 above shows that the mean of the price series of Crompton Greeves for 2748 days of observation is 216.63 . The median value is 143.35 . There is difference between mean and median. Therefore the distribution is not normal because in normal distribution the mean, median and mode are the same. RWH (Random-walk Hypothesis) presupposes a normal distribution to constitute an efficient market. The difference between the minimum and maximum prices is very high. The standard deviation 239.47 is bigger. The coefficient of variation $=\frac{\sigma}{\overline{\mathrm{X}}}=\frac{239.47}{216.63}=110.54 \%$. The $\sigma$ is too large for normal distribution. There is high degree of positive skewness to the tune of 1.897. In a normal distribution, skewness will be zero. The high positive skewness nullifies the null hypothesis and confirms non-randomness. The coefficient of kurtosis of the price series is 3.514. A kurtosis value with 3 is the normal distribution. Since the actual kurtosis is greater than the normal i.e. 3.514>3 the shape of the distribution is leptokurtic. The descriptive statistics of price series of Crompton Greeves confirms asymmetry and non-randomness in the series.

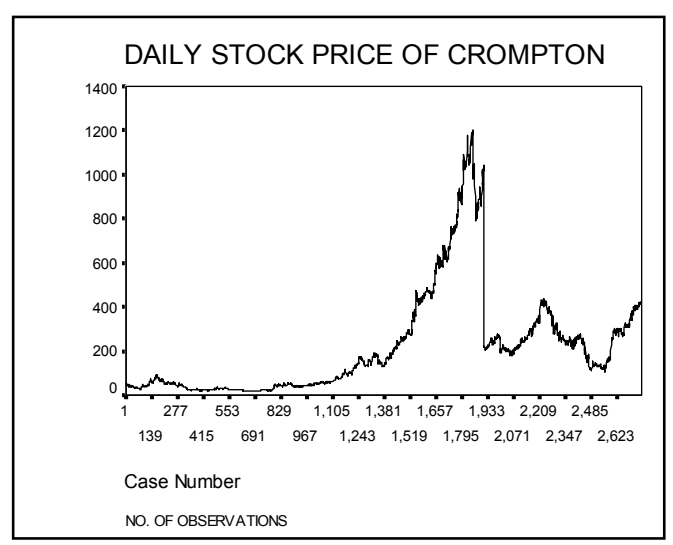

Figure 7.10.1: Daily Stock Price of Crompton Greeves for 2748 days.

Fig.7.10.1 depicts the behavior of stock price of Crompton Greeves. The daily stock prices of Crompton Greeves has lot of fluctuations. The opening price of the stock in 1999 was Rs.52.20. With lot of 
minor and major fluctuations the price reached to the peak level at Rs.771 in 2005 . Then fell abruptly down to Rs.208 in 2006. Then recovered and settled at Rs.425.85 in 2009. The overall tendency of the stock of Crompton Greeves was to decline. As the standard deviation denoted, the price series was expressing major and minor fluctuations along its movement. It gave larger and smaller surprises to the market. The steady flow of the line with turbulent zigzags can be viewed from the graph. There is high volatility in prices. This shows large scale mispricing in the market, an evidence for market inefficiency.

Table No.7.10.2: Autocorrelation of prices of Crompton Greeves in 16 lags

\begin{tabular}{|l|r|r|r|r|r|r|r|r|r|r|r|r|r|r|r|r|}
\hline Lags & 1 & 2 & 3 & 4 & 5 & 6 & 7 & 8 & 9 & 10 & 11 & 12 & 13 & 14 & 15 & 16 \\
\hline cromp & 0.9 & 0.9 & 0.9 & 0.9 & 0.9 & 0.9 & 0.9 & 0.9 & 0.9 & 0.9 & 0.9 & 0.9 & 0.9 & 0.9 & 0.9 & 0.9 \\
ton & 98 & 97 & 95 & 94 & 93 & 92 & 90 & 89 & 87 & 86 & 84 & 82 & 80 & 79 & 77 & 77 \\
\hline
\end{tabular}

TABLE No.7.10.2 provides autocorrelation coefficient of Crompton Greeves' price series in 16 lags. Although correlation is given for 16 lags the value of correlation in the first lag is statistically significant. It can be seen from the table that the auto correlation in all 16 lags is above 0.9 . Auto correlation above 0.5 is significant. Therefore, the null hypothesis that the price series is random is rejected. It signals significant evidence for interdependence and non-randomness.

Table No.7.10.3: Student's ' $t$ ' test in Lag 1

\begin{tabular}{|l|c|c|c|c|c|c|c|c|c|}
\hline Stock & $\mathbf{r}$ & $\mathbf{N}-2$ & $\sqrt{\mathrm{N}}-2$ & \multicolumn{1}{|c}{$\mathbf{r}^{\mathbf{2}}$} & $\mathbf{1}-\mathbf{r}^{\mathbf{2}}$ & $\sqrt{ } \mathbf{1}-\mathbf{r}^{\mathbf{2}}$ & $\mathbf{r} / \sqrt{\mathbf{1}-\mathbf{r}^{\mathbf{2}}}$ & $\mathbf{H}^{*} \mathbf{D}$ & Table \\
\hline crompton & 0.998 & 2745 & 52.39275 & 0.996 & 0.004 & 0.063 & 15.78 & 827 & 1.96 \\
\hline
\end{tabular}

As per Table No.7.10.3 above, the auto correlation of Crompton Greeves in the first lag is 0.998. The $t$ value calculated is 827 and table value at 5\% significance is 1.96 . T value calculated is greater than the table value $(827>1.96)$. Therefore, the autocorrelation coefficient is significant in the first lag.

Table No.7.10.4: Student's t test in Lag 16

\begin{tabular}{|c|l|l|l|r|r|r|r|r|r|}
\hline Scrip & \multicolumn{1}{|l|}{$\mathrm{N}-2$} & $\sqrt{\mathrm{N}-2}$ & $\mathrm{r}^{2}$ & $1-\mathrm{r}^{2}$ & $\sqrt{1-\mathrm{r}^{2}}$ & $\mathrm{r} / \sqrt{ } 1-\mathrm{r}^{2}$ & $\mathrm{H}^{*} \mathrm{D}$ & Table \\
\hline crompton & 0.9775 & 2745 & 52.39275 & 0.956 & 0.044 & 0.210 & 4.66 & 244 & 1.96 \\
\hline
\end{tabular}

TABLE No.7.10.4 above shows that test for the $16^{\text {th }}$ lag of price of stock Crompton Greeves. Auto correlation in the $16^{\text {th }} \mathrm{lag}$ is 0.9775 . The calculated value of $\mathrm{t}$ is given as 244 . The table value for the same is 1.96. The calculated $t$ value 244 is greater than the table value 1.96 . Hence the autocorrelation in $16^{\text {th }}$ lag is significant.

Table No.7.10.5

Calculation of Probable Error in Lag 1

\begin{tabular}{|l|r|r|r|r|l|l|r|l|l|}
\hline Stock & \multicolumn{1}{|l|}{$\mathrm{r}$} & \multicolumn{1}{l|}{$\mathrm{r}^{2}$} & \multicolumn{1}{l|}{$1-\mathrm{r}^{2}$} & $\mathrm{~N}$ & $\sqrt{\mathrm{N}}$ & $1-\mathrm{r}^{2} / \sqrt{ } \mathrm{N}$ & multiplier & PE & $6(\mathrm{PE})$ \\
\hline crompton & 0.998 & 0.996 & 0.004 & 2747 & 52.41183 & 0.00008 & 0.6745 & 0.00005 & 0.0003 \\
\hline
\end{tabular}

Probable error for the autocorrelation 0.998 in the first lag is 0.00005. See TABLE No.7.10.5 above. The coefficient of autocorrelation is greater than the PE $(0.998>0.00005)$. The autocorrelation 0.998 is still higher than the 6 times PE (0.0003) i.e., $r>6(\mathrm{PE})$. Hence the autocorrelation 0.998 of Crompton Greeves is significant.

Table No.7.10.6

Calculation of Probable Error in Lag 16.

\begin{tabular}{|c|c|c|c|c|c|c|c|c|c|}
\hline Stock & $\mathrm{r}$ & $r^{2}$ & $1-\mathrm{r}^{2}$ & $\mathrm{~N}$ & $\sqrt{N}$ & $1-\mathrm{r}^{2} / \sqrt{N}$ & multiplier & $\mathrm{PE}$ & $6(\mathrm{PE})$ \\
\hline crompton & 0.9775 & 0.956 & 0.044 & 2747 & 52.41 & 0.00084 & 0.6745 & 0.00057 & 0.00342 \\
\hline
\end{tabular}

Probable error for the autocorrelation 0.9775 in lag 16 is 0.00057 . See TABLE No.7.10.6 above. The coefficient of autocorrelation is greater than the PE $(0.9775>0.00057)$. The autocorrelation 0.9775 is still higher than the 6 times PE (0.00342) i.e., $r>6(P E)$. Hence the autocorrelation 0.9775 of Crompton Greeves in lag 16 is significant.

Table No.7.10.7

Run test descriptive statistics of Crompton Greeves

\begin{tabular}{|l|l|}
\hline Test Values & 216.63 \\
\hline Cases $<$ Test Values & 1687 \\
\hline Cases $>$ Test Values & 1061 \\
\hline Total Cases & 2748 \\
\hline No. of runs & 24 \\
\hline Z & -51.51 \\
\hline Asym.sig (2-tailed) & 0.0 \\
\hline Expected runs R & 1303.7 \\
\hline$\sigma$ of runs & 24.85 \\
\hline Table Value @ 5\% significance & -1.96 \\
\hline
\end{tabular}


As per TABLE No.7.10.7, the mean value of stock price is 216.63. Cases below the mean are 1687 and above are 1061. There are 24 runs in the series. The expected runs are 1303.7 and the standard deviation of runs is 24.85 . The actual runs in the price series are lower than the expected $(24<1303.7)$. Too few runs indicate stationary state of the series. The $\mathrm{z}$ value calculated is -51.51 whereas the table value for the same at $5 \%$ level of significance is -1.96 on the left tail. The $\mathrm{z}$ calculated is lower than the table value $(-51.51<-1.96)$. Therefore the null hypothesis that the series is random is rejected and resolved that there is interdependence and nonrandomness in the closing price series of Crompton Greeves.

\subsection{Garware Polyester}

Table No.7.11.1

Descriptive Statistics of Garware Polyester

\begin{tabular}{|l|l|}
\hline MINIMUM & 3.2 \\
\hline MAXIMUM & 94.5 \\
\hline MEAN & 31.13 \\
\hline MEDIAN & 33.8 \\
\hline STANDARD DEVIATION & 18.86 \\
\hline SKEWNESS & 0.161 \\
\hline KURTOSIS & -0.765 \\
\hline NO. OF OBSERVATION & 2722 \\
\hline
\end{tabular}

TABLE No.7.11.1 above shows that the mean of the price series of Garware Polyester for 2722 days of observation is Rs.31.13. The median value is Rs.33.80. There is difference between mean and median. Therefore the distribution is not normal because in normal distribution the mean, median and mode are the same. RWH (Random-walk Hypothesis) presupposes a normal distribution to constitute an efficient market. The difference between the minimum and maximum prices is very wide. The standard deviation Rs.18.86 is bigger. The coefficient of variation $=\frac{\sigma}{\bar{X}}=\frac{18.86}{31.13}=60.58 \%$. The $\sigma$ is too large for normal distribution. There is a positive skewness to the tune of 0.161 . In a normal distribution, skewness will be zero. The positive skewness nullifies the null hypothesis and confirms non-randomness. The coefficient of kurtosis of the price series is -0.765 . A kurtosis value with 3 is the normal distribution. Since the actual kurtosis is lower than the normal i.e. $-0.765<3$ the shape of the distribution is platikurtic on the left side. The descriptive statistics of price series of Garware Polyester confirms asymmetry and non-randomness in the series.

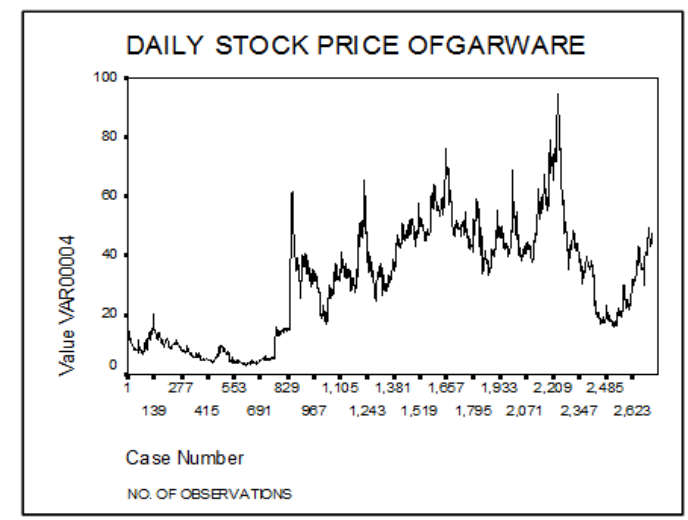

Figure 7.11.1: Daily Stock Price of Garware Polyester for 2722 days.

Fig.7.11.1 depicts the behavior of stock price of Garware Polyester. The daily stock prices of Crompton Greeves had lot of fluctuations. The opening price of the stock in 1999 was Rs.11.2. With lot of minor and major fluctuations the price reached to the peak level at Rs.91.5 in 2007. Then fell abruptly down to Rs.17.8 in 2008. Then recovered and settled at Rs.48 in 2009. The overall tendency of the stock of Crompton Greeves was to rise. As the standard deviation denoted, the price series was expressing major and minor fluctuations along its movement. It gave larger and smaller surprises to the market. The steady flow of the line with turbulent zigzags can be viewed from the graph. There is high volatility in prices. This shows large scale mispricing in the market, an evidence for the absence of market efficiency.

Table No.7.11.2

Autocorrelation of prices of Garware Polyester in 16 lags

\begin{tabular}{|c|c|c|c|c|c|c|c|c|c|c|c|c|c|c|c|c|}
\hline Lags & 1 & 2 & 3 & 4 & 5 & 6 & 7 & 8 & 9 & 10 & 11 & 12 & 13 & 14 & 15 & 16 \\
\hline Garwar & 0.99 & 0.99 & 0.99 & 0.98 & 0.98 & 0.98 & 0.97 & 0.97 & 0.97 & 0.96 & 0.96 & 0.95 & 0.95 & 0.95 & 0.94 & 0.94 \\
\hline $\mathrm{e}$ & 7 & 3 & 0 & 7 & 4 & 0 & 7 & 4 & 0 & 7 & 3 & 9 & 5 & 1 & 7 & 3 \\
\hline
\end{tabular}


TABLE No7.11.2 provides autocorrelation coefficient of Crompton Greeves' price series in 16 lags. Although correlation is given for 16 lags the value of correlation in the first lag is statistically significant. It can be seen from the table that the auto correlation in all 16 lags is above 0.9. Auto correlation above 0.5 is significant. Therefore, the null hypothesis that the price series is random is rejected. It signals significant evidence for interdependence and non-randomness.

Table No.7.11.3

Student's ' $t$ ' test in Lag 1

\begin{tabular}{|l|c|c|c|c|c|r|r|r|r|}
\hline Stock & $\mathbf{r}$ & $\mathbf{N}-2$ & $\sqrt{\mathrm{N}}-2$ & $\mathbf{r}^{\mathbf{2}}$ & $\mathbf{1}^{\mathbf{2}}$ & $\sqrt{\mathbf{1}-\mathbf{r}^{\mathbf{2}}}$ & $\mathbf{r}^{\mathbf{2}} \sqrt{\mathbf{1}-\mathbf{r}^{\mathbf{2}}}$ & $\mathbf{H}^{*} \mathbf{D}$ & Table $^{2}$ \\
\hline Garware & 0.997 & 2719 & 52.14403 & 0.994 & 0.006 & 0.077 & 12.87 & 671 & 1.96 \\
\hline
\end{tabular}

As per TABLE No.7.11.3 above, the auto correlation of Garware Polyester in the first lag is 0.997. The $\mathrm{t}$ value calculated is 671 and table value at $5 \%$ significance is 1.96 . T value calculated is greater than the table value (671>1.96). Therefore, the autocorrelation coefficient is significant in the first lag.

Table No.7.11.4

Student's t test in Lag 16

\begin{tabular}{|c|r|r|r|r|r|r|r|r|r|}
\hline Scrip & $\mathrm{r}$ & $\mathrm{N}-2$ & $\sqrt{\mathrm{N}-2}$ & $\mathrm{r}^{2}$ & $1-\mathrm{r}^{2}$ & $\sqrt{1-\mathrm{r}^{2}}$ & $\mathrm{r} / \sqrt{1} 1-\mathrm{r}^{2}$ & $\mathrm{H}^{*} \mathrm{D}$ & Table \\
\hline Garware & 0.943 & 2719 & 52.14403 & 0.889 & 0.111 & 0.333 & 2.83 & 148 & 1.96 \\
\hline
\end{tabular}

TABLE No.7.11.4 above shows that $t$ test for the $16^{\text {th }}$ lag of price of stock Garware Polyester. Auto correlation in the $16^{\text {th }}$ lag is 0.943 . The calculated value of $t$ is given as 148 . The table value for the same is 1.96 . The calculated $t$ value 148 is greater than the table value 1.96 . Hence the autocorrelation in $16^{\text {th }}$ lag is significant.

Table No.7.11.5

Calculation of Probable Error in Lag 1

\begin{tabular}{|c|c|c|c|c|c|c|c|c|c|}
\hline Stock & $\mathrm{r}$ & $r^{2}$ & $1-r^{2}$ & $\mathrm{~N}$ & $\sqrt{N}$ & $1-\mathrm{r}^{2} / \sqrt{\mathrm{N}}$ & multiplier & $\mathrm{PE}$ & $6(\mathrm{PE})$ \\
\hline Garware & 0.997 & 0.994 & 0.006 & 2721 & 52.16321 & 0.00012 & 0.6745 & 0.00008 & 0.00048 \\
\hline
\end{tabular}

Probable error for the autocorrelation 0.997 in the first lag is 0.00008. See TABLE No.7.11.5 above.

The coefficient of autocorrelation is greater than the PE (0.997>0.00008). The autocorrelation 0.997 is still higher than the 6 times PE (0.00048) i.e., $r>6(\mathrm{PE})$. Hence the autocorrelation 0.997 of Garware Polyester is significant.

Table No.7.11.6

Calculation of Probable Error in Lag 16.

\begin{tabular}{|c|c|c|c|c|c|c|c|c|c|}
\hline Stock & $\mathrm{r}$ & $\mathrm{r}^{2}$ & $1-\mathrm{r}^{2}$ & $\mathrm{~N}$ & $\sqrt{\mathrm{N}}$ & $1-\mathrm{r}^{2} / \sqrt{\mathrm{N}}$ & multiplier & $\mathrm{PE}$ & 6 (PE) \\
\hline Garware & 0.943 & 0.889 & 0.111 & 2721 & 52.16321 & 0.00213 & 0.6745 & 0.00144 & 0.00864 \\
\hline
\end{tabular}

Probable error for the autocorrelation 0.943 in lag 16 is 0.00144 . See TABLE No.7.11.6 above. The coefficient of autocorrelation is greater than the PE $(0.943>0.00144)$. The autocorrelation 0.943 is still higher than the 6 times PE (0.00864) i.e., $r>6(\mathrm{PE})$. Hence the autocorrelation 0.943 of Garware Polyester in lag 16 is significant.

Table No.7.11.7

Run test descriptive statistics of Garware Polyester

\begin{tabular}{|l|l|}
\hline Test Values & 31.13 \\
\hline Cases $<$ Test Values & 1206 \\
\hline Cases $>$ Test Values & 1516 \\
\hline Total Cases & 2722 \\
\hline No. of runs & 36 \\
\hline Z & -50.82 \\
\hline Asym.sig (2-tailed) & 0.0 \\
\hline Expected runs R & 1344.35 \\
\hline$\sigma$ of runs & 25.74 \\
\hline Table Value @ 5\% significance & -1.96 \\
\hline
\end{tabular}

As per TABLE No.7.11.7, the mean value of stock price is Rs.31.13. Cases below the mean are 1206 and above are 1516. There are 36 runs in the series. The expected runs are 1344.35 and the standard deviation of runs is 25.74 . The actual runs in the price series are lower than the expected $(36<1344.35)$. Too few runs indicate stationary state of the series. The $\mathrm{z}$ value calculated is -50.82 whereas the table value for the same at $5 \%$ level of significance is -1.96 on the left tail. The $\mathrm{z}$ calculated is lower than the table value $(-50.82<-1.96)$. Therefore the null hypothesis that the series is random is rejected and resolved that there is interdependence and non-randomness in the closing price series of Garware Polyester. 
7.12. Gujarat Narmada

Table No.7.12.1

Descriptive Statistics of Gujarat Narmada

\begin{tabular}{|l|l|}
\hline MINIMUM & 11.5 \\
\hline MAXIMUM & 223.6 \\
\hline MEAN & 65.84 \\
\hline MEDIAN & 54.50 \\
\hline STANDARD DEVIATION & 43.95 \\
\hline SKEWNESS & 0.9 \\
\hline KURTOSIS & 0.25 \\
\hline NO. OF OBSERVATION & 2751 \\
\hline
\end{tabular}

TABLE No.7.12.1 above shows that the mean of the price series of Gujarat Narmada for 2751 days of observation is Rs.65.84. The median value is Rs.54.50. There is difference between mean and median. Therefore the distribution is not normal because in normal distribution the mean, median and mode are the same. RWH (Random-walk Hypothesis) presupposes a normal distribution to constitute an efficient market. The difference between the minimum and maximum prices is high. The standard deviation Rs.43.95 is bigger. The coefficient of variation $=\frac{\sigma}{\overline{\mathrm{X}}}=\frac{43.95}{65.84}=66.75 \%$. The $\sigma$ is too large for normal distribution. There is a high positive skewness to the tune of 0.9 . In a normal distribution, skewness will be zero. The positive skewness nullifies the null hypothesis and confirms non-randomness. The coefficient of kurtosis of the price series is 0.25 . A kurtosis value with 3 is the normal distribution. Since the actual kurtosis is lower than the normal i.e. $0.25<3$ the shape of the distribution is platykurtic. The descriptive statistics of price series of Gujarat Narmada confirms asymmetry and non-randomness in the series.

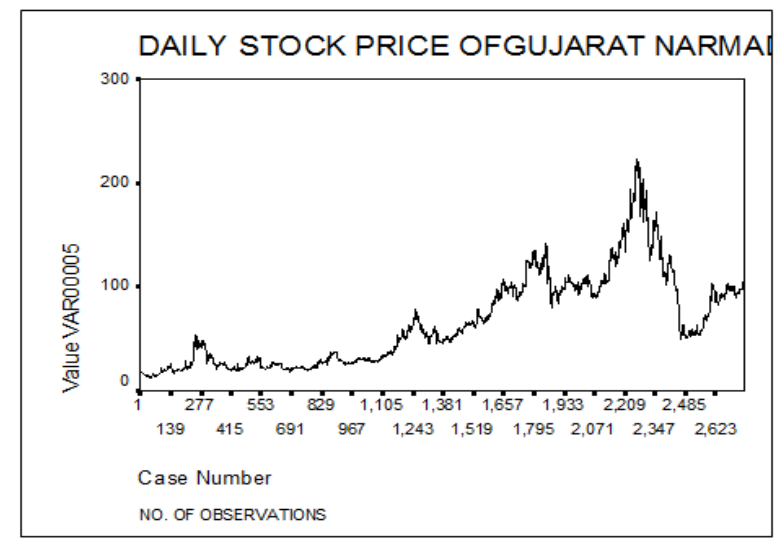

Figure 7.12.1: Daily Stock Price of Gujarat Narmada for 2722 days.

Fig.7.12.1 depicts the behavior of stock price of Gujarat Narmada. The daily stock prices of Gujarat Narmada had lot of fluctuations. The opening price of the stock in 1999 was Rs.18.50. With lot of minor and major fluctuations the price reached to the peak level at Rs.218.35 in 2008. Then fell abruptly down. Then recovered and settled at Rs.101.50 in 2009. The overall tendency of the stock of Gujarat Narmada was to rise. As the standard deviation denoted, the price series was expressing major and minor fluctuations along its movement. It gave larger and smaller surprises to the market. The steady flow of the line with violent zigzags can be viewed from the graph. There is high volatility in prices. This shows large scale mispricing in the market, an evidence for the presence of market inefficiency.

Table No.7.12.2

Autocorrelation of prices of Gujarat Narmada in 16 lags

\begin{tabular}{|l|r|r|r|r|r|r|r|r|r|r|r|r|r|r|r|r|}
\hline Lags & $\mathbf{1}$ & $\mathbf{2}$ & $\mathbf{3}$ & $\mathbf{4}$ & $\mathbf{5}$ & $\mathbf{6}$ & $\mathbf{7}$ & $\mathbf{8}$ & $\mathbf{9}$ & $\mathbf{1 0}$ & $\mathbf{1 1}$ & $\mathbf{1 2}$ & $\mathbf{1 3}$ & $\mathbf{1 4}$ & $\mathbf{1 5}$ & $\mathbf{1 6}$ \\
\hline Gujrat & 0.99 & 0.99 & 0.99 & 0.99 & 0.98 & 0.98 & 0.98 & 0.98 & 0.98 & 0.98 & 0.97 & 0.97 & 0.97 & 0.97 & 0.97 & 0.96 \\
nar & 8 & 6 & 3 & 1 & 9 & 8 & 6 & 4 & 3 & 1 & 9 & 7 & 5 & 4 & 2 & 9 \\
\hline
\end{tabular}

TABLE No.7.12.2 provides autocorrelation coefficient of Gujarat Narmada's price series in 16 lags. Although correlation is given for 16 lags the value of correlation in the first lag is statistically significant. It can be seen from the table that the auto correlation in all 16 lags is above 0.9. Auto correlation above 0.5 is significant. Therefore, the null hypothesis that the price series is random is rejected. It signals significant evidence for interdependence and non-randomness.

Table No.7.12.3

Student's ' $t$ ' test in Lag 1

\begin{tabular}{|l|c|c|c|c|c|r|r|r|r|}
\hline Stock & $\mathbf{r}$ & $\mathbf{N}-\mathbf{2}$ & $\sqrt{\mathrm{N}-2}$ & \multicolumn{1}{|c|}{$\mathbf{r}^{\mathbf{2}}$} & $\mathbf{1}-\mathbf{r}^{\mathbf{2}}$ & $\sqrt{1} \mathbf{1}-\mathbf{r}^{\mathbf{2}}$ & $\mathbf{r} / \sqrt{\mathbf{1}-\mathbf{r}^{2}}$ & $\mathbf{H} * \mathbf{D}$ & Table \\
\hline Gujrat nar & 0.998 & 2748 & 52.42137 & 0.996 & 0.004 & 0.063 & 15.78 & 827 & 1.96 \\
\hline
\end{tabular}


As per TABLE No.7.12.3 above, the auto correlation of Gujarat Narmada in the first lag is 0.998. The $t$ value calculated is 827 and table value at $5 \%$ significance is 1.96 . T value calculated is greater than the table value (827>1.96). Therefore, the autocorrelation coefficient is significant in the first lag.

Table No.7.12.4

Student's $\mathrm{t}$ test in Lag 16

\begin{tabular}{|c|r|r|l|l|l|l|l|l|r|}
\hline Scrip & $\mathrm{r}$ & $\mathrm{N}-2$ & $\sqrt{\mathrm{N}-2}$ & $\mathrm{r}^{2}$ & $1-\mathrm{r}^{2}$ & $\sqrt{1-\mathrm{r}^{2}}$ & $\mathrm{r} / \sqrt{1-\mathrm{r}^{2}}$ & $\mathrm{H}^{*} \mathrm{D}$ & Table \\
\hline Gujrat nar & 0.969 & 2748 & 52.42137 & 0.939 & 0.061 & 0.247 & 3.92 & 205 & 1.96 \\
\hline
\end{tabular}

TABLE No.7.12.4 above shows the $\mathrm{t}$ test for the $16^{\text {th }}$ lag of price of stock Gujarat Narmada. Auto correlation in the $16^{\text {th }}$ lag is 0.969 . The calculated value of $t$ is given as 205 . The table value for the same is 1.96 . The calculated $t$ value 205 is greater than the table value 1.96 . Hence the autocorrelation in $16^{\text {th }}$ lag is significant.

Table No.7.12.5

Calculation of Probable Error in Lag 1

\begin{tabular}{|c|c|c|c|c|c|c|c|c|c|}
\hline Stock & $\mathrm{r}$ & $\mathrm{r}^{2}$ & $1-\mathrm{r}^{2}$ & $\mathrm{~N}$ & $\sqrt{N}$ & $1-\mathrm{r}^{2} / \sqrt{\mathrm{N}}$ & multiplier & $\mathrm{PE}$ & $6(\mathrm{PE})$ \\
\hline Gujrat & 0.998 & 0.996 & 0.004 & 2750 & 52.44044 & 0.00008 & 0.6745 & 0.00005 & 0.0003 \\
\hline
\end{tabular}

Probable error for the autocorrelation 0.998 in the first lag is 0.00005. See TABLE No.7.12.5 above. The coefficient of autocorrelation is greater than the PE $(0.998>0.00005)$. The autocorrelation 0.998 is still higher than the 6 times PE (0.0003) i.e., $r>6(\mathrm{PE})$. Hence the autocorrelation 0.998 of Gujarat Narmada is significant.

Table No.7.12.6

Calculation of Probable Error in Lag 16.

\begin{tabular}{|c|c|c|c|c|c|c|c|c|c|}
\hline Stock & $\mathrm{r}$ & $r^{2}$ & $1-r^{2}$ & $\mathrm{~N}$ & $\sqrt{\mathrm{N}}$ & $1-\mathrm{r}^{2} / \sqrt{\mathrm{N}}$ & multiplier & PE & $6(\mathrm{PE})$ \\
\hline Gujrat & 0.969 & 0.939 & 0.061 & 2750 & 52.44044 & 0.00116 & 0.6745 & 0.00078 & 0.00468 \\
\hline
\end{tabular}

Probable error for the autocorrelation 0.969 in lag 16 is 0.00078 . See TABLE No.7.12.6 above. The coefficient of autocorrelation is greater than the PE $(0.969>0.00078)$. The autocorrelation 0.969 is still higher than the 6 times PE (0.00468) i.e., r $>6(\mathrm{PE})$. Hence the autocorrelation 0.969 of Gujarat Narmada in lag 16 is significant.

Table No.7.12.7

Runs test descriptive statistics of Gujarat Narmada

\begin{tabular}{|l|l|}
\hline Test Values & 65.84 \\
\hline Cases $<$ Test Values & 1611 \\
\hline Cases $>$ Test Values & 1140 \\
\hline Total Cases & 2751 \\
\hline No. of runs & 16 \\
\hline Z & -51.87 \\
\hline Asym.sig (2-tailed) & 0.0 \\
\hline Expected runs R & 1336.18 \\
\hline$\sigma$ of runs & 25.45 \\
\hline Table Value @ 5\% significance & -1.96 \\
\hline
\end{tabular}

As per TABLE No.7.12.7, the mean value of stock price is Rs.65.84. Cases below the mean are 1611 and above are 1140. There are 16 runs in the series. The expected runs are 1336.18 and the standard deviation of runs is 25.45. The actual runs in the price series are lower than the expected $(16<1336.18)$. Too few runs indicate stationary state of the series. The $\mathrm{z}$ value calculated is -51.87 whereas the table value for the same at $5 \%$ level of significance is -1.96 on the left tail. The $z$ calculated is lower than the table value $(-51.87<-1.96)$. Therefore the null hypothesis that the series is random is rejected and resolved that there is interdependence and non-randomness in the closing price series of Gujarat Narmada.

7.13. Harrisons Malayalam

Table No.7.13.1

Descriptive Statistics of Harrisons Malayalam

\begin{tabular}{|l|l|}
\hline Minimum & 4.25 \\
\hline Maximum & 184.25 \\
\hline MEAN & 51.04 \\
\hline MEDIAN & 35.10 \\
\hline STANDARD DEVIATION & 39.30 \\
\hline SKEWNESS & 0.721 \\
\hline KURTOSIS & -0.416 \\
\hline NO. OF OBSERVATION & 2678 \\
\hline
\end{tabular}

TABLE No.7.13.1 above shows that the mean of the price series of Harrisons Malayalam for 2678 days of observation is Rs.51.04. The median value is Rs.35.10. There is difference between mean and median. Therefore the distribution is not normal because in normal distribution the mean, median and mode are the 
same. RWH (Random-walk Hypothesis) presupposes a normal distribution to constitute an efficient market. The range between the maximum and minimum prices is very great. The standard deviation Rs.39.30 is bigger. The coefficient of variation $=\frac{\sigma}{\bar{X}}=\frac{39.30}{51.04}=77 \%$. The $\sigma$ is too large for normal distribution. There is a high positive skewness to the tune of 0.721 . In a normal distribution, skewness will be zero. The positive skewness nullifies the null hypothesis and confirms non-randomness. The coefficient of kurtosis of the price series is -0.416 . A kurtosis value with 3 is the normal distribution. Since the actual kurtosis is lower than the normal i.e. $-0.416<3$ the shape of the distribution is platikurtic on the left tail. The descriptive statistics of price series of Harrisons Malayalam confirms asymmetry and non-randomness in the series.

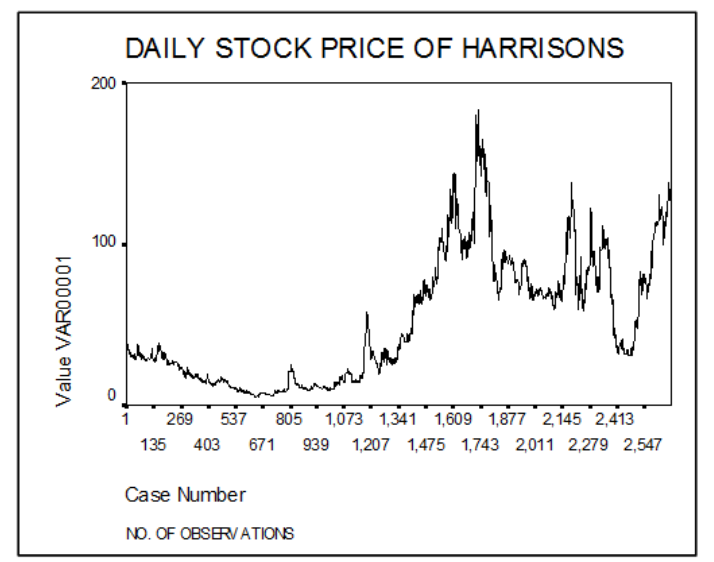

Figure 7.13.1: Daily Stock Price of Harrisons Malayalam for 2678 days.

Fig.7.13.1 depicts the behavior of stock price of Harrisons Malayalam. The daily stock prices of Harrisons Malayalam had lot of fluctuations. The opening price of the stock in 1999 was Rs.36.45. With lot of minor and major fluctuations the price reached to the peak level at Rs.132.95 in 2008. Then fell abruptly down. Then recovered and settled at Rs.134.4 in 2009. The overall tendency of the stock of Gujarat Narmada was to rise. As the standard deviation denoted, the price series was expressing major and minor fluctuations along its movement. It gave larger and smaller surprises to the market. The steady flow of the line with turbulent zigzags can be viewed from the graph. There is high volatility in prices. This shows large scale mispricing in the market, an evidence for the absence of market efficiency.

Table No.7.13.2

Autocorrelation of prices of Harrisons Malayalam in 16 lags

\begin{tabular}{|l|l|l|l|r|r|r|r|r|r|r|r|r|r|r|r|r|l|}
\hline Lags & 1 & 2 & 3 & 4 & 5 & 6 & 7 & 8 & 9 & 10 & 11 & 12 & 13 & 14 & 15 & 16 \\
\hline Harriso & 0.99 & 0.99 & 0.98 & 0.98 & 0.98 & 0.97 & 0.97 & 0.97 & 0.96 & 0.96 & 0.96 & 0.95 & 0.95 & 0.95 & 0.94 & 0.94 \\
n & 7 & 3 & 9 & 5 & 2 & 8 & 5 & 1 & 8 & 5 & 2 & 9 & 6 & 3 & 9 & 5 \\
\hline
\end{tabular}

TABLE No.7.13.2 provides autocorrelation coefficient of Harrisons Malayalam's price series in 16 lags.

It can be seen from the table that the auto correlation in all 16 lags is above 0.9. Auto correlation above 0.5 is significant. Therefore, the null hypothesis that the price series is random is rejected. It signals significant evidence for interdependence and non-randomness.

Table No.7.13.3

Student's ' $\mathrm{t}$ ' test in Lag 1

\begin{tabular}{|c|c|c|c|c|c|c|c|c|c|}
\hline Stock & $\mathbf{r}$ & $\mathrm{N}-2$ & $\sqrt{ } \mathrm{N}-2$ & $\mathbf{r}^{2}$ & $1-r^{2}$ & $\sqrt{ } \mathbf{1}-\mathbf{r}^{2}$ & $\mathbf{r} / \sqrt{ } \mathbf{1}-\mathbf{r}^{2}$ & $H * D$ & Table \\
\hline Harrison & 0.997 & 2675 & 51.7204 & 0.994 & 0.006 & 0.077 & 12.87 & 666 & 1.96 \\
\hline
\end{tabular}

As per TABLE No.7.13.3 above, the auto correlation of Harrisons Malayalam in the first lag is 0.997 . The $t$ value calculated is 666 and table value at $5 \%$ significance is 1.96 . T value calculated is greater than the table value $(666>1.96)$. Therefore, the autocorrelation coefficient is significant in the first lag.

Table No.7.13.4

Student's t test in Lag 16

\begin{tabular}{|c|c|c|c|r|r|r|r|r|r|}
\hline Scrip & $\mathrm{r}$ & $\mathrm{N}-2$ & $\sqrt{\mathrm{N}}-2$ & $\mathrm{r}^{2}$ & $1-\mathrm{r}^{2}$ & $\sqrt{1-\mathrm{r}^{2}}$ & $\mathrm{r} / \sqrt{1-r^{2}}$ & $\mathrm{H}^{*} \mathrm{D}$ & $\mathrm{Table}^{2}$ \\
\hline Harrison & 0.945 & 2675 & 51.7204 & 0.893 & 0.107 & 0.327 & 2.89 & 149 & 1.96 \\
\hline
\end{tabular}

TABLE No.7.13.4 above shows the $\mathrm{t}$ test for the $16^{\text {th }}$ lag of price of stock Harrisons Malayalam. Auto correlation in the $16^{\text {th }}$ lag is 0.945 . The calculated value of $t$ is given as 149 . The table value for the same is 1.96 . The calculated $\mathrm{t}$ value 149 is greater than the table value 1.96 . Hence the autocorrelation in $16^{\text {th }}$ lag is significant. 
Table No.7.13.5

Calculation of Probable Error in Lag 1

\begin{tabular}{|c|c|c|c|c|c|c|c|c|c|}
\hline Stock & $\mathrm{r}$ & $\mathrm{r}^{2}$ & $1-r^{2}$ & $\mathrm{~N}$ & $\sqrt{\mathrm{N}}$ & $1-\mathrm{r}^{2} / \sqrt{\mathrm{N}}$ & multiplier & PE & $6(\mathrm{PE})$ \\
\hline Harrison & 0.997 & 0.994 & 0.006 & 2677 & 51.73973 & 0.00012 & 0.6745 & 0.00008 & 0.00048 \\
\hline
\end{tabular}

Probable error for the autocorrelation 0.997 in the first lag is 0.00008. See TABLE No.7.13.5 above. The coefficient of autocorrelation is greater than the PE $(0.997>0.00008)$. The autocorrelation 0.997 is still higher than the 6 times PE (0.00048) i.e., $r>6(\mathrm{PE})$. Hence the autocorrelation 0.997 of Harrisons Malayalam is significant.

Table No.7.13.6

Calculation of Probable Error in Lag 16.

\begin{tabular}{|c|c|c|c|c|c|c|c|c|c|}
\hline Stock & $\mathrm{r}$ & $r^{2}$ & $1-\mathrm{r}^{2}$ & $\mathrm{~N}$ & $\sqrt{N}$ & $1-\mathrm{r}^{2} / \sqrt{\mathrm{N}}$ & multiplier & $\mathrm{PE}$ & $6(\mathrm{PE})$ \\
\hline Harrison & 0.945 & 0.893 & 0.107 & 2677 & 51.73973 & 0.00207 & 0.6745 & 0.0014 & 0.0084 \\
\hline
\end{tabular}

Probable error for the autocorrelation 0.945 in lag 16 is 0.0014. See TABLE No.7.13.6 above. The coefficient of autocorrelation is greater than the PE $(0.945>0.0014)$. The autocorrelation 0.945 is still higher than the 6 times PE (0.0084) i.e., $r>6(\mathrm{PE})$. Hence the autocorrelation 0.945 of Harrisons Malayalam in lag 16 is significant.

Table No.7.13.7

Run test descriptive statistics of Harrisons Malayalam

\begin{tabular}{|l|l|}
\hline Test Values & 51.04 \\
\hline Cases $<$ Test Values & 1516 \\
\hline Cases $>$ Test Values & 1162 \\
\hline Total Cases & 2678 \\
\hline No. of runs & 14 \\
\hline Z & -51.25 \\
\hline Asym.sig (2-tailed) & 0.0 \\
\hline Expected runs R & 1316.6 \\
\hline$\sigma$ of runs & 25.42 \\
\hline Table Value @ 5\% significance & -1.96 \\
\hline
\end{tabular}

As per TABLE No.7.13.7, the mean value of stock price is Rs.51.04. Cases below the mean are 1516 and above are 1162. There are 14 runs in the series. The expected runs are 1316.6 and the standard deviation of runs is 25.42 .The actual runs in the price series are lower than the expected $(14<1316.6)$. Too few runs indicate stationary state of the series. The $\mathrm{z}$ value calculated is -51.25 whereas the table value for the same at $5 \%$ level of significance is -1.96 on the left tail. The $\mathrm{z}$ calculated is lower than the table value $(-51.25<-1.96)$. Therefore the null hypothesis that the series is random is rejected and resolved that there is interdependence and nonrandomness in the closing price series of Harrisons Malayalam.

\subsection{Hindalco}

Table No.7.14.1

Descriptive Statistics of Hindalco

\begin{tabular}{|l|l|}
\hline MINIMUM & 37.3 \\
\hline MAXIMUM & 1480.45 \\
\hline MEAN & 581.37 \\
\hline MEDIAN & 602.70 \\
\hline STANDARD DEVIATION & 408.69 \\
\hline SKEWNESS & 0.335 \\
\hline KURTOSIS & -1.044 \\
\hline NO. OF OBSERVATION & 2766 \\
\hline
\end{tabular}

TABLE No.7.14.1 above shows that the mean of the price series of Hindalco for 2766 days of observation is Rs.581.37. The median value is Rs.602.70. There is difference between mean and median. Therefore the distribution is not normal because in normal distribution the mean, median and mode are the same. RWH (Random-walk Hypothesis) presupposes a normal distribution to constitute an efficient market. The difference between the minimum and maximum prices is very high. The standard deviation Rs.408.69 is bigger. The coefficient of variation $=\frac{\sigma}{\overline{\mathrm{X}}}=\frac{408.69}{581.37}=70.3 \%$. The $\sigma$ is too large for normal distribution. There is a positive skewness to the tune of 0.335 . In a normal distribution, skewness will be zero. The positive skewness nullifies the null hypothesis and confirms non-randomness. The coefficient of kurtosis of the price series is -1.044 . A kurtosis value with 3 is the normal distribution. Since the actual kurtosis is lower than the normal i.e. $-1.044<3$ the shape of the distribution is platikurtic on the left tail. The descriptive statistics of price series of Hindalco confirms asymmetry and non-randomness in the series. 


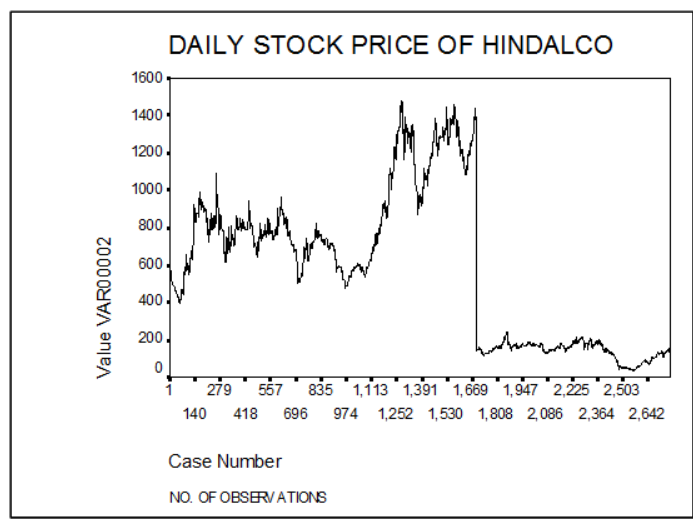

Figure 7.14.1: Daily Stock Price of Hindalco for 2766 days.

Fig.No.7.14.1 depicts the behavior of stock price of Hindalco. The daily stock prices of Hindalco had lot of fluctuations. The opening price of the stock in 1999 was Rs.517.25. With lot of minor and major fluctuations the price reached to the peak level at Rs.1442.85 in 2005. Then fell abruptly down to Rs.143.40. Then with minor fluctuations the price settled at Rs.160.75 in 2009. The overall tendency of the stock of Gujarat Narmada was to decline. As the standard deviation denoted, the price series was expressing major and minor fluctuations along its movement. It gave larger and smaller surprises to the market. The steady flow of the line with turbulent zigzags can be viewed from the graph. There is high volatility in prices. This shows large scale mispricing in the market, an evidence for the absence of market efficiency.

Table No.7.14.2

Autocorrelation of prices of Hindalco in 16 lags

\begin{tabular}{|c|c|c|c|c|c|c|c|c|c|c|c|c|c|c|c|c|}
\hline Lags & 1 & 2 & 3 & 4 & 5 & 6 & 7 & 8 & 9 & 10 & 11 & 12 & 13 & 14 & 15 & 16 \\
\hline Hindalc & 0.99 & 0.99 & 0.99 & 0.98 & 0.98 & 0.98 & 0.98 & 0.97 & 0.97 & 0.97 & 0.97 & 0.96 & 0.96 & 0.96 & 0.95 & 0.95 \\
\hline $\mathrm{o}$ & 7 & 5 & 2 & 9 & 6 & 4 & 1 & 8 & 5 & 2 & 0 & 7 & 4 & 2 & 9 & 7 \\
\hline
\end{tabular}

TABLE No.7.14.2 provides autocorrelation coefficient of Hindalco 's price series in 16 lags. It can be seen from the table that the auto correlation in all 16 lags is above 0.9. Auto correlation above 0.5 is significant. Therefore, the null hypothesis that the price series is random is rejected. It signals significant evidence for interdependence and non-randomness.

Table No.7.14.3

Student's ' $t$ ' test in Lag 1

\begin{tabular}{|l|c|c|c|c|c|c|r|r|r|}
\hline Stock & $\mathrm{r}$ & $\mathrm{N}-2$ & $\sqrt{\mathrm{N}-2}$ & $\mathrm{r}^{2}$ & $1-\mathrm{r}^{2}$ & $\sqrt{1-\mathrm{r}^{2}}$ & $\mathrm{r} / \sqrt{1-\mathrm{r}^{2}}$ & $\mathrm{H}^{*} \mathrm{D}$ & Table \\
\hline Hindalco & 0.997 & 2763 & 52.56425 & 0.994 & 0.006 & 0.077 & 12.87 & 677 & 1.96 \\
\hline
\end{tabular}

As per TABLE No.7.14.3 above, the auto correlation of Hindalco in the first lag is 0.997. The $t$ value calculated is 677 and table value at $5 \%$ significance is 1.96 . T value calculated is greater than the table value (677>1.96). Therefore, the autocorrelation coefficient is significant in the first lag.

Table No.7.14.4

Student's t test in Lag 16

\begin{tabular}{|c|r|r|r|r|r|r|r|r|r|}
\hline Scrip & $\mathrm{r}$ & $\mathrm{N}-2$ & $\sqrt{\mathrm{N}-2}$ & $\mathrm{r}^{2}$ & \multicolumn{1}{c|}{$1-\mathrm{r}^{2}$} & $\sqrt{1-\mathrm{r}^{2}}$ & $\mathrm{r} / \sqrt{1-\mathrm{r}^{2}}$ & $\mathrm{H} * \mathrm{D}$ & Table \\
\hline Hindalco & 0.957 & 2763 & 52.56425 & 0.916 & 0.084 & 0.290 & 3.3 & 173 & 1.96 \\
\hline
\end{tabular}

TABLE No.7.14.4 above shows the t test for the $16^{\text {th }}$ lag of price of stock Hindalco. Auto correlation in the $16^{\text {th }}$ lag is 0.957 . The calculated value of $t$ is given as 173 . The table value for the same is 1.96 . The calculated t value 173 is greater than the table value 1.96 . Hence the autocorrelation in $16^{\text {th }}$ lag is significant.

Table No.7.14.5

Calculation of Probable Error in Lag 1

\begin{tabular}{|l|r|r|r|r|r|r|r|r|r|}
\hline Stock & $\mathrm{r}$ & \multicolumn{1}{|l|}{$\mathrm{r}^{2}$} & $1-\mathrm{r}^{2}$ & $\mathrm{~N}$ & $\sqrt{\mathrm{N}}$ & $1-\mathrm{r}^{2} / \sqrt{\mathrm{N}}$ & multiplier & PE & $6(\mathrm{PE})$ \\
\hline Hindalco & 0.997 & 0.994 & 0.006 & 2765 & 52.58327 & 0.00011 & 0.6745 & 0.00007 & 0.00042 \\
\hline
\end{tabular}

Probable error for the autocorrelation 0.997 in the first lag is 0.00007. See TABLE No.7.14.5 above.

The coefficient of autocorrelation is greater than the PE $(0.997>0.00007)$. The autocorrelation 0.997 is still higher than the 6 times PE (0.00042) i.e., $r>6(\mathrm{PE})$. Hence the autocorrelation 0.997 of Hindalco is significant.

Table No.7.14.6

Calculation of Probable Error in Lag 16.

\begin{tabular}{|c|c|c|c|c|c|c|c|c|c|}
\hline Stock & $r$ & $r^{2}$ & $1-r^{2}$ & $\mathrm{~N}$ & $\mathrm{VN}$ & $1-r^{2} / \mathrm{VN}$ & multiplier & $\mathrm{PE}$ & $6(\mathrm{PE})$ \\
\hline Hindalco & 0.957 & 0.916 & 0.084 & 2765 & 52.58327 & 0.0016 & 0.6745 & 0.00108 & 0.00648 \\
\hline
\end{tabular}


Probable error for the autocorrelation 0.957 in lag 16 is 0.00108 . See TABLE No.7.14.6 above. The coefficient of autocorrelation is greater than the PE $(0.957>0.00108)$. The autocorrelation 0.957 is still higher than the 6 times PE (0.00648) i.e., $r>6(\mathrm{PE})$. Hence the autocorrelation 0.957 of Hindalco in lag 16 is significant.

Table No.7.14.7

Runs test descriptive statistics of Hindalco

\begin{tabular}{|l|l|}
\hline Test Values & 581.37 \\
\hline Cases $<$ Test Values & 1300 \\
\hline Cases $>$ Test Values & 1466 \\
\hline Total Cases & 2766 \\
\hline No. of runs & 25 \\
\hline Z & -51.69 \\
\hline Asym.sig (2-tailed) & 0.0 \\
\hline Expected runs R & 1379.02 \\
\hline$\sigma$ of runs & 26.20 \\
\hline Table Value @ 5\% significance & -1.96 \\
\hline
\end{tabular}

As per TABLE No.7.14.7, the mean value of stock price is Rs.58137. Cases below the mean are 1300 and above are 1466. There are 25 runs in the series. The expected runs are 1379.02 and the standard deviation of runs is 26.20 . The actual runs in the price series are lower than the expected $(25<1379.02)$. Too few runs indicate stationary state of the series. The $\mathrm{z}$ value calculated is -51.69 whereas the table value for the same at $5 \%$ level of significance is -1.96 on the left tail. The $\mathrm{z}$ calculated is lower than the table value $(-51.69<-1.96)$. Therefore the null hypothesis that the series is random is rejected and resolved that there is interdependence and nonrandomness in the closing price series of Hindalco.

\subsection{Indian Hotels}

Table No.7.15.1

Descriptive Statistics of Indian Hotels

\begin{tabular}{|l|l|}
\hline MINIMUM & 34.4 \\
\hline MAXIMUM & 1536.5 \\
\hline MEAN & 337.69 \\
\hline MEDIAN & 221.78 \\
\hline STANDARD DEVIATION & 318.61 \\
\hline SKEWNESS & 1.912 \\
\hline KURTOSIS & 3.123 \\
\hline NO. OF OBSERVATION & 2748 \\
\hline
\end{tabular}

TABLE No.7.15.1 above shows that the mean of the price series of Indian Hotels for 2748 days of observation is Rs.337.69. The median value is Rs.221.78. There is difference between mean and median. Therefore the distribution is not normal because in normal distribution the mean, median and mode are the same. RWH (Random-walk Hypothesis) presupposes a normal distribution to constitute an efficient market. The difference between the minimum and maximum of prices is very high. The standard deviation Rs.318.61 is bigger. The coefficient of variation $=\frac{\sigma}{\overline{\mathrm{x}}}=\frac{318.61}{337.69}=94.35 \%$. The $\sigma$ is too large for normal distribution. There is a high positive skewness to the tune of 1.912. In a normal distribution, skewness will be zero. The positive skewness nullifies the null hypothesis and confirms non-randomness. The coefficient of kurtosis of the price series is 3.123. A kurtosis value with 3 is the normal distribution. Since the actual kurtosis is higher than the normal i.e. 3.123>3 the shape of the distribution is leptokurtic. The descriptive statistics of price series of Indian Hotels confirms asymmetry and non-randomness in the series.

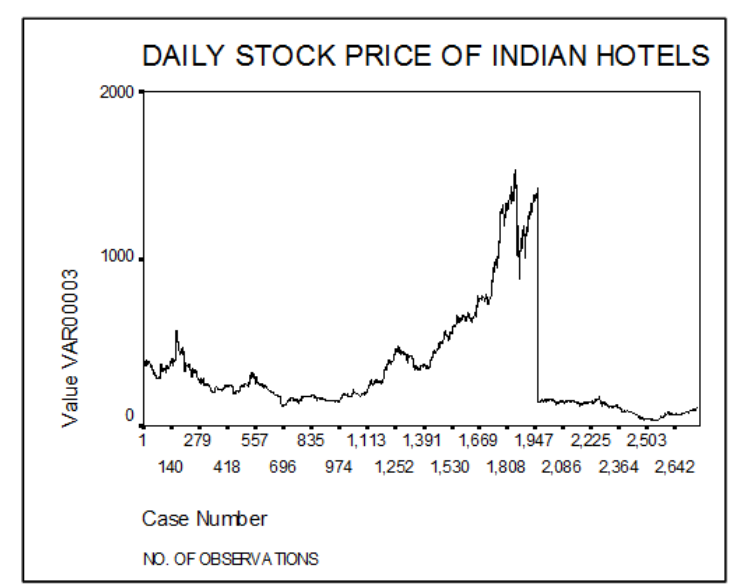

Figure 7.15.1: Daily Stock Price of Indian Hotels for 2748 days. 
Fig.7.15.1 depicts the behavior of stock price of Indian Hotels. The daily stock prices of Indian Hotels had lot of fluctuations. The opening price of the stock in 1999 was Rs.356.25. With lot of minor and major fluctuations the price reached to the peak level at Rs.988.05 in 2005. Then fell sharply down to Rs.154.25. Then with minor fluctuations the price settled at Rs.102.25 in 2009. The overall tendency of the stock of Indian Hotels was to decline. As the standard deviation denoted, the price series was expressing major and minor fluctuations along its movement. It gave larger and smaller surprises to the market. The steady flow of the line with turbulent zigzags can be viewed from the graph. There is high volatility in prices. This shows large scale mispricing in the market, an evidence for the absence of market efficiency.

Table No.7.15.2

Autocorrelation of prices of Indian Hotels in 16 lags

\begin{tabular}{|c|c|c|c|c|c|c|c|c|c|c|c|c|c|c|c|c|}
\hline Lags & 1 & 2 & 3 & 4 & 5 & 6 & 7 & 8 & 9 & 10 & 11 & 12 & 13 & 14 & 15 & 16 \\
\hline Ind.Hot & 0.99 & 0.99 & 0.98 & 0.98 & 0.98 & 0.97 & 0.97 & 0.97 & 0.96 & 0.96 & 0.96 & 0.95 & 0.95 & 0.94 & 0.94 & 0.94 \\
\hline el & 6 & 2 & 9 & 5 & 1 & 7 & 4 & 0 & 7 & 3 & 0 & 6 & 3 & 9 & 6 & 2 \\
\hline
\end{tabular}

TABLE No.7.15.2 provides autocorrelation coefficient of Indian Hotels's price series in 16 lags. It can be seen from the table that the auto correlation in all 16 lags is above 0.9 . Auto correlation above 0.5 is significant. Therefore, the null hypothesis that the price series is random is rejected. It signals significant evidence for interdependence and non-randomness.

Table No.7.15.3

Student's ' $t$ ' test in Lag 1

\begin{tabular}{|c|c|c|c|c|c|c|c|c|c|}
\hline Stock & $\mathbf{r}$ & $\mathrm{N}-2$ & $\sqrt{\mathrm{N}-2}$ & $\mathbf{r}^{2}$ & $1-r^{2}$ & $\sqrt{ } 1-r^{2}$ & $r / \sqrt{ } 1-r^{2}$ & H*D & Table \\
\hline Ind.Hotel & 0.996 & 2745 & 52.39275 & 0.992 & 0.008 & 0.089 & 11.14 & 584 & 1.96 \\
\hline
\end{tabular}

As per TABLE 7.15.3 above, the auto correlation of Indian Hotels in the first lag is 0.996. The $t$ value calculated is 584 and table value at $5 \%$ significance is 1.96 . T value calculated is greater than the table value (584>1.96). Therefore, the autocorrelation coefficient is significant in the first lag.

Table 7.15.4

Student's t test in Lag 16

\begin{tabular}{|c|c|r|r|r|r|r|r|r|r|}
\hline Scrip & $\mathrm{r}$ & $\mathrm{N}-2$ & $\sqrt{\mathrm{N}}-2$ & $\mathrm{r}^{2}$ & $1-\mathrm{r}^{2}$ & $\sqrt{1-\mathrm{r}^{2}}$ & $\mathrm{r} / \sqrt{1-\mathrm{r}^{2}}$ & $\mathrm{H}^{*} \mathrm{D}$ & $\mathrm{Table}$ \\
\hline Ind.Hotel & 0.942 & 2745 & 52.39275 & 0.887 & 0.113 & 0.336 & 2.8 & 147 & 1.96 \\
\hline
\end{tabular}

TABLE No.7.15.4 above shows the $t$ test for the $16^{\text {th }}$ lag of price of stock Indian Hotels. Auto correlation in the $16^{\text {th }}$ lag is 0.942 . The calculated value of $t$ is given as 147 . The table value for the same is 1.96 . The calculated $t$ value 147 is greater than the table value 1.96 . Hence the autocorrelation in $16^{\text {th }}$ lag is significant.

Table No.7.15.5

Calculation of Probable Error in Lag 1

\begin{tabular}{|c|c|c|c|c|c|c|c|c|c|}
\hline Stock & $\mathrm{r}$ & $\mathrm{r}^{2}$ & $1-r^{2}$ & $\mathrm{~N}$ & $\sqrt{N}$ & $1-r^{2} / \sqrt{ } N$ & multiplier & $\mathrm{PE}$ & $6(\mathrm{PE})$ \\
\hline Ind.Hotel & 0.996 & 0.992 & 0.008 & 2747 & 52.41183 & 0.00015 & 0.6745 & 0.0001 & 0.0006 \\
\hline
\end{tabular}

Probable error for the autocorrelation 0.996 in the first lag is 0.0001. See TABLE No.7.15.5 above. The coefficient of autocorrelation is greater than the PE $(0.996>0.0001)$. The autocorrelation 0.996 is still higher than the 6 times PE (0.0006) i.e., $r>6(P E)$. Hence the autocorrelation 0.996 of Indian Hotels is significant. Table No.7.15.6

Calculation of Probable Error in Lag 16.

\begin{tabular}{|c|c|c|c|c|c|c|c|c|c|}
\hline Stock & $\mathrm{r}$ & $r^{2}$ & $1-\mathrm{r}^{2}$ & $\mathrm{~N}$ & $\sqrt{\mathrm{N}}$ & $1-\mathrm{r}^{2} / \sqrt{\mathrm{N}}$ & multiplier & $\mathrm{PE}$ & $6(\mathrm{PE})$ \\
\hline Ind.Hotel & 0.942 & 0.887 & 0.113 & 2747 & 52.41 & 0.00216 & 0.6745 & 0.00146 & 0.00876 \\
\hline
\end{tabular}

Probable error for the autocorrelation 0.942 in lag 16 is 0.00146 . See TABLE No.7.15.6 above. The coefficient of autocorrelation is greater than the PE (0.942>0.00146). The autocorrelation 0.942 is still higher than the 6 times PE (0.00875) i.e., r $>6(\mathrm{PE})$. Hence the autocorrelation 0.942 of Indian Hotels in lag 16 is significant.

Table No.7.15.7

Runs test descriptive statistics of Indian Hotels

\begin{tabular}{|l|l|}
\hline Test Values & 337.69 \\
\hline Cases < Test Values & 1814 \\
\hline Cases > Test Values & 934 \\
\hline Total Cases & 2748 \\
\hline No. of runs & 28 \\
\hline Z & -51.29 \\
\hline Asym.sig (2-tailed) & 0.0 \\
\hline Expected runs R & 1234.1 \\
\hline$\sigma$ of runs & 23.52 \\
\hline Table Value @ 5\% significance & -1.96 \\
\hline
\end{tabular}

As per TABLE No.7.15.7, the mean value of stock price is Rs.337.69. Cases below the mean are 1814 and above are 934. There are 28 runs in the series. The expected runs are 1234.1 and the standard deviation of 
runs is 23.52 . The actual runs in the price series are lower than the expected $(28<1234.1)$. Too few runs indicate stationary state of the series. The $\mathrm{z}$ value calculated is -51.29 whereas the table value for the same at $5 \%$ level of significance is -1.96 on the left tail. The $\mathrm{z}$ calculated is lower than the table value $(-51.29<-1.96)$. Therefore the null hypothesis that the series is random is rejected and resolved that there is interdependence and nonrandomness in the closing price series of Indian Hotels.

\subsection{Indian Reyons}

Table No.7.16.1

Descriptive Statistics of Indian Reyons

\begin{tabular}{|l|l|}
\hline MINIMUM & 46.5 \\
\hline MAXIMUM & 2435.6 \\
\hline MEAN & 488.97 \\
\hline MEDIAN & 245.48 \\
\hline STANDARD DEVIATION & 498.91 \\
\hline SKEWNESS & 1.13 \\
\hline KURTOSIS & 0.37 \\
\hline NO. OF OBSERVATION & 2746 \\
\hline
\end{tabular}

TABLE No.7.16.1 above shows that the mean of the price series of Indian Reyons for 2746 days of observation is Rs.488.97. The median value is Rs.245.48. There is difference between mean and median. Therefore the distribution is not normal because in normal distribution the mean, median and mode are the same. RWH (Random-walk Hypothesis) presupposes a normal distribution to constitute an efficient market. The range between the minimum and maximum prices is very high. The standard deviation Rs. 498.91 is bigger. The coefficient of variation $=\frac{\sigma}{\overline{\mathrm{X}}}=\frac{498.91}{488.97}=102.03 \%$. The $\sigma$ is too large for normal distribution. There is a high positive skewness to the tune of 1.13. In a normal distribution, skewness will be zero. The positive skewness nullifies the null hypothesis and confirms non-randomness. The coefficient of kurtosis of the price series is 0.37 . A kurtosis value with 3 is the normal distribution. Since the actual kurtosis is lower than the normal i.e. $0.37<3$ the shape of the distribution is platykurtic. The descriptive statistics of price series of Indian Reyons confirms asymmetry and non-randomness in the series.

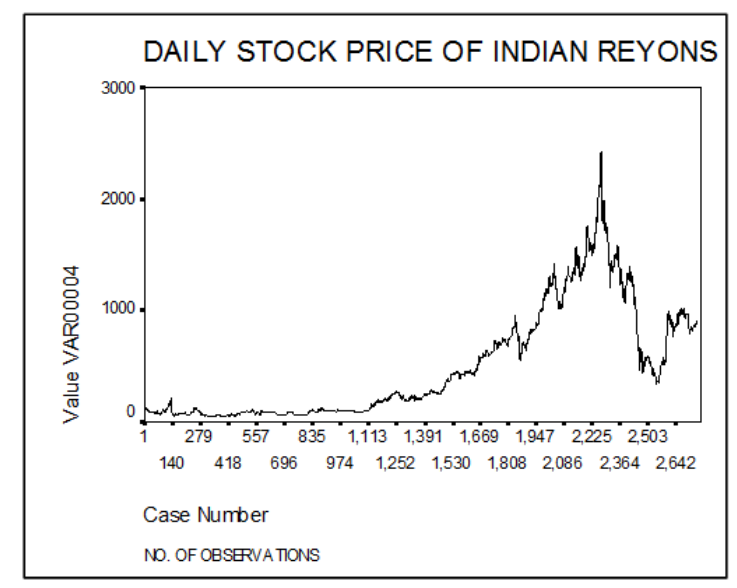

Figure No.7.16.1: Daily Stock Price of Indian Reyons for 2746 days.

Fig.7.16.1 depicts the behavior of stock price of Indian Reyons. The daily stock prices of Indian Hotels had lot of fluctuations. The opening price of the stock in 1999 was Rs.113.8. With lot of minor and major fluctuations the price reached to the peak level at Rs.2028.05 in 2008. Then fell sharply down to Rs.574.65. Then with minor fluctuations the price settled at Rs.876.3 in 2009. The overall tendency of the stock of Indian Hotels was to rise. As the standard deviation denoted, the price series was expressing major and minor fluctuations along its movement. It gave larger and smaller surprises to the market. The steady flow of the line with turbulent zigzags can be viewed from the graph. There is high volatility in prices. This shows large scale mispricing in the market, an evidence for the presence of market inefficiency.

$$
\text { Table No.7.16.2 }
$$

Autocorrelation of prices of Indian Reyons in 16 lags

\begin{tabular}{|l|r|r|r|r|r|r|r|r|r|r|r|r|r|r|r|r|}
\hline Lags & 1 & 2 & 3 & 4 & 5 & 6 & 7 & 8 & 9 & 10 & 11 & 12 & 13 & 14 & 15 & 16 \\
\hline $\begin{array}{l}\text { Ind.Rey } \\
\text { on }\end{array}$ & 0.99 & 0.99 & 0.99 & 0.99 & 0.99 & 0.99 & 0.99 & 0.99 & 0.98 & 0.98 & 0.98 & 0.98 & 0.98 & 0.98 & 0.98 & 0.97 \\
\hline
\end{tabular}

TABLE No.7.16.2 provides autocorrelation coefficient of Indian Reyons' price series in 16 lags. It can be seen from the table that the auto correlation in all 16 lags is above 0.9 . Auto correlation above 0.5 is significant. 
Therefore, the null hypothesis that the price series is random is rejected. It signals significant evidence for interdependence and non-randomness.

Table No.7.16.3

Student's ' $t$ ' test in Lag 1

\begin{tabular}{|l|c|c|c|c|c|c|c|c|c|}
\hline Stock & $\mathbf{r}$ & $\mathbf{N}-\mathbf{2}$ & $\sqrt{\mathrm{N}-2}$ & $\mathbf{r}^{\mathbf{2}}$ & $\mathbf{1}-\mathbf{r}^{\mathbf{2}}$ & $\sqrt{1} \mathbf{1}-\mathbf{r}^{\mathbf{2}}$ & $\mathbf{r} / \sqrt{1} \mathbf{1} \mathbf{r}^{\mathbf{2}}$ & $\mathbf{H}^{* \mathbf{D}}$ & Table \\
\hline Ind.Reyon & 0.999 & 2743 & 52.37366 & 0.998 & 0.002 & 0.045 & 22.34 & 1170 & 1.96 \\
\hline
\end{tabular}

As per TABLE No.7.16.3 above, the auto correlation of Indian Reyons in the first lag is 0.999. The $t$ value calculated is 1170 and table value at $5 \%$ significance is 1.96 . T value calculated is greater than the table value (1170>1.96). Therefore, the autocorrelation coefficient is significant in the first lag.

Table No.7.16.4

Student's t test in Lag 16

\begin{tabular}{|c|r|r|r|r|r|r|r|r|r|}
\hline Scrip & $\mathrm{r}$ & $\mathrm{N}-2$ & $\sqrt{\mathrm{N}-2}$ & $\mathrm{r}^{2}$ & $1-\mathrm{r}^{2}$ & $\sqrt{1-\mathrm{r}^{2}}$ & $\mathrm{r} / \sqrt{1-\mathrm{r}^{2}}$ & $\mathrm{H} * \mathrm{D}$ & Table \\
\hline Ind.Reyon & 0.978 & 2743 & 52.37366 & 0.956 & 0.044 & 0.210 & 4.66 & 244 & 1.96 \\
\hline
\end{tabular}

TABLE No.7.16.4 above shows the $t$ test for the $16^{\text {th }}$ lag of price of stock Indian Reyons. Auto correlation in the $16^{\text {th }}$ lag is 0.978 . The calculated value of $t$ is given as 244 . The table value for the same is 1.96 . The calculated t value 244 is greater than the table value 1.96 . Hence the autocorrelation in $16^{\text {th }}$ lag is significant.

Table No.7.16.5

Calculation of Probable Error in Lag 1

\begin{tabular}{|l|r|r|r|r|r|r|r|r|l|}
\hline Stock & $\mathrm{r}$ & \multicolumn{1}{|l|}{$\mathrm{r}^{2}$} & \multicolumn{1}{|l}{$1-\mathrm{r}^{2}$} & $\mathrm{~N}$ & $\sqrt{\mathrm{N}}$ & $1-\mathrm{r}^{2} / \sqrt{\mathrm{N}}$ & multiplier & PE & 6 (PE) \\
\hline Ind.Reyon & 0.999 & 0.998 & 0.002 & 2745 & 52.39275 & 0.00004 & 0.6745 & 0.00003 & 0.00018 \\
\hline
\end{tabular}

Probable error for the autocorrelation 0.999 in the first lag is 0.00003. See TABLE No.7.16.5 above. The coefficient of autocorrelation is greater than the PE $(0.999>0.00003)$. The autocorrelation 0.999 is still higher than the 6 times PE (0.00018) i.e., $r>6(\mathrm{PE})$. Hence the autocorrelation 0.999 of Indian Reyons is significant.

Table No.7.16.6

Calculation of Probable Error in Lag 16.

\begin{tabular}{|c|c|c|c|c|c|c|c|c|c|}
\hline Stock & $\mathrm{r}$ & $\mathrm{r}^{2}$ & $1-\mathrm{r}^{2}$ & $\mathrm{~N}$ & $\sqrt{N}$ & $1-\mathrm{r}^{2} / \sqrt{\mathrm{N}}$ & multiplier & $\mathrm{PE}$ & $6(\mathrm{PE})$ \\
\hline Ind.Reyon & 0.978 & 0.956 & 0.044 & 2745 & 52.39 & 0.00084 & 0.6745 & 0.00057 & 0.00342 \\
\hline
\end{tabular}

Probable error for the autocorrelation 0.978 in lag 16 is 0.00057 . See TABLE No.7.16.6 above. The coefficient of autocorrelation is greater than the PE $(0.978>0.00057)$. The autocorrelation 0.978 is still higher than the 6 times PE (0.00342) i.e., $r>6(\mathrm{PE})$. Hence the autocorrelation 0.978 of Indian Reyons in lag 16 is significant.

Table No.7.16.7

Runs test descriptive statistics of Indian Reyons

\begin{tabular}{|l|l|}
\hline Test Values & 488.97 \\
\hline Cases $<$ Test Values & 1710 \\
\hline Cases > Test Values & 1036 \\
\hline Total Cases & 2746 \\
\hline No. of runs & 8 \\
\hline Z & -52.13 \\
\hline Asym.sig (2-tailed) & 0.0 \\
\hline Expected runs R & 1291.28 \\
\hline$\sigma$ of runs & 24.62 \\
\hline Table Value @ 5\% significance & -1.96 \\
\hline
\end{tabular}

As per TABLE No.7.16.7, the actual runs in the price series are lower than the expected $(8<1291.28)$.

Too few runs indicate stationary state of the series. The $\mathrm{z}$ value calculated is -52.13 whereas the table value for the same at $5 \%$ level of significance is -1.96 on the left tail. The $\mathrm{z}$ calculated is lower than the table value ($52.13<-1.96)$. Therefore the null hypothesis that the series is random is rejected and resolved that there is interdependence and non-randomness in the closing price series of Indian Reyons.

7.17. ITC

Table No.7.17.1

Descriptive Statistics of ITC

\begin{tabular}{|l|c|}
\hline MINIMUM & 115.25 \\
\hline MAXIMUM & 1939.9 \\
\hline MEAN & 621.29 \\
\hline MEDIAN & 676.63 \\
\hline STANDARD DEVIATION & 403.61 \\
\hline SKEWNESS & 0.511 \\
\hline KURTOSIS & -0.29 \\
\hline NO. OF OBSERVATION & 2772 \\
\hline
\end{tabular}

TABLE No.7.17.1 above shows that the mean of the price series of ITC for 2772 days of observation is Rs.621.29. The median value is Rs.676.63. There is difference between mean and median. Therefore the distribution is not normal. In normal distribution the mean, median and mode will coincide with each other. 
RWH (Random-walk Hypothesis) presupposes a normal distribution to constitute an efficient market. The difference in the minimum and maximum of prices is huge. The standard deviation Rs.403.61 is bigger. The coefficient of variation $=\frac{\sigma}{\overline{\mathrm{X}}}=\frac{403.61}{621.29}=64.96 \%$. The $\sigma$ is too large for normal distribution. There is a high positive skewness to the tune of 0.511 . In a normal distribution, skewness will be zero. The positive skewness nullifies the null hypothesis and confirms non-randomness. The coefficient of kurtosis of the price series is -0.29 . A kurtosis value with 3 is the normal distribution. Since the actual kurtosis is lower than the normal i.e. $-0.29<3$ the shape of the distribution is platykurtic on the left tail. The descriptive statistics of price series of ITC confirms asymmetry and non-randomness in the series.

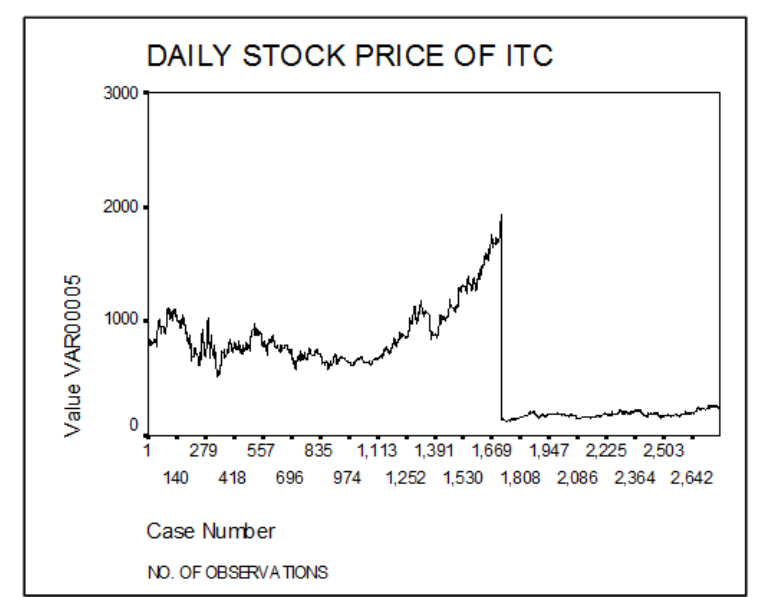

Figure 7.17.1 Daily Stock Price of ITC for 2772 days.

Fig.7.17.1 depicts the behavior of stock price of ITC. The daily stock prices of ITC had lot of fluctuations. The opening price of the stock in 1999 was Rs.754. With lot of minor and major fluctuations the price reached to the peak level at Rs.1313.05 in 2005. Then fell sharply down to Rs.142. Then with minor fluctuations the price settled at Rs.250.85 in 2009. The overall tendency of the stock of Indian Hotels was to decline. As the standard deviation denoted, the price series was expressing major and minor fluctuations along its movement. It gave larger and smaller surprises to the market. The steady flow of the line with turbulent zigzags can be viewed from the graph. There is high volatility in prices. This shows large scale mispricing in the market, an evidence for the absence of market efficiency.

Table No.7.17.2

Autocorrelation of prices of ITC in 16 lags

\begin{tabular}{|l|r|r|r|r|r|r|r|r|r|r|r|r|r|r|r|r|}
\hline Stocks & 1 & 2 & 3 & 4 & 5 & 6 & 7 & 8 & 9 & 10 & 11 & 12 & 13 & 14 & 15 & 16 \\
\hline ITC & 0.99 & 0.99 & 0.98 & 0.98 & 0.97 & 0.97 & 0.96 & 0.96 & 0.96 & 0.95 & 0.95 & 0.94 & 0.94 & 0.94 & 0.93 & 0.93 \\
badra & 5 & 1 & 7 & 2 & 8 & 3 & 9 & 5 & 1 & 7 & 3 & 9 & 5 & 2 & 8 & 5 \\
\hline
\end{tabular}

TABLE No.7.17.2 provides autocorrelation coefficient of ITC's price series in 16 lags. It can be seen from the table that the auto correlation in all 16 lags is above 0.9 . Auto correlation above 0.5 is significant. Therefore, the null hypothesis that the price series is random is rejected. It signals significant evidence for interdependence and non-randomness.

Table No.7.17.3

Student's ' $t$ ' test in Lag 1

\begin{tabular}{|l|c|c|c|c|c|c|r|r|r|}
\hline Stock & $\mathrm{r}$ & $\mathrm{N}-2$ & $\sqrt{\mathrm{N}}-2$ & $\mathrm{r}^{2}$ & $1-\mathrm{r}^{2}$ & $\sqrt{1-\mathrm{r}^{2}}$ & $\mathrm{r} / \sqrt{1-\mathrm{r}^{2}}$ & $\mathrm{H}^{*} \mathrm{D}$ & Table \\
\hline ITC badra & 0.995 & 2770 & 52.63079 & 0.99 & 0.01 & 0.100 & 9.95 & 524 & 1.96 \\
\hline
\end{tabular}

As per TABLE No.7.17.3 above, the auto correlation of ITC in the first lag is 0.995. The t value calculated is 524 and table value at $5 \%$ significance is 1.96 . T value calculated is greater than the table value (524>1.96). Therefore, the autocorrelation coefficient is significant in the first lag.

Table No.7.17.4

Student's t test in Lag 16

\begin{tabular}{|c|l|l|l|l|r|r|r|r|r|}
\hline Scrip & $\mathrm{r}$ & $\mathrm{N}-2$ & $\sqrt{\mathrm{N}}-2$ & $\mathrm{r}^{2}$ & $1-\mathrm{r}^{2}$ & $\sqrt{1-\mathrm{r}^{2}}$ & $\mathrm{r} / \sqrt{1-\mathrm{r}^{2}}$ & $\mathrm{H}^{*} \mathrm{D}$ & $\mathrm{T}$ \\
\hline ITC badra & 0.935 & 2770 & 52.63079 & 0.874 & 0.126 & 0.355 & 2.63 & 138 & 1.96 \\
\hline
\end{tabular}


TABLE No.7.17.4 above shows the $t$ test for the $16^{\text {th }}$ lag of price of stock ITC. Auto correlation in the $16^{\text {th }}$ lag is 0.935 . The calculated value of $t$ is given as 138 . The table value for the same is 1.96 . The calculated $t$ value 138 is greater than the table value 1.96 . Hence the autocorrelation in $16^{\text {th }}$ lag is significant.

Table No.7.17.5

Calculation of Probable Error in Lag 1

\begin{tabular}{|c|c|c|c|c|c|c|c|c|c|}
\hline Stock & $\mathrm{r}$ & $\mathrm{r}^{2}$ & $1-\mathrm{r}^{2}$ & $\mathrm{~N}$ & $\sqrt{\mathrm{N}}$ & $1-\mathrm{r}^{2} / \sqrt{\mathrm{N}}$ & multiplier & $\mathrm{PE}$ & $6(\mathrm{PE})$ \\
\hline ITC badra & 0.995 & 0.99 & 0.01 & 2772 & 52.64979 & 0.00019 & 0.6745 & 0.00013 & 0.00078 \\
\hline
\end{tabular}

Probable error for the autocorrelation 0.995 in the first lag is 0.00013. See TABLE No.7.17.5 above. The coefficient of autocorrelation is greater than the PE $(0.995>0.00013)$. The autocorrelation 0.995 is still higher than the 6 times PE $(0.00078)$ i.e., $r>6(\mathrm{PE})$. Hence the autocorrelation 0.995 of ITC is significant.

Table No.7.17.6

Calculation of Probable Error in Lag 16.

\begin{tabular}{|c|c|c|c|c|c|c|c|c|c|}
\hline Stock & $\mathrm{r}$ & $\mathrm{r}^{2}$ & $1-\mathrm{r}^{2}$ & $\mathrm{~N}$ & $\sqrt{N}$ & $1-\mathrm{r}^{2} / \sqrt{\mathrm{N}}$ & multiplier & $\mathrm{PE}$ & $6(\mathrm{PE})$ \\
\hline ITC badra & 0.935 & 0.874 & 0.126 & 2772 & 52.649 & 0.00239 & 0.6745 & 0.00161 & 0.00966 \\
\hline
\end{tabular}

Probable error for the autocorrelation 0.935 in lag 16 is 0.00161 . See TABLE No.7.17.6 above. The coefficient of autocorrelation is greater than the PE $(0.935>0.00161)$. The autocorrelation 0.935 is still higher than the 6 times PE (0.00966) i.e., $r>6(P E)$. Hence the autocorrelation 0.935of ITC in lag 16 is significant.

Table No.7.17.7

Runs test descriptive statistics of ITC

\begin{tabular}{|l|l|}
\hline Test Values & 621.29 \\
\hline Cases $<$ Test Values & 1136 \\
\hline Cases $>$ Test Values & 1636 \\
\hline Total Cases & 2772 \\
\hline No. of runs & 26 \\
\hline Z & -51.68 \\
\hline Asym.sig (2-tailed) & 0.0 \\
\hline Expected runs R & 1341.91 \\
\hline$\sigma$ of runs & 25.46 \\
\hline Table Value @ 5\% significance & -1.96 \\
\hline
\end{tabular}

As per TABLE No.7.17.7, the actual runs in the price series are lower than the expected $(26<1341.91)$. Too few runs indicate stationary state of the series. The $\mathrm{z}$ value calculated is -51.68 whereas the table value for the same at $5 \%$ level of significance is -1.96 on the left tail. The $\mathrm{z}$ calculated is lower than the table value $(-51.68<-$ 1.96). Therefore the null hypothesis that the series is random is rejected and resolved that there is interdependence and non-randomness in the closing price series of ITC.

7.18. ONGC

Table No.7.18.1

Descriptive Statistics of ONGC

\begin{tabular}{|l|l|}
\hline MINIMUM & 97 \\
\hline MAXIMUM & 1484.45 \\
\hline MEAN & 632.23 \\
\hline MEDIAN & 698.98 \\
\hline STANDARD DEVIATION & 386.29 \\
\hline SKEWNESS & 0.007 \\
\hline KURTOSIS & -1.424 \\
\hline NO. OF OBSERVATION & 2752 \\
\hline
\end{tabular}

TABLE No.7.18.1 above shows that the mean of the price series of ONGC for 2752 days of observation is Rs.632.23. The median value is Rs.698.98. There is difference between mean and median. Therefore the distribution is not normal because in normal distribution the mean, median and mode are the same. RWH (Random-walk Hypothesis) presupposes a normal distribution to constitute an efficient market. The difference in the minimum and maximum prices is very big. The standard deviation Rs.386.29 is bigger. The coefficient of variation $=\frac{\sigma}{\overline{\mathrm{X}}}=\frac{386.29}{632.23}=61.09 \%$. The $\sigma$ is too large for normal distribution. There is a positive skewness to the tune of 0.007 . In a normal distribution, skewness will be zero. The coefficient of kurtosis of the price series is -1.424 . A kurtosis value with 3 is the normal distribution. Since the actual kurtosis is lower than the normal i.e- $1.424<3$ the shape of the distribution is platykurtic on the left tail. The descriptive statistics of price series of ONGC confirms asymmetry and non-randomness in the series. 


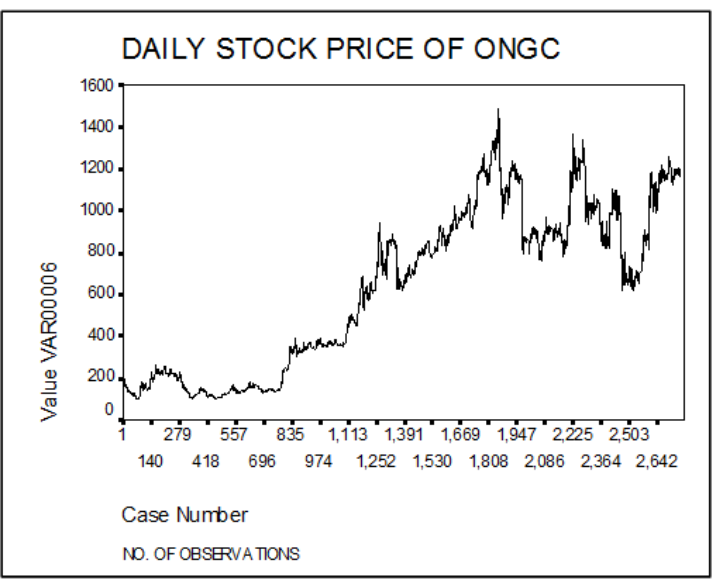

Figure 7.18.1: Daily Stock Price of ONGC for 2752 days.

Fig.7.18.1 depicts the behavior of stock price of ONGC. The daily stock prices of ONGC had lot of fluctuations. The opening price of the stock in 1999 was Rs.202.60. With lot of minor and major fluctuations the price reached to the peak level at Rs. 1249.50 in 2008. Then fell marginally and cyclically went up and settled at Rs.1177.55 in 2009. The overall tendency of the stock of Indian Hotels was to go up. As the standard deviation denoted, the price series was expressing major and minor fluctuations along its movement. It gave larger and smaller surprises to the market. The steady flow of the line with turbulent zigzags can be viewed from the graph. There is high volatility in prices. This shows large scale mispricing in the market, an evidence for the absence of market efficiency.

Table No.7.18.2

Autocorrelation of prices of ONGC in 16 lags

\begin{tabular}{|l|r|r|r|r|r|r|r|r|r|r|r|r|r|r|r|r|}
\hline Stock & 1 & 2 & 3 & 4 & 5 & 6 & 7 & 8 & 9 & 10 & 11 & 12 & 13 & 14 & 15 & 16 \\
$\mathrm{~s}$ & 1 & 0.99 & 0.99 & 0.99 & 0.99 & 0.98 & 0.98 & 0.98 & 0.98 & 0.98 & 0.98 & 0.97 & 0.97 & 0.97 & 0.97 & 0.97 \\
\hline ONG & 0.99 & 0.99 & 9 \\
$\mathrm{C}$ & 8 & 6 & 4 & 2 & 0 & 9 & 7 & 5 & 3 & 1 & 0 & 8 & 6 & 6 & 4 & 0 \\
\hline
\end{tabular}

TABLE No.7.18.2 provides autocorrelation coefficient of ONGC's price series in 16 lags. It can be seen from the table that the auto correlation in all 16 lags is above 0.9 . Auto correlation above 0.5 is significant. Therefore, the null hypothesis that the price series is random is rejected. It signals significant evidence for interdependence and non-randomness.

Table No.7.18.3

Student's ' $t$ ' test in Lag 1

\begin{tabular}{|l|c|c|c|c|c|c|c|r|r|}
\hline Stock & $\mathrm{r}$ & $\mathrm{N}-2$ & $\sqrt{\mathrm{N}-2}$ & $\mathrm{r}^{2}$ & $1-\mathrm{r}^{2}$ & $\sqrt{1-\mathrm{r}^{2}}$ & $\mathrm{r} / \sqrt{1} 1-\mathrm{r}^{2}$ & $\mathrm{H}^{*} \mathrm{D}$ & Table \\
\hline ONGC & 0.998 & 2750 & 52.44044 & 0.996 & 0.004 & 0.063 & 15.78 & 828 & 1.96 \\
\hline
\end{tabular}

As per TABLE No.7.18.3 above, the auto correlation of ONGC in the first lag is 0.998. The t value calculated is 828 and table value at $5 \%$ significance is 1.96 . T value calculated is greater than the table value (828>1.96). Therefore, the autocorrelation coefficient is significant in the first lag.

Table No.7.18.4

Student's t test in Lag 16

\begin{tabular}{|c|c|c|r|r|r|r|r|r|r|}
\hline Scrip & $\mathrm{r}$ & $\mathrm{N}-2$ & $\sqrt{\mathrm{N}-2}$ & $\mathrm{r}^{2}$ & $1-\mathrm{r}^{2}$ & $\sqrt{1-\mathrm{r}^{2}}$ & $\mathrm{r} / \sqrt{1-\mathrm{r}^{2}}$ & $\mathrm{H} * \mathrm{D}$ & Table \\
\hline ONGC & 0.97 & 2750 & 52.44044 & 0.941 & 0.059 & 0.243 & 3.99 & 209 & 1.96 \\
\hline
\end{tabular}

TABLE No.7.18.4 above shows the $t$ test for the $16^{\text {th }}$ lag of price of stock ONGC. Auto correlation in the $16^{\text {th }}$ lag is 0.97 . The calculated value of $t$ is given as 209. The table value for the same is 1.96 . The calculated $\mathrm{t}$ value 209 is greater than the table value 1.96 . Hence the autocorrelation in $16^{\text {th }}$ lag is significant.

Table No.7.18.5

Calculation of Probable Error in Lag 1

\begin{tabular}{|c|c|c|c|c|c|c|c|c|c|}
\hline Stock & $\mathrm{r}$ & $r^{2}$ & $1-\mathrm{r}^{2}$ & $\mathrm{~N}$ & $\sqrt{N}$ & $1-\mathrm{r}^{2} / \sqrt{\mathrm{N}}$ & multiplier & $\mathrm{PE}$ & $6(\mathrm{PE})$ \\
\hline ONGC & 0.998 & 0.996 & 0.004 & 2752 & 52.45951 & 0.00008 & 0.6745 & 0.00005 & 0.0003 \\
\hline
\end{tabular}

Probable error for the autocorrelation 0.998 in the first lag is 0.00005. See TABLE No.7.18.5 above.

The coefficient of autocorrelation is greater than the PE $(0.998>0.00005)$. The autocorrelation 0.998 is still higher than the 6 times PE (0.0003) i.e., $r>6(\mathrm{PE})$. Hence the autocorrelation 0.998 of ONGC is significant.

Table No.7.18.6

Calculation of Probable Error in Lag 16.

\begin{tabular}{|c|c|c|c|c|c|c|c|c|c|}
\hline Stock & $\mathrm{r}$ & $\mathrm{r}^{2}$ & $1-\mathrm{r}^{2}$ & $\mathrm{~N}$ & $\sqrt{N}$ & $1-\mathrm{r}^{2} / \sqrt{\mathrm{N}}$ & multiplier & $\mathrm{PE}$ & $6(\mathrm{PE})$ \\
\hline ONGC & 0.97 & 0.941 & 0.059 & 2752 & 52.45 & 0.00112 & 0.6745 & 0.00076 & \begin{tabular}{|l|l|l}
0.00456 \\
\end{tabular} \\
\hline
\end{tabular}


Probable error for the autocorrelation 0.97 in lag 16 is 0.00076 . See TABLE No.7.18.6 above. The coefficient of autocorrelation is greater than the PE $(0.97>0.00076)$. The autocorrelation 0.97 is still higher than the 6 times PE (0.00456) i.e., $r>6(\mathrm{PE})$. Hence the autocorrelation 0.97 of ONGC in lag 16 is significant.

Table No.7.18.7

Runs test descriptive statistics of ONGC

\begin{tabular}{|l|l|}
\hline Test Values & 632.23 \\
\hline Cases $<$ Test Values & 1238 \\
\hline Cases $>$ Test Values & 1514 \\
\hline Total Cases & 2752 \\
\hline No. of runs & 26 \\
\hline Z & -51.51 \\
\hline Asym.sig (2-tailed) & 0.0 \\
\hline Expected runs R & 1363.16 \\
\hline$\sigma$ of runs & \\
\hline Table Value @ 5\% significance & \\
\hline
\end{tabular}

As per TABLE No.7.18.7, the actual runs in the price series are lower than the expected $(26<1363.16)$. Too few runs indicate persistence state of the series. The $\mathrm{z}$ value calculated is -51.51 whereas the table value for the same at $5 \%$ level of significance is -1.96 on the left tail. The $\mathrm{z}$ calculated is lower than the table value ($51.51<-1.96)$. Therefore the null hypothesis that the series is random is rejected and resolved that there is interdependence and non-randomness in the closing price series of ONGC.

7.19. Tata Steel Limited

Table No.7.19.1

Descriptive Statistics of Tata Steel

\begin{tabular}{|l|l|}
\hline MINIMUM & 67.15 \\
\hline MAXIMUM & 990.6 \\
\hline MEAN & 318.98 \\
\hline MEDIAN & 282.70 \\
\hline STANDARD DEVIATION & 214.57 \\
\hline SKEWNESS & 0.853 \\
\hline KURTOSIS & -0.102 \\
\hline NO. OF OBSERVATION & 2772 \\
\hline
\end{tabular}

TABLE No.7.19.1 above shows that the mean of the price series of Tata Steel for 2772 days of observation is Rs.318.98. The median value is Rs.282.70. There is difference between mean and median. Therefore the distribution is not normal because in normal distribution the mean, median and mode are the same. RWH (Random-walk Hypothesis) presupposes a normal distribution to constitute an efficient market. The difference between the minimum price and maximum price is very high. The standard deviation Rs.214.57 is bigger. The coefficient of variation $=\frac{\sigma}{\overline{\mathrm{X}}}=\frac{214.57}{318.98}=67.27 \%$. The $\sigma$ is too large for normal distribution. There is a high positive skewness to the tune of 0.853 . In a normal distribution, skewness will be zero. The coefficient of kurtosis of the price series is -0.102 . A kurtosis value with 3 is the normal distribution. Since the value of kurtosis is lower than the normal i.e. $-0.102<3$ the shape of the distribution is platykurtic on the left tail. The descriptive statistics of price series of Tata Steel confirms asymmetry and non-randomness in the series.

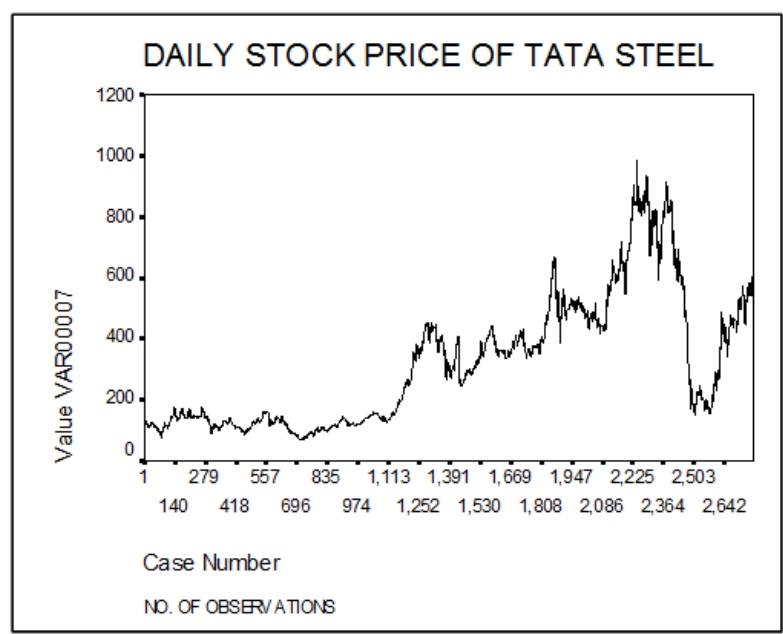

Figure 7.19.1 : Daily Stock Price of Tata Steel for 2772 days. 
Fig.7.19.1 depicts the behavior of stock price of Tata Steel. The daily stock prices of Tata Steel had lot of fluctuations. From a lower point the price line tended to rise to reach the maximum and then fell sharply and recovered. The opening price of the stock in 1999 was Rs.123.50. With lot of minor and major fluctuations the price reached to the peak level at Rs.934.8 in 2007. Then fell sharply and recovered and went up to settle at Rs.617.6 in 2009. The overall tendency of the stock of Tata Steel was to go up. As the standard deviation denoted, the price series was expressing major and minor fluctuations along its movement. It gave larger and smaller surprises to the market. The steady flow of the line with turbulent zigzags can be viewed from the graph. There is high volatility in prices. This shows large scale mispricing in the market, an evidence for the presence of market inefficiency.

Table No.7.19.2

Autocorrelation of prices of Tata Steel in 16 lags

\begin{tabular}{|c|c|c|c|c|c|c|c|c|c|c|c|c|c|c|c|c|}
\hline Stocks & 1 & 2 & 3 & 4 & 5 & 6 & 7 & 8 & 9 & 10 & 11 & 12 & 13 & 14 & 15 & 16 \\
\hline Tata & 0.99 & 0.99 & 0.99 & 0.99 & 0.98 & 0.98 & 0.98 & 0.98 & 0.98 & 0.97 & 0.97 & 0.97 & 0.97 & 0.96 & 0.96 & 0.96 \\
\hline Steel & 8 & 6 & 3 & 1 & 9 & 7 & 5 & 3 & 0 & 8 & 6 & 3 & 1 & 9 & 7 & 4 \\
\hline
\end{tabular}

TABLE No.7.19.2 provides autocorrelation coefficient of Tata Steel's price series in 16 lags. It can be seen from the table that the auto correlation in all 16 lags is above 0.9 . Auto correlation above 0.5 is significant. Therefore, the null hypothesis that the price series is random is rejected. It signals significant evidence for interdependence and non-randomness.

Table No.7.19.3

Student's ' $t$ ' test in Lag 1

\begin{tabular}{|l|c|c|c|c|c|r|r|r|r|r|}
\hline Stock & $\mathrm{r}$ & $\mathrm{N}-2$ & $\sqrt{\mathrm{N}-2}$ & $\mathrm{r}^{2}$ & $1-\mathrm{r}^{2}$ & $\sqrt{ } 1-\mathrm{r}^{2}$ & $\mathrm{r} / \sqrt{ } 1-\mathrm{r}^{2}$ & $\mathrm{H}^{*} \mathrm{D}$ & $\mathrm{Table}^{2}$ \\
\hline Tata Steel & 0.998 & 2770 & 52.63079 & 0.996 & 0.004 & 0.063 & 15.78 & 831 \\
\hline
\end{tabular}

As per TABLE No.7.19.3 above, the auto correlation of Tata Steel in the first lag is 0.998 . The $\mathrm{t}$ value calculated is 831 and table value at $5 \%$ significance is 1.96 . T value calculated is greater than the table value $(831>1.96)$. Therefore, the autocorrelation coefficient is significant in the first lag.

Table No.7.19.4

Student's t test in Lag 16

\begin{tabular}{|c|r|r|r|r|r|r|r|r|r|r|}
\hline Scrip & $\mathbf{r}$ & $\mathbf{N}-2$ & $\sqrt{\mathrm{N}-2}$ & $\mathbf{r}^{\mathbf{2}}$ & $\mathbf{1}^{\mathbf{1}-\mathbf{r}^{\mathbf{2}}}$ & $\sqrt{\mathbf{1}-\mathbf{r}^{\mathbf{2}}}$ & $\mathbf{r} / \sqrt{\mathbf{1}-\mathbf{r}^{\mathbf{2}}}$ & $\mathbf{H}^{*} \mathbf{D}$ & $\mathbf{T a b l e}$ \\
\hline Tata Steel & 0.964 & 2770 & 52.63079 & 0.929 & 0.071 & 0.266 & 3.62 & 191 & 1.96 \\
\hline
\end{tabular}

TABLE No.7.19.4 above shows the $t$ test for the $16^{\text {th }}$ lag of price of stock Tata Steel. Auto correlation in the $16^{\text {th }}$ lag is 0.964 . The calculated value of $t$ is given as 191 . The table value for the same is 1.96 . The calculated t value 191 is greater than the table value 1.96 . Hence the autocorrelation in $16^{\text {th }}$ lag is significant.

Table No.7.19.5

Calculation of Probable Error in Lag 1

\begin{tabular}{|l|r|r|r|r|r|r|r|r|r|}
\hline Stock & $\mathrm{r}$ & $\mathrm{r}^{2}$ & $1-\mathrm{r}^{2}$ & $\mathrm{~N}$ & $\sqrt{\mathrm{N}}$ & $1-\mathrm{r}^{2} / \sqrt{\mathrm{N}}$ & multiplier & PE & $6(\mathrm{PE})$ \\
\hline Tata Steel & 0.998 & 0.996 & 0.004 & 2772 & 52.64979 & 0.00008 & 0.6745 & 0.00005 & 0.0003 \\
\hline
\end{tabular}

Probable error for the autocorrelation 0.998 in the first lag is 0.00005. See TABLE No.7.19.5 above.

The coefficient of autocorrelation is greater than the PE $(0.998>0.00005)$. The autocorrelation 0.998 is still higher than the 6 times PE (0.0003) i.e., $r>6(P E)$. Hence the autocorrelation 0.998 of Tata Steel is significant.

Table No.7.19.6

Calculation of Probable Error in Lag 16.

\begin{tabular}{|c|c|c|c|c|c|c|c|c|c|}
\hline Stock & $\mathrm{r}$ & $\mathrm{r}^{2}$ & $1-r^{2}$ & $\mathrm{~N}$ & $\sqrt{N}$ & $1-\mathrm{r}^{2} / \sqrt{\mathrm{N}}$ & multiplier & $\mathrm{PE}$ & $6(\mathrm{PE})$ \\
\hline Tata Steel & 0.964 & 0.929 & 0.071 & 2772 & 52.64979 & 0.00135 & 0.6745 & 0.00091 & 0.00546 \\
\hline
\end{tabular}

Probable error for the autocorrelation 0.964 in lag 16 is 0.00091. See TABLE No.7.19.6 above. The coefficient of autocorrelation is greater than the PE $(0.964>0.00091)$. The autocorrelation 0.964 is still higher than the 6 times PE (0.00546) i.e., $r>6(\mathrm{PE})$. Hence the autocorrelation 0.964 of Tata Steel in lag 16 is significant.

Table No.7.19.7

Run test descriptive statistics of Tata Steel

\begin{tabular}{|l|l|}
\hline Test Values & 318.98 \\
\hline Cases $<$ Test Values & 1481 \\
\hline Cases > Test Values & 1291 \\
\hline Total Cases & 2772 \\
\hline No. of runs & 14 \\
\hline Z & -52.16 \\
\hline Asym.sig (2-tailed) & 0.0 \\
\hline Expected runs R & 1380.49 \\
\hline$\sigma$ of runs & 26.20 \\
\hline Table Value @ 5\% significance & -1.96 \\
\hline
\end{tabular}


As per TABLE No.7.19.7, the actual runs in the price series are lower than the expected $(14<1380.49)$. Too few runs indicate stationary state of the series. The $\mathrm{z}$ value calculated is -52.16 whereas the table value for the same at $5 \%$ level of significance is -1.96 on the left tail. The $\mathrm{z}$ calculated is lower than the table value ($52.16<-1.96)$. Therefore the null hypothesis that the series is random is rejected and resolved that there is interdependence and non-randomness in the closing price series of Tata Steel.

7.20. Wipro

Table No.7.20.1

Descriptive Statistics of Wipro

\begin{tabular}{|l|l|}
\hline MINIMUM & 200.5 \\
\hline MAXIMUM & 9624 \\
\hline MEAN & 1368.20 \\
\hline MEDIAN & 901.15 \\
\hline STANDARD DEVIATION & 1259.83 \\
\hline SKEWNESS & 2.066 \\
\hline KURTOSIS & 5.183 \\
\hline NO. OF OBSERVATION & 2819 \\
\hline
\end{tabular}

TABLE No.7.20.1 above shows that the mean of the price series of Wipro for 2819 days of observation is Rs.1368.20. The median value is Rs.901.15. There is huge difference between mean and median. Therefore the distribution is not normal because in normal distribution the mean, median and mode are the same. RWH (Random-walk Hypothesis) presupposes a normal distribution to constitute an efficient market. The difference between the minimum price and maximum price is very much wide. The standard deviation Rs.1259.83 is bigger. The coefficient of variation $=\frac{\sigma}{\overline{\mathrm{X}}}=\frac{1259.83}{1368.20}=92.08 \%$. The $\sigma$ is too large for normal distribution. There is a high positive skewness to the tune of 2.066. In a normal distribution, skewness will be zero. The coefficient of kurtosis of the price series is 5.183. A kurtosis value with 3 is the normal distribution. Since the value of kurtosis is greater than the normal i.e. 5.183>3 the shape of the distribution is leptokurtic. The descriptive statistics of price series of Wipro confirms asymmetry and non-randomness in the series.

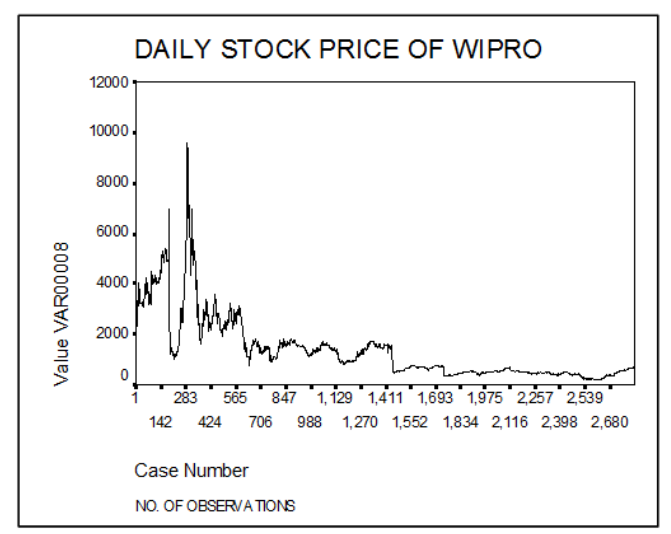

Figure 7.20.1: Daily Stock Price of Wipro for 2819 days.

Fig.7.20.1 depicts the behavior of stock price of Wipro. The daily stock prices of Tata Steel had lot of fluctuations. The stock had higher prices in the initial days. After the $706^{\text {th }}$ observation the price had fallen deeply and stayed so till the end of 2009. The opening price of the stock in 1999 was Rs.1820.75. With lot of minor and major fluctuations the price reached to the peak level at Rs.2808.85 in 2000. Then fell sharply and inclined to decline gradually and successively to settle at Rs.679.40 in 2009. The overall tendency of the stock of Indian Hotels was to go down. As the standard deviation denoted, the price series was expressing major and minor fluctuations along its movement. It gave larger and smaller surprises to the market. The steady flow of the line with turbulent zigzags can be viewed from the graph. There is high volatility in prices. This shows large scale mispricing in the market, an evidence for the absence of market efficiency.

Table No.7.20.2

Autocorrelation of prices of Wipro in 16 lags

\begin{tabular}{|c|c|c|c|c|c|c|c|c|c|c|c|c|c|c|c|c|}
\hline $\begin{array}{l}\text { Stock } \\
\text { S }\end{array}$ & 1 & 2 & 3 & 4 & 5 & 6 & 7 & 8 & 9 & 10 & 11 & 12 & 13 & 14 & 15 & 16 \\
\hline Wipr & 0.99 & 0.98 & 0.97 & 0.97 & 0.96 & 0.95 & 0.95 & 0.94 & 0.94 & 0.93 & 0.93 & 0.92 & 0.91 & 0.91 & 0.90 & 0.89 \\
\hline o & 3 & 7 & 9 & 2 & 5 & 8 & 3 & 8 & 2 & 7 & 1 & 5 & 8 & 0 & 3 & 5 \\
\hline
\end{tabular}


TABLE No.7.20.2 provides autocorrelation coefficient of Wipro's price series in 16 lags. It can be seen from the table that the auto correlation in all 15 lags is above 0.9 . The autocorrelation in the $16^{\text {th }}$ lag is 0.895 . Auto correlation above 0.5 is significant. Therefore, the null hypothesis that the price series is random is rejected. It signals significant evidence for interdependence and non-randomness.

Table No.7.20.3

Student's ' $\mathrm{t}$ ' test in Lag 1

\begin{tabular}{|l|c|c|c|r|r|r|r|r|r|}
\hline Stock & $\mathrm{r}$ & $\mathrm{N}-2$ & $\sqrt{\mathrm{N}-2}$ & $\mathrm{r}^{2}$ & $1-\mathrm{r}^{2}$ & $\sqrt{1-\mathrm{r}^{2}}$ & $\mathrm{r} / \sqrt{1-\mathrm{r}^{2}}$ & $\mathrm{H}^{*} \mathrm{D}$ & Table \\
\hline Wipro & 0.993 & 2817 & 53.07542 & 0.986 & 0.014 & 0.118 & 8.39 & 445 & 1.96 \\
\hline
\end{tabular}

As per TABLE No.7.20.3 above, the auto correlation of Wipro in the first lag is 0.993 . The $t$ value calculated is 445 and table value at $5 \%$ significance is 1.96 . T value calculated is greater than the table value $(445>1.96)$. Therefore, the autocorrelation coefficient is significant in the first lag.

Table No.7.20.4

Student's t test in Lag 16

\begin{tabular}{|c|c|c|r|r|r|r|r|r|r|}
\hline Scrip & $\mathrm{r}$ & $\mathrm{N}-2$ & $\sqrt{\mathrm{N}-2}$ & $\mathrm{r}^{2}$ & $1-\mathrm{r}^{2}$ & $\sqrt{1-\mathrm{r}^{2}}$ & $\mathrm{r} / \sqrt{1-\mathrm{r}^{2}}$ & $\mathrm{H} \mathrm{H}^{*} \mathrm{D}$ & Table \\
\hline Wipro & 0.895 & 2817 & 53.07542 & 0.801 & 0.199 & 0.446 & 2.01 & 107 & 1.96 \\
\hline
\end{tabular}

TABLE No.7.20.4 above shows the $t$ test for the $16^{\text {th }}$ lag of price of stock Wipro. Auto correlation in the $16^{\text {th }}$ lag is 0.895 . The calculated value of $t$ is given as 107 . The table value for the same is 1.96 . The calculated t value 107 is greater than the table value 1.96 . Hence the autocorrelation in $16^{\text {th }}$ lag is significant.

Table No.7.20.5

Calculation of Probable Error in Lag 1

\begin{tabular}{|c|c|c|c|c|c|c|c|c|c|}
\hline Stock & $\mathrm{r}$ & $r^{2}$ & $1-\mathrm{r}^{2}$ & $\mathrm{~N}$ & $\sqrt{\mathrm{N}}$ & $1-\mathrm{r}^{2} / \sqrt{\mathrm{N}}$ & multiplier & PE & $6(\mathrm{PE})$ \\
\hline Wipro & 0.993 & 0.986 & 0.014 & 2819 & 53.09426 & 0.00026 & 0.6745 & 0.00018 & 0.00108 \\
\hline
\end{tabular}

Probable error for the autocorrelation 0.993 in the first lag is 0.00018. See TABLE No.7.20.5 above.

The coefficient of autocorrelation is greater than the PE $(0.993>0.00018)$. The autocorrelation 0.993 is still higher than the 6 times PE (0.00108) i.e., $r>6(\mathrm{PE})$. Hence the autocorrelation 0.993 of Wipro is significant.

Table No.7.20.6

Calculation of Probable Error in Lag 16.

\begin{tabular}{|l|l|l|l|l|l|r|r|r|r|}
\hline Stock & $\mathrm{r}$ & $\mathrm{r}^{2}$ & \multicolumn{1}{l|}{$1-\mathrm{r}^{2}$} & $\mathrm{~N}$ & $\sqrt{\mathrm{N}}$ & $1-\mathrm{r}^{2} / \sqrt{\mathrm{N}}$ & multiplier & PE & $6(\mathrm{PE})$ \\
\hline Wipro & 0.895 & 0.801 & 0.199 & 2819 & 53.09 & 0.00375 & 0.6745 & 0.00253 & 0.01518 \\
\hline
\end{tabular}

Probable error for the autocorrelation 0.895 in lag 16 is 0.00253 . See TABLE No.7.20.6 above. The coefficient of autocorrelation is greater than the PE $(0.895>0.00253)$. The autocorrelation 0.895 is still higher than the 6 times PE (0.01518) i.e., $r>6(P E)$. Hence the autocorrelation 0.895 of Wipro in lag 16 is significant.

Table No.7.20.7

Run test descriptive statistics of Wipro

\begin{tabular}{|l|l|}
\hline Test Values & 1368.20 \\
\hline Cases $<$ Test Values & 1728 \\
\hline Cases > Test Values & 1091 \\
\hline Total Cases & 2819 \\
\hline No. of runs & 42 \\
\hline Z & -51.48 \\
\hline Asym.sig (2-tailed) & 0.0 \\
\hline Expected runs R & 1339 \\
\hline$\sigma$ of runs & 25 \\
\hline Table Value @ 5\% significance & -1.96 \\
\hline
\end{tabular}

As per TABLE No.7.20.7, the actual runs in the price series are lower than the expected $(42<1339)$. Too few runs indicate stationary state of the series. The $\mathrm{z}$ value calculated is -51.48 whereas the table value for the same at $5 \%$ level of significance is -1.96 on the left tail. The $\mathrm{z}$ calculated is lower than the table value ($51.48<-1.96)$. Therefore the null hypothesis that the series is random is rejected and resolved that there is interdependence and non-randomness in the closing price series of Tata Steel.

7.21. BSE Sensex30

Table No.7.21.1

Descriptive Statistics of BSE SENSEX30

\begin{tabular}{|l|l|}
\hline MINIMUM & 2600.12 \\
\hline MAXIMUM & 20873.33 \\
\hline MEAN & 7927.93 \\
\hline MEDIAN & 5679.83 \\
\hline
\end{tabular}


Indian stock market not efficient in weak form: An Empirical Analysis

\begin{tabular}{|l|l|}
\hline STANDARD DEVIATION & 4895.11 \\
\hline SKEWNESS & 0.815 \\
\hline KURTOSIS & -0.684 \\
\hline NO. OF OBSERVATION & 2743 \\
\hline
\end{tabular}

TABLE No.7.21.1 above shows that the mean of the price series of BSE SENSEX30 for 2743days of observation is Rs.7927.93. The median value is Rs.5679.83. There is huge difference between mean and median. Therefore the distribution is not normal because in normal distribution the mean, median and mode are the same. RWH (Random-walk Hypothesis) presupposes a normal distribution to constitute an efficient market. There is big difference between the minimum and maximum daily price index. The standard deviation Rs.4895.11 is bigger. The coefficient of variation $=\frac{\sigma}{\overline{\mathrm{X}}}=\frac{4895.11}{7927.93}=61.74 \%$. The $\sigma$ is too large for normal distribution. There is a high positive skewness to the tune of 0.815 . In a normal distribution, skewness will be zero. The coefficient of kurtosis of the price series is -0.684 . A kurtosis value with 3 is the normal distribution. Since the value of kurtosis is lower than the normal i.e. $-0.684<3$ the shape of the distribution is platykurtic on the left tail. The descriptive statistics of price series of BSE SENSEX30 confirms asymmetry and nonrandomness in the series.

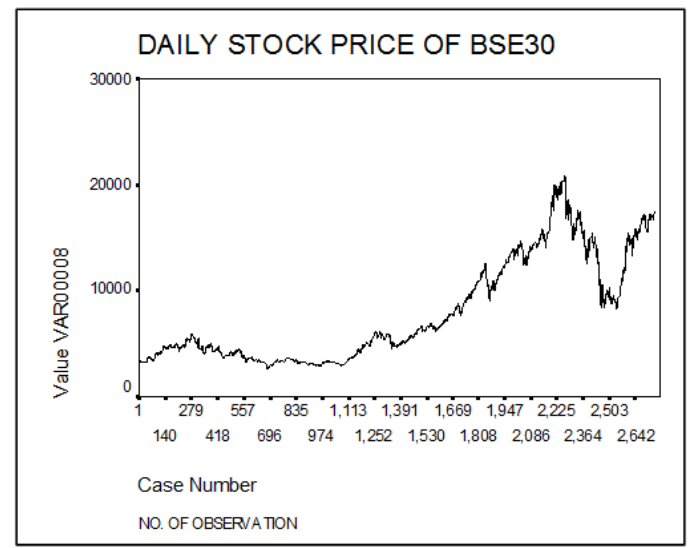

Figure 7.21.1: Daily Stock Price of BSE SENSEX30 for 2743 days.

Fig.7.21.1 depicts the behavior of stock price of BSE SENSEX30. The daily stock price index of BSE SENSEX30 had lot of fluctuations. The opening price index of the stock in 1999 was 3060.34. With lot of minor and major fluctuations the price index reached to the peak level at 20300.71 in 2008 . Then fell sharply and settled at 17464.8 in 2009. The overall tendency of the stock of Indian Hotels was to go down. As the standard deviation denoted, the price series was expressing major and minor fluctuations along its movement. It gave larger and smaller surprises to the market. The steady flow of the line with turbulent zigzags can be viewed from the graph. There is high volatility in prices. This shows large scale mispricing in the market, an evidence for the absence of market efficiency.

Table No.7.21.2

Autocorrelation of prices of BSE SENSEX30 in 16 lags

\begin{tabular}{|c|c|c|c|c|c|c|c|c|c|c|c|c|c|c|c|c|}
\hline $\begin{array}{l}\text { Stock } \\
\mathrm{s}\end{array}$ & 1 & 2 & 3 & 4 & 5 & 6 & 7 & 8 & 9 & 10 & 11 & 12 & 13 & 14 & 15 & 16 \\
\hline BSE & $\begin{array}{l}0.99 \\
8 \\
\end{array}$ & $\begin{array}{r}0.99 \\
7 \\
\end{array}$ & $\begin{array}{r}0.99 \\
5 \\
\end{array}$ & $\begin{array}{r}0.99 \\
4 \\
\end{array}$ & $\begin{array}{r}0.99 \\
2 \\
\end{array}$ & $\begin{array}{r}0.99 \\
1 \\
\end{array}$ & $\begin{array}{r}0.9 \\
9\end{array}$ & $\begin{array}{r}0.98 \\
8 \\
\end{array}$ & $\begin{array}{r}0.98 \\
7 \\
\end{array}$ & $\begin{array}{r}0.98 \\
5 \\
\end{array}$ & $\begin{array}{l}0.98 \\
4\end{array}$ & $\begin{array}{r}0.98 \\
2 \\
\end{array}$ & $\begin{array}{r}0.98 \\
1 \\
\end{array}$ & $\begin{array}{r}0.97 \\
9 \\
\end{array}$ & $\begin{array}{r}0.97 \\
8 \\
\end{array}$ & $\begin{array}{l}0.97 \\
6 \\
\end{array}$ \\
\hline
\end{tabular}

TABLE No.7.21.2 provides autocorrelation coefficient of BSE SENSEX30's price series in 16 lags. It can be seen from the table that the auto correlation in all 16 lags is above 0.9 . Auto correlation above 0.5 is significant. Therefore, the null hypothesis that the price index series is random is rejected. It signals significant evidence for interdependence and non-randomness.

Table No.7.21.3

Student's ' $t$ ' test in Lag 1

\begin{tabular}{|c|c|c|c|c|r|r|r|r|r|}
\hline Stock & $\mathbf{r}$ & $\mathbf{N}-2$ & $\sqrt{\mathrm{N}-2}$ & \multicolumn{1}{|c|}{$\mathbf{r}^{\mathbf{2}}$} & \multicolumn{1}{|c|}{$\mathbf{1}^{\mathbf{2}}$} & $\sqrt{\mathbf{1}-\mathbf{r}^{\mathbf{2}}}$ & $\mathbf{r} / \sqrt{\mathbf{1}-\mathbf{r}^{2}}$ & $\mathbf{H}^{*} \mathbf{D}$ & Table \\
\hline BSE 30 & 0.998 & 2741 & 52.35 & 0.996 & 0.004 & 0.063 & 15.79 & 827 & 1.96 \\
\hline
\end{tabular}

As per TABLE No.7.21.3 above, the auto correlation of BSE SENSEX30 in the first lag is 0.998. The $t$ value calculated is 827 and table value at 5\% significance is 1.96 . T value calculated is greater than the table value $(827>1.96)$. Therefore, the autocorrelation coefficient is significant in the first lag.

Table No.7.21.4

Student's t test in Lag 16

\begin{tabular}{|l|l|l|l|l|l|l|l|l|l|l|l|l|} 
Scrip & $\mathrm{r}$ & $\mathrm{N}-2$ & $\sqrt{\mathrm{N}}-2$ & $\mathrm{r}^{2}$ & $1-\mathrm{r}^{2}$ & $\sqrt{1-\mathrm{r}^{2}}$ & $\mathrm{r} / \sqrt{ } 1-\mathrm{r}^{2}$ & $\mathrm{H} * \mathrm{D}$ & $\mathrm{Table}$ \\
\hline
\end{tabular}


Indian stock market not efficient in weak form: An Empirical Analysis

\begin{tabular}{|l|r|r|r|r|r|r|r|r|r|}
\hline BSE 30 & 0.976 & 2741 & 52.35 & 0.953 & 0.047 & 0.218 & 4.48 & 235 & 1.96 \\
\hline
\end{tabular}

TABLE No.7.21.4 above shows the $t$ test for the $16^{\text {th }}$ lag of price index of BSE SENSEX30. Auto correlation in the $16^{\text {th }}$ lag is 0.976 . The calculated value of $t$ is given as 235 . The table value for the same is 1.96 . The calculated $t$ value 235 is greater than the table value 1.96 . Hence the autocorrelation in $16^{\text {th }}$ lag is significant.

Table No.7.21.5

Calculation of Probable Error in Lag 1

\begin{tabular}{|c|r|r|r|r|r|r|r|r|r|}
\hline Stock & $\mathrm{r}$ & \multicolumn{1}{|c|}{$\mathrm{r}^{2}$} & \multicolumn{1}{|c|}{$1-\mathrm{r}^{2}$} & $\mathrm{~N}$ & $\sqrt{\mathrm{N}}$ & $1-\mathrm{r}^{2} / \sqrt{\mathrm{N}}$ & multiplier & PE & $6(\mathrm{PE})$ \\
\hline BSE 30 & 0.998 & 0.996 & 0.004 & 2743 & 52.37 & 0.00008 & 0.6745 & 0.00005 & 0.00031 \\
\hline
\end{tabular}

Probable error for the autocorrelation 0.998 in the first lag is 0.00005. See TABLE No.7.21.5 above. The coefficient of autocorrelation is greater than the PE $(0.998>0.00005)$. The autocorrelation 0.998 is still higher than the 6 times PE (0.00031) i.e., $r>6(\mathrm{PE})$. Hence the autocorrelation 0.998 of BSE SENSEX30 is significant.

Table No.7.21.6

Calculation of Probable Error in Lag 16.

\begin{tabular}{|c|c|c|c|c|c|c|c|c|c|}
\hline Stock & $\mathrm{r}$ & $\mathrm{r}^{2}$ & $1-\mathrm{r}^{2}$ & $\mathrm{~N}$ & $\sqrt{N}$ & $1-\mathrm{r}^{2} / \sqrt{\mathrm{N}}$ & multiplier & $\mathrm{PE}$ & $6(\mathrm{PE})$ \\
\hline BSE 30 & 0.976 & 0.953 & 0.047 & 2743 & 52.37 & 0.00091 & 0.6745 & 0.00061 & 0.00366 \\
\hline
\end{tabular}

Probable error for the autocorrelation 0.976 in lag 16 is 0.00061 . See TABLE No.7.21.6 above. The coefficient of autocorrelation is greater than the PE $(0.976>0.00061)$. The autocorrelation 0.976 is still higher than the 6 times PE (0.00366) i.e., $r>6(\mathrm{PE})$. Hence the autocorrelation 0.976 of BSE SENSEX30 in lag 16 is significant.

Table No.7.21.7

Run test descriptive statistics of BSE SENSEX30

\begin{tabular}{|l|l|}
\hline Test Values & 7927.93 \\
\hline Cases $<$ Test Values & 1679 \\
\hline Cases $>$ Test Values & 1064 \\
\hline Total Cases & 2743 \\
\hline No. of runs & 6 \\
\hline Z & -52.18 \\
\hline Asym.sig (2-tailed) & 0.0 \\
\hline Expected runs $\bar{R}$ & 1303.56 \\
\hline$\sigma$ of runs & 24.87 \\
\hline Table Value @ 5\% significance & -1.96 \\
\hline
\end{tabular}

As per TABLE No.7.21.7, the actual runs in the price index series are lower than the expected $(6<1303.56)$. Too few runs indicate stationary state of the series. The $\mathrm{z}$ value calculated is -52.18 whereas the table value for the same at $5 \%$ level of significance is -1.96 on the left tail. The $\mathrm{z}$ calculated is lower than the table value $(-52.18<-1.96)$. Therefore the null hypothesis that the series is random is rejected and resolved that there is interdependence and non-randomness in the closing price series of BSE SENSEX30.

\section{Empirical results}

Auto correlation for 16 lags was worked out in the case of all stocks under study and for the market surrogate BSE SENSEX30. It was found that the coefficient of auto correlation for all lags is above 0.9. Student's t test was employed to verify the significance of autocorrelation. T values worked out are all higher than the table value of 1.96 at 5\% level of significance. Probable Error is also used to test the significance of autocorrelation. The coefficient of autocorrelation of all stocks and the market index is higher than the probable error. Moreover, the autocorrelation was even higher than the six times probable error. These tests all confirm that the autocorrelation in the price series of stocks and BSE Sensex 30 are significant. Hence there are strong parametrical evidences for interdependence and non-randomness within the price series of 20 stocks and BSE Sensex 30 .

The descriptive statistics of the stocks and the BSE SENSEX30 reveal that all are positively skewed. The standard deviations are all very high. The difference between the mean and median is high. The range of difference between the minimum and maximum value is also very high. The kurtosis of all stocks is either leptokurtic or patykurtic in shape. Volatility in prices is common to all stocks and market index. There are strong evidences for stating that the price series of the stocks and BSE SENSEX30 are not normally distributed.

Since the price series are not found normally distributed, the non-parametric runs test is employed for finding non-randomness between variables within series. Runs test is employed without the presumption of a distribution. On verification of actual runs $(R)$, Expected runs $(\bar{R})$, Standard deviation of runs $\left(\bar{S}_{R}\right)$ and Standard normal approximate $(\mathrm{z})$ it is found that there are strong evidences for non-randomness. The actual runs are 
considerably lower than the expected runs. On average there were only 26 runs in the series of price of stocks and index of BSE Sensex30. The average expected runs were 1309. This gives ostentatious evidence for more stationary behavior of prices. Due to the lower number of runs the $\mathrm{z}$ values of all stocks and index were negative. The average $\mathrm{z}$ value was -51.4. The critical value at $5 \%$ level of significance is 1.96 on the left tail. It is resolved that as the calculated $\mathrm{z}$ value is lower than the table values the null hypothesis $\left(\mathrm{H}_{0}\right)$ is rejected and interdependence and non-randomness is confirmed.

\section{Summary and conclusions}

This paper is devoted to study the randomness of stock prices and the efficiency of the market according to the Efficient market Hypothesis (EMH). Twenty scrips were selected from among the stocks listed in Bombay Stock Exchange belonging to twenty industries. The closing prices of the stocks were collected and put to empirical test and analysis. Conclusions were drawn accordingly.

In order to test randomness autocorrelation coefficients were found for the price series of all the twenty stocks and the market index sensex 30. The coefficient of autocorrelation was further tested for their significance by the $t$ value and probable error. The autocorrelation of all stocks were found very high above 0.9 . The significance of the autocorrelation was tested by the $t$ test and found that the calculated $t$ values are greater than the critical value as per the table \pm 1.96 . The probable error was also calculated and found that the coefficients of autocorrelation of all stocks and BSE Sensex 30 are higher than the Standard error, even higher than six times the probable error. Both the student's $t$ test and the probable error confirmed the significance of autocorrelation. Hence it is concluded that the price series of all twenty stocks and the BSE Sensex 30 had high autocorrelation signaling interdependence and non-randomness. Therefore the null hypothesis that the price series are random is rejected.

When the summary statistics of the stocks were studied it was found that the price series were not normal distribution. Therefore non-parametric test runs were employed to study the randomness of stock prices. The study brought out that the price series had only few runs when compared to the expected. Due to this, the $z$ values of the stocks were negative. The $\mathrm{z}$ values calculated were less than the critical value or $\mathrm{z}$ table value of 1.96 on the left tail. If the $\mathrm{z}$ value is not lying within \pm 1.96 the variables are non-random. In all cases the $\mathrm{z}$ values are lying below the -1.96 at $5 \%$ level of significance. Therefore the null hypothesis is rejected and concluded that there is non-randomness and interdependence of variables in the price series.

\section{References}

[1]. Eugene F.Fama, “Efficient Capital Markets: A review of Theory and Empirical Work” The Journal of Finance, Vol. 25, No. 2, Papers and Proceedings of the Twenty-Eighth Annual Meeting of the American Finance Association New York, N.Y. December, 28-30, 1969 (May, 1970), pp. 383-417.

[2]. Seyyed Ali Paytakhti Oskooe, Hong Li and Ali Shamsavari, "The Random Walk Hypothesis in Emerging Stock Market", International Research Journal of Finance and Economics, ISSN 1450-2887 Issue 50 (2010).

[3]. Philip S Russel and Violet M Torbey, "The efficient market on trial-Survey."B $>$ Qest., Jounal of applied topics in business and economics, 2002.

[4]. Ishmael Radikoko, "Testing The Random Walk (Rw) Behaviour of Botswana's Equity Returns", Journal of Business Theory and Practice, ISSN 2329-2644 Vol. 2, No. 1, 2014.

[5]. Anup Agrawal \& Kishore Tandon, "Anomalies or illusions? Evidence from stock markets in eighteen countries", Journal of International Money and Finance, 1994, 13 083-106.

[6]. Warren Buffet, Fortune April 3,1995.

[7]. Cooray, Arusha and Wickremasinghe, Guneratne (2005): "The Efficiency of Emerging Stock Markets: Empirical Evidence from the South Asian Region", Published in: Journal of Developing Areas, Vol. 1, No. 41 (2007): pp. 171-184.

[8]. Fischer Black, "Noise", The Journal of Finance, The Journal of American Financial Association, Volume 41, Issue 3, pages 529543, July 1986 DOI: 10.1111/j.1540-6261.1986.tb04513.x 30 APR 2012

[9]. Ibrahim Awad and Zahran Daraghma, "Testing the Weak-Form Efficiency of the Palestinian Securities Market", International Research Journal of Finance and Economics, ISSN 1450-2887 Issue $32 \quad$ (2009), (C) EuroJournalsPublishing,Inc.2009,http://www.eurojournals.com/finance.htm.

[10]. T.P.Madhusoodanan, Vikalpa The Journal for Decision Makers, The Indian Institute of Management Ahamedabad, Vo] 23, No 4, October-December 1998.

[11]. Pankunni.V, "Stock Price Movement in India”, Doctoral diss., Department of Commerce, University of Kerala, 2013.

[12]. S.K.Chaudhari, "Short-run Share Price Behaviour: New Evidence on Weak Form of Market Efficiency", Vikalpa The Journal for Decision Makers, The Indian Institute of Management Ahamedabad, Vol. 16, No 4, October-December 1991.

[13]. Denis Kwiatkowski, Peter C.B. Phillips, Peter Schmidt and Yongcheol Shin, "Testing the null hypothesis of stationarity against the alternative of a unit root. How sure are we that economic time series have a unit root?", Journal of Econometrics 54 (1992) 159-178. North-Holland.

[14]. Ankitha Mishra and Vinod Mishra, "Is the Indian stock market efficient? Evidence from a TAR model with an autoregressive unit root", Applied Economics Letters, 2011, Vol 18, Issue 5, pp. 467-472.

[15]. M.A.Noustaffa, "Testing the Weak-Form Efficiency of the United Arab Emirates Stock Market", INTERNATIONAL JOURNAL OF BUSINESS, 9(3), 2004, ISSN: 1083-4346.

[16]. Nikunj R. Patel, Nitesh Radadia and Juhi Dhawan, “An Empirical Study on Weak-Form of Market Efficiency of Selected Asian Stock Markets”, Journal of Applied Finance \& Banking, vol.2, no.2, 2012, 99-148, ISSN: 1792-6580 (print version), 1792-6599 (online), International Scientific Press, 2012. 
[17]. P.K.Mishra and B.B.Pradhan, "Capital market efficiency and financial innovation-A Perspective Analysis", The Research Network, Vol.4, No.1, March, 2009, http://ssm.com/abstract=1392580.

[18]. James M. Poterba and Lawrence H. Summers, Mean Reversion in Stock Prices: Evidence and Implications, NBER Working Paper No. 2343 (Also Reprint No. r1233), Issued in August 1987.

[19]. Priyanka Sing and Brajesh Kumar, "Variance Ratio Tests of the Random Walk Hypothesis for Indian Stock Index Futures: Evidence from High Frequency Data", Indian Institute of Management Ahmadabad, www.nseindia.com.

[20]. Sunita Mehla and S.K.Goyal, "Empirical Evidence on Weak Form of Efficiency in Indian Stock Market", Asia-Pacific Journal of Management Research and Innovation, 8(1) 59-68, Institute of Management SAGE Publications, Los Angeles, London, New Delhi, Singapore, Washington DC. DOI:10.1177/2319510X1200800107.

[21]. Saheli Das, "Testing Weak Form Market Efficiency: Empirical Evidence from India”, Asian Journal of Research in Banking and Finance, Vol. 4, No. 6, June 2014, pp. 38-47. ISSN 2249-7323 